\title{
Enzyme inhibitors as controllers of neurodegenerative diseases: An update of in vitro effects of medicinal plants
}

\author{
Ana Alimpić Aradski ${ }^{1, *}$, Mariana Oaløe Pavlović ${ }^{1}$, Smiljana Janković ${ }^{1}$, Petar D. Marin $^{1}$, \\ AND SONJA DULETIĆ-LAUŠEVIĆ ${ }^{1}$ \\ ${ }^{1}$ University of Belgrade, Faculty of Biology, Institute of Botany and Botanical Garden "Jevremovac", Studentski trg 16, 11000 Belgrade, Serbia \\ *Corresponding author: alimpic.ana@bio.bg.ac.rs
}

Published: December 25, 2021

Received: February 14, 2021

Accepted: April 12, 2021

Published on-line: October 15, 2021

\begin{abstract}
Considering the increase of the elderly population in recent years, the growing prevalence of age-related neurodegenerative diseases (NDDs), including Alzheimer's disease (AD) and Parkinson's disease (PD), has become one of the leading healthcare problems. Currently, available therapies for AD and PD are still limited, while medicinal plants used in traditional medicine for millennia can inhibit enzymes involved in the neurodegeneration processes in AD (acetylcholinesterase, AChE, and butyrylcholinesterase, BChE) and PD (tyrosinase, TYR), hence their inhibiting effects are continuously being investigated especially in the past decade. This study was aimed to review data on medicinal plants as potential cholinesterases and TYR inhibitors reported from January 2018 until May 2021. The literature search was performed using several online bibliographical databases (Scopus, Web of Science, Science Direct, Google Scholar, PubMed, and ResearchGate) and two websites. Data analysis showed that the highest number of representatives belongs to Lamiaceae family (up to $20 \%$ ), followed by Asteraceae. Almost half of the tested samples were prepared from whole plant/aerial plant parts followed by leaves. The most frequently tested preparations were methanolic extracts (about $25 \%$ of the samples examined). Additionally, synergistic interactions between different herbs and/or isolated compounds were considered as a promising strategy for further research. The presented data showed that medicinal plants preparations represent an unlimited source for research of new and more effective $\mathrm{AD}$ and $\mathrm{PD}$ treatments. This review will provide a useful starting point for further research on this topic.
\end{abstract}

Key words: Alzheimer's disease; Parkinson's disease; cholinesterase inhibition; tyrosinase inhibition; medicinal plants; synergistic effects

http://dx.doi.org/10.5937/leksir2141072A

\section{ABBREVIATIONS}

NDDs - neurodegenerative diseases; AD - Alzheimer's disease PD - Parkinson's disease; AChE - acetylcholinesterase; BChE butyrylcholinesterase; TYR - tyrosinase, T2D - type 2 diabetes.

\section{INTRODUCTION}

The term neurodegenerative diseases (NDDs) covers many insidious and incurable diseases featured by increasing prevalence, in part because the elderly population has increased in recent years (Gitler et al., 2017). NDDs represent a huge public concern and one of the largest healthcare issues, with the physical, psychological, social, and economic impacts on people suffering from NDDs, their families, caregivers and society. Accordingly, there is a great scientific interest to develop new and more effective strategies for NDDs prevention and treatment.

The main characteristics of NDDs include progressive loss of both structure and function of neuronal cells, causing changes in nervous system structure, which finally results in degeneration and/or death of neurons (Magalingam et al., 2018). NDDs are manifested by movement problems and mental dysfunction such as dementia, both of which are commonly observed symptoms in NDDs such as Alzheimer's disease (AD), Parkinson's disease (PD), Huntington's disease, amyotrophic lateral sclerosis, frontotemporal dementia and spinocerebellar ataxias (Fadaka et al., 2019; Gitler et al., 2017). Among them, AD and $\mathrm{PD}$ are the most common NDDs affecting a large population worldwide.

NDDs, including AD and PD, share some common characteristics such as age-related decline, multiple genetic defects distributed across the genome, deposits of abnormal proteins 
in the brain, and diverse environmental risk factors (Cacabelos, 2020). Although the exact mechanisms underlying the pathogenesis of NDDs have not yet been fully understood, it has been proven that oxidative stress and neuroinflammation are the initiators of NDDs. Elevated levels of oxidative stress are responsible for the activation of several biochemical pathways that induce oxidative damage of neuronal cells, leading to their neurodegeneration and death. On the other hand, neuroinflammation arises due to a complex immune response of the brain to injury, leading to the activation of glial cells and release of inflammatory cytokines, causing serious consequences related to NDDs (Fadaka et al., 2019; Khan et al., 2020). The main risk factors included in NDDs development are summarized in Figure 1.

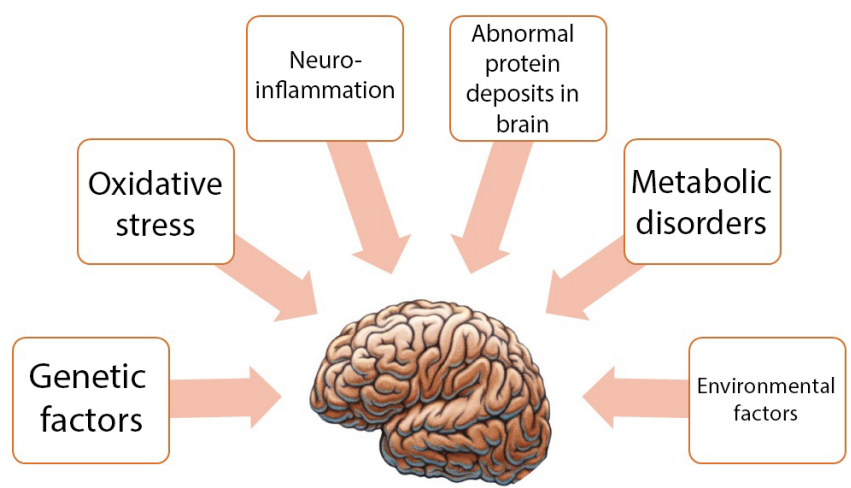

Fig. 1. Main risk factors for neurodegenerative diseases (NDDs) development

Dementia involves progressive neurodegenerative brain disorders characterized by cognitive impairment and gradual decay of mental functions, followed by progressive deterioration of physical function, leading to disability and ultimately - death. According to the newest data reported by the World Health Organization (WHO, 2021) and Alzheimer's Disease International (ADI, 2021), over 50 million people are living with dementia globally, and this number is projected to reach 82 million by 2030 and 152 by 2050. Alzheimer's Disease International (ADI, 2021) reported that already $60 \%$ of people with dementia live in low and middle-income countries, however, it is estimated that by 2050 this number will rise to $71 \%$, with occurence of new case every 3 seconds in the world.

AD represents the most common form of dementia (60-80\% of dementia cases worldwide), which is manifested by a decline of memory and cognitive functions. The majority of AD cases are recognized as sporadic with increasing prevalence over the age of 65 . One of the main characteristics of $A D$ is the lack of neurotransmitter acetylcholine (ACh), which is degraded by the enzyme acetylcholinesterase (AChE). Thus, the prevention of ACh degradation by inhibiting AChE in cholinergic synapses represents a promising approach in AD management (Bui and Nguyen, 2017; Damuka et al., 2020; Dohrmann et al., 2019; Edwards III et al., 2019; Hampel et al., 2018; Kumar et al., 2015; Podcasy and Epperson, 2016). PD represents the second most common age-related, progressive NDD after AD, affecting 7-10 million people worldwide. The prevalence of the disease ranges from 41 people per 100,000 in the fourth decade of life to more than 1,900 per 100,000 in people aged 80 and older (Parkinson's News Today, 2021). The main symptom of PD, slowness of movement (bradykinesia), is due to progressive dopamine (DA) deficiency in the dopaminergic neurons of neuromelanin-containing neurons of substantia nigra. Tyrosinase (TYR) plays a significant role in neuromelanin formation, and its overproduction together with oxidative stress could be responsible for the PD-associated neurodegeneration (Jiang et al., 2018; Zucca et al., 2014). Thus, inhibition of TYR and the reduction of oxidative stress are recognized as indirect and non-conventional strategies for the treatment of PD.

Numerous studies have shown that medicinal plants represent a rich source of diverse secondary metabolites, including terpenes, phenolic acids, flavonoids, alkaloids, lignans, sterols, tannins, displaying various beneficial biological activities, such as antioxidant, anti-inflammatory, enzyme inhibiting, antimicrobial, and many others (Bui and Nguyen, 2017; Kamal et al., 2019; Khan et al., 2020; Santos et al., 2018; Zolghadri et al., 2019).

Similarly to many commercial synthetic substances, medicinal plants and their isolated metabolites inhibit efficiently the activities of AChE and TYR. As a natural source of biologically active compounds, medicinal plants possess many advantages compared to synthetic drugs: they are safer to use and easily available, have less pronounced side effects, their production supports green sustainability standards, and are economically justified. The potential of medicinal plants in AChE and TYR inhibition, recognized as one of the prospective alternative therapeutic strategies for $\mathrm{AD}$ and $\mathrm{PD}$, will be discussed in detail hereinafter.

One of the current trends in natural products research includes testing the potential interactions of extracts and/or their components to discover potential synergistic interactions, i.e. the best-expressed activity for combination of extracts and/or their components compared to individual extracts/components. Thus, special attention in this review will be paid to synergistic interactions between plants, in the light of bioactivities that could be exploited in NDDs management. Bearing that in mind, this study is aimed to review data on medicinal plants as potential AChE and TYR inhibitors reported from January 2018 until May 2021. The data were obtained by searching Scopus, Web of Science, Science Direct, Google Scholar, PubMed, and ResearchGate databases, and selected research articles published in this period are presented in tabular manner. This period is considered as long enough to notice research trends regarding the choice of plant species, material for extraction, isolation techniques, isolated compounds, tests employed for assessment of enzyme inhibition activity, as well as the presentation of the obtained data. Thus, this study is intended to provide a useful starting point for further research on this topic.

\section{METHODOLOGY}

For the present study, an extensive search of review and original research articles was conducted. In order to provide a comprehensive literature survey, several complementary online bibliographical databases such as Scopus, Web of Science, Science Direct, Google Scholar, PubMed and ResearchGate were used. Moreover, only articles published in English have been taken into consideration. The articles' search was performed by combining the following keywords: neurodegenerative diseases, Alzheimer's disease, Parkinson's disease, medicinal plants, in vitro AChE inhibition, in vitro BChE inhibition, in vitro TYR inhibition, plant extracts, essential oils, synergistic effects.

Numerous search results were filtered according to relevance, and selected review articles and original research studies were used to provide background for the general part of the text describing symptoms, pathophysiology and current therapeutical strategies of both AD and PD. Among them, the papers published in the last decade were predominantly selected. 
Moreover, website sources such as Alzheimer's Disease International (ADI, 2021) and Parkinson's News Today (2021) were also used to report the newest statistical data on both diseases. A preliminary search of original research articles related to the inhibition of AChE, BChE and TYR by medicinal plants was additionally filtered to cover a 40 months-period from the beginning of 2018 until May 2021, and initially about 1000 research papers were screened. The comprehensive research papers involving all of these enzymes were predominantly included, while those dealing with one of these enzymes separately were subsequently added to the selected article list. The papers dealing with more than one examined plant species were also rather selected.

Finally, of totally cited 288 references, the results of 211 research papers were analysed and presented in tabular manner in the main part of this study. Subsequently, data were additionally processed and presented graphically as pie charts drawn using MS Excel (2013). To provide a clear, systematic survey of published results, which could be useful for planning the succeeding researches, we have shown the next parameters for both AD and PD:

- Participation percentage of plant families' representatives examined for anticholinesterase and antityrosinase activity regarding the total number of taxa;

- Participation percentage of plant parts used for investigation of anticholinesterase and antityrosinase activity regarding the total number of examined samples;

- Participation percentage of plant preparations tested for anticholinesterase and antityrosinase inhibiting activity regarding the total number of examined samples.

Data on synergistic effects of medicinal plants and their compounds in the AChE and TYR inhibition were obtained by an exhaustive search of the available databases and the most relevant papers were presented, regardless of the year of publication.

Considering that this research has been limited to in vitro studies, the results of in vivo studies and clinical trials were excluded from the search. Additionally, the research articles exclusively focused on isolated compounds and synthetic inhibitors were also excluded, as well as papers which were not available in full. Moreover, conference papers and proceedings were also not taken into consideration.

\section{ALZHEIMER'S DISEASE (AD)}

\subsection{Description, symptoms, and pathophysiology of AD}

Alzheimer's disease (AD), described for the first time by Dr. Alois Alzheimer in 1907, is the most frequent form of dementia and one of the major healthcare problems in developed countries (Bui and Nguyen, 2017; Damuka et al., 2020; Edwards III et al., 2019; Folch et al., 2016; Kumar et al., 2015). Females are at greater risk of developing AD dementia, whereas males are at greater risk of developing vascular dementia (Podcasy and Epperson, 2016). AD is a slowly evolving disease manifested by progressive declines in cognition, memory, attention, and language and by the inability to learn (Hampel et al., 2018, Kumar et al., 2015; Magalingam et al., 2018). Two forms of AD should be distinguished, familial AD with genetic predisposition (occurs in up to $5 \%$ of cases), while the majority of cases are recognized as sporadic AD (Bui and Nguyen, 2017; Dohrmann et al., 2019; Edwards III et al., 2019; Folch et al., 2016; Kumar et al., 2015). Considering clinical phenotypes and genetic risks observed in AD patients, the sporadic AD cases could be segregated into two subgroups, early-onset $\mathrm{AD}$ under age 65 (3-5\% prevalence) and late-onset $\mathrm{AD}$ with typical onset after the age of 65 (95-97\% prevalence) (Folch et al., 2016; Jagust, 2018).

Besides common risk factors for AD (aging, sex, and genetics), modifiable risk factors, including medical conditions such as hypertension and other cardiovascular problems, diabetes, epilepsy, brain injuries, and depression as well as lifestyle choices (poor nutrition, sleeping disturbance, lack of physical activity, smoking, etc.) may have a significant role in the development of AD (Edwards III et al., 2019). There is an increasing evidence on the coexistence of type 2 diabetes (T2D) and AD in many patients, which could be explained by elevated levels of oxidative stress and chronic inflammation. Furthermore, it is reported that both $\mathrm{AD}$ and $\mathrm{T} 2 \mathrm{D}$ patients are more susceptible to severe outcomes after SARS-CoV-2 infection because the immune response and excessive inflammation in COVID-19 may also accelerate the progression of inflammatory neurodegeneration of the AD brain (Naughton et al., 2020). As previously stated, Japanese and Mediterranean diets rich in mono- and polyunsaturated fatty acids and antioxidants have the preventive potential for the development of senile dementia and AD (Dohrmann et al., 2019; Edwards III et al., 2019).

The pathophysiology of $\mathrm{AD}$ is not yet completely resolved, however aging is currently recognized as a key factor that activates several neurodegenerative pathways resulting in loss of neuronal cells (Karakaya et al., 2019a; Magalingam et al., 2018). Hallmarks of AD include $\beta$-amyloid (A $\beta$ ) proteins aggregation to senile plaques, $\tau$-protein hyperphosphorylation, neurofibrillary tangles, low level of ACh, neuroinflammation, dendritic pathology, etc. (Bui and Nguyen, 2017; Damuka et al., 2020; Edwards III et al., 2019; Folch et al., 2016; Jagust, 2018; Magalingam et al., 2018; Thakur et al., 2019). Among several existing hypotheses on the origins of $\mathrm{AD}, \mathrm{A} \beta$ cascade and cholinergic hypotheses are the most widely accepted.

According to the $\beta$-amyloid cascade (or $\mathrm{A} \beta$ ) hypothesis, developed in 1991, the extracellular $\beta$-amyloid plaques are the main cause of AD. Precisely, small clusters of accumulated $\mathrm{A} \beta$ proteins tend to form so-called amyloid or senile plaques in the brain. Amyloid plaques also provoke the formation of neurofibrillary tangles of $\tau$-protein, which along with $\mathrm{A} \beta$ plaques provoke the destruction of neuronal cells. Additionally, the formation of $\mathrm{A} \beta$ plaques leads to oxidative stress in the neurons, which accelerates the development of AD (Bui and Nguyen, 2017; Folch et al., 2016; Kawamoto et al., 2019; Kumar et al., 2015; Magalingam et al., 2018; Selkoe and Hardy, 2016).

The cholinergic hypothesis explains the pathophysiology of $\mathrm{AD}$ by a decrease of neurotransmitter ACh. It is proven that cognitive decline and memory loss are linked to the loss of cholinergic activity in the neocortex and hippocampus of AD patients brain (Bui and Nguyen, 2017; Damuka et al., 2020; Folch et al., 2016; Hampel et al., 2018; Kawamoto et al., 2019). AChE primarily degrades ACh in cholinergic synapses, while a closely related enzyme $\mathrm{BChE}$ has a role as a coregulator of cholinergic neurotransmission by hydrolyzing ACh. The inhibition of these enzymes is a key target for the management of AD since this inhibition leads to an increase in the availability of ACh in several brain regions (Bui and Nguyen, 2017; Hampel et al., 2018; Penumala et al., 2018), which is why it represents the main pharmacotherapeutic approach in the treatment of AD (Blažević et al., 2019).

According to the literature data, there are several other hypotheses aimed at explaining AD pathophysiology focusing on the hyperphosphorylated $\tau$-protein, dendritic abnormalities, oxidative stress, mitochondrial dysfunction, metal ions, neuroinflammation, and even metabolic disorders (Fadaka et al., 2019; Folch et al., 2016; Thakur et al., 2019). 


\subsection{Current therapeutic strategies for $A D$}

The potential therapeutic strategies for AD are developed according to the existing hypotheses on AD pathophysiology, and should be classified into two main groups:

a) Strategies focused on reducing $A \beta$ aggregation and plaque formation. This strategy recognizes $\mathrm{A} \beta$ dyshomeostasis as the most extensively validated model in the development of potential treatments (Bui and Nguyen, 2017; Folch et al., 2016; Jagust, 2018; Selkoe and Hardy, 2016). It is reported that this group involves inhibitors of $\beta$-secretase and $\gamma$-secretase, nonsteroidal inhibitors of cyclooxygenase activity (NSAIDs), inhibitors of $\mathrm{A} \beta$ aggregation, modulators of $\beta$-amyloid transport and active immunotherapy (Folch et al., 2016; Kumar et al., 2015). Finally, a study claimed AD in older ages can be prevented if a subject took inhibitors of $\beta$-secretase and $\mathrm{A} \beta$ aggregation regularly from adolescence (Kawamoto et al., 2019).

b) Strategies focused on increasing the ACh level and improving cholinergic transmission. This group includes various therapeutic strategies directed towards elevating ACh levels, inhibiting ACh hydrolysis using AChE inhibitors, stimulating nicotinic and muscarinic receptors, and cholinomimetic substances (Bui and Nguyen, 2017; Damuka et al., 2020; Folch et al., 2016; Hampel et al., 2018).

c) Other therapeutic strategies include different approaches focusing on $\tau$-protein pathology, dendritic pathology (N-methyl-D-aspartate (NMDA)-receptor antagonists), 5-HT6 receptors (their inhibitors were shown to promote ACh release), the linkage between AD and T2DM pathologies ("type 3 diabetes" hypothesis, suggesting antidiabetic drugs for the AD treatment), neuroprotection (antioxidants such as vitamins $\mathrm{C}$ and $\mathrm{E}$, and polyphenols can prevent, delay or even reverse neuronal damage), etc. (Fadaka et al., 2019; Folch et al., 2016; Kamal et al., 2019; Kumar et al., 2015; Thakur et al., 2019).

Despite many research efforts, therapeutic options for AD are still limited to four drugs approved by The Food and Drug Administration (FDA): donepezil, galanthamine, and rivastigmine as a class of cholinesterase inhibitors and memantine, NMDA-receptor antagonist (Hampel et al., 2018; Kumar et al., 2015; Thakur et al., 2019). Cholinesterase inhibitors, e.g. galantamine, donepezil, and rivastigmine inhibit the activity of $\mathrm{AChE}$, increase the level of $\mathrm{ACh}$ and enhance cholinergic transmission in the central nervous system (Bui and Nguyen, 2017). They are most effective when treatment begins in the early stages, while memantine is shown to be effective in the later stages of AD (Kumar et al., 2015). Galanthamine, acting as an allosteric modulator at nicotinic ACh receptors, is an alkaloid isolated from the snowdrop (Galanthus spp.) and it is also found in other members of the Amaryllidaceae family, e.g. Narcissus and Leucojum species (Kawamoto et al., 2019; Thakur et al., 2019), while donepezil and rivastigmine are synthetic drugs. It has been reported that the aforementioned AChE inhibitors have numerous harmful effects including diarrhea, abdominal pain, skin rash, hepatotoxicity (Bui and Nguyen, 2017), which leads to the conclusion that there is an urgent need to search for new, efficient and safe AChE inhibitors.

\subsection{Potential of medicinal plants in AD therapy}

The effects of aromatic and medicinal plants, crucial in the Mediterranean diet, in the prevention of neurocognitive disorders are well known (Dohrmann et al., 2019). On the other hand, medicinal plants have been continuously used as folk remedies for thousands of years, and the investigation of plants and their constituents provided scientific evidence on their immense potential for the treatment of various health disorders, including neurodegeneration. The advantage of herbs is that they have low toxicity compared to pharmaceutical agents, and they can be used together with drugs, providing possible synergistic effects (Singhal et al., 2012).

Although the synthetic drugs used in the treatment of AD are available, the search for new compounds originating from natural sources is of great importance. Numerous researchers around the world are investigating the cholinesterase inhibitory potential of a variety of plants, focusing on the compounds which demonstrated antioxidant, anti-amyloidogenic, anti-inflammatory and anti-apoptotic properties, so that could represent important sources of potential drug candidates against AD (D'Onofrio et al., 2017; Fadaka et al., 2019; Libro et al., 2016).

Previous reviews comprised a high number of literature data concerning the $\mathrm{AChE}$ and $\mathrm{BChE}$ inhibitors obtained from medicinal plants collected in different regions. The representatives of more than 150 plant families have been examined for $\mathrm{AChE}$ and BChE inhibition ability and reviewed as potential herbal drugs for AD treatment (Bui and Nguyen, 2017; Howes and E., 2011; Kumar et al., 2015; Mukherjee et al., 2007; Murray et al., 2013; Raghunath et al., 2018; Santos et al., 2018).

According to the reviewed literature, many papers present results obtained for plants collected in Turkey (Bozkurt et al., 2021; Deveci et al., 2018; 2019; Emir and Emir, 2021; Karakaya et al., 2020; 2019a; 2018; 2019b; ; Orhan et al., 2019; Ozkan et al., 2018b;a; Saleem et al., 2020c; 2019b; 2020a; 2019a; 2020b; 2021; 2019c; Sarikurkcu and Zengin, 2020; Sut et al., 2019b;a; Uysal et al., 2019a; 2018a;b;c; 2019b; 2021; Yilmaz et al., 2018; Zengin et al., 2018a; 2019a;b;c; 2018b;c;d; 2019d;e; 2018e; 2019f;g; 2018f; 2019h; 2021; 2020a;b; 2019i; 2018g; 2019j; 2018h; 2019k;l; 2018i). Turkey has unique geomorphology, topography, climate due to its position at the intersection of three phytogeographical regions (Euro-Siberian, Mediterranean and Irano-Turanian), which makes it a biodiversity hotspot with 12000 plant taxa, among which is $32 \%$ endemic (Zengin et al., 2018b).

Covering examined 40 months-period, selected papers on the anticholinesterase activity of 289 taxa belonging to 68 families are presented in Table 1 . The Figure 2 illustrates the percentage of representatives of families regarding the total number of taxa encompassed within this study. As can be seen in Table 1 and Figure 2, the largest number of examined taxa belongs to the families Lamiaceae (20\%), Asteraceae (12\%), Apiaceae (8\%), Fabaceae (5\%), Amaryllidaceae (4\%), Rosaceae (4\%), Caryophyllaceae (3\%) and Hypericaceae (3\%). Among Lamiaceae species, the most frequently examined taxa belong to Salvia, Thymus, Stachys, Origanum and Sideritis genera (Table 1), although the most quoted species known for their neuroprotective action wereSalvia officinalis, Rosmarinus officinalis and Melissa officinalis. Some of the plant families comprising less than 3\% are Brassicaceae, Araliaceae, Myrtaceae, Lauraceae, Rutaceae, Bogarinaceae, Plumbaginaceae, etc.

The representatives of the Lamiaceae family, often aromatic, are widely distributed and cultivated, having a long history of usage for food and medicinal purposes. In attempts of finding new natural compounds for the treatment of AD based on the cholinesterase inhibitory mechanism, numerous researchers analyzed various plants belonging to the Lamiaceae, and such trend can be also seen in the latest published papers. The important phenolic compounds found in the Lamiaceae representatives are rosmarinic and carnosic acid, which demonstrated neuroprotective effects in various studies, including the activity against diverse modes of neuronal cell death (Taram 


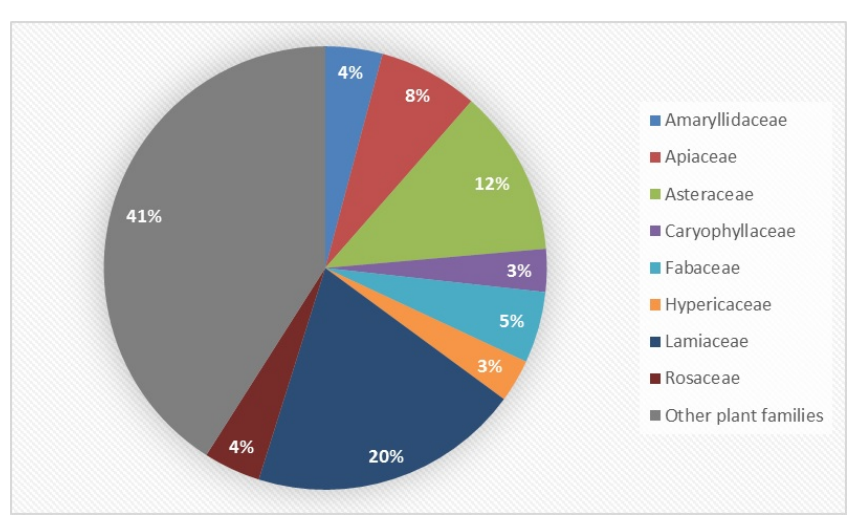

Fig. 2. Participation percentage of plant families' representatives examined for anticholinesterase activity regarding the total number of taxa

et al., 2018). Rosmarinic acid was the most abundant phenolic compound in Thymus argaeus and Salvia modesta methanolic extracts, which contributed to the AChE inhibition activity, while in the case of T. argaeus dichloromethane extract was the strongest inhibitor of both enzymes (Zengin et al., 2019b).

According to data presented in the Table 1, Salvia species have been the most extensively studied representatives of the Lamiaceae family, due to the high content of active compounds which could enhance cognitive activity and protect from neurodegenerative diseases (Lopresti, 2017). In vitro and in vivo studies revealed that several Salvia species extracts and oils (S. officinalis, S. lavandulifolia, S. miltiorrhiza, S. fruticosa) and their constituents are effective $\mathrm{AChE}$ and $\mathrm{BChE}$ inhibitors. Phenolic acids, such as caffeic, rosmarinic, salvianolic acids, flavonoids (luteolin, apigenin, hispidulin, kaempferol, and quercetin) and terpenoids (camphor, carnosic acid, carnosol, ursolic acid) are among frequently isolated compounds from the Salvia representatives. Because of its richness in different chemical constituents, Salvia species can influence multiple physiological pathways in the brain (Lopresti, 2017). Several Salvia species were studied lately for their possible antineurodegenerative effect. Three Turkish Salvia species showed the best cholinesterase inhibitory effects when dichloromethane was used as a solvent, with a slightly better result obtained for S. euphratica var. leiocalycina (Zengin et al., 2018e). Turkish endemic plant $S$. eriophora aqueous and methanolic leaf extracts strongly inhibited AChE and BChE (Bursal et al., 2019). Several Salvia species extracts were evaluated for their AChE inhibition by our research group. Libyan $S$. lanigera ethanol and water extracts showed better results than S. fruticosa in AChE inhibition (Duletić-Laušević et al., 2018b), while ethyl acetate extract of Cretan S. pomifera was the most potent AChE inhibitor compared to other tested extracts (Duletić Laušević et al., 2018c). As S. officinalis was previously proved due to its memory-enhancing properties, Duletić-Laušević et al. (2019a) tested AChE inhibition potential of ethanolic, aqueous and hydroethanolic extracts of S. officinalis collected in the three locations in Montenegro. All examined Salvia species samples performed anti-AChE effect, nevertheless, it was weaker than galathamine used as positive control. In the study of Uysal et al. (2021), the dichloromethane extract obtained from S. ceratophylla roots exhibited the strongest inhibitory effects against AChE compared to other tested extracts.

Besides extracts, essential oils of Lamiaceae species were also proved to be effective enzyme inhibitiors, especially those of the species belonging to genera Salvia, Satureja, Thymus, Origanum which are well-known to be rich in thymol, carvacrol, $\beta$-pinene and 1,8-cineole. Moreover, Savelev et al. (2004) concluded that synergy among essential oil components of several tested Salvia oils contributes to anticholiesterase activity of total essential oil.

Various plant parts are being analyzed for the evaluation of anticholinesterase activity - whole plant or separately roots, leaves, stems (including branches, stem bark and wood), flowers and individual flower parts, fruits and fruit parts, seeds, rhizomes, bulbs (Table 1). In aforementioned period, in the view of total number of samples examined for anticholinesterase activity, whole plant/aerial parts (46\%) are the most frequently used, followed by leaves $(20 \%)$, roots $(9 \%)$, flowers/flower parts and stems. Among the other plant parts, rhizomes and seeds are included in a part below $3 \%$ regarding the total sample number (Figure 3).

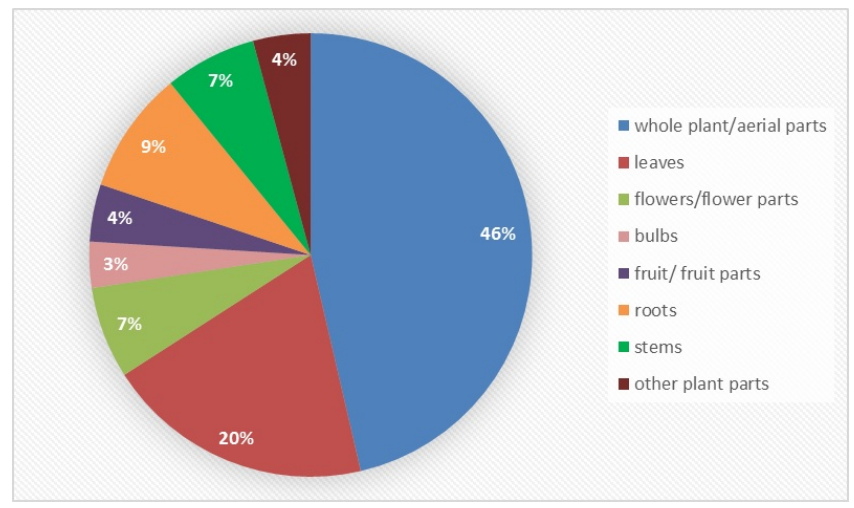

Fig. 3. Participation percentage of plant parts used for anticholinesterase activity regarding the total number of examined samples

The results of numerous studies indicated that the extracts obtained from various plant parts possessed different anticholinesterase inhibiton potential. For example, Sut et al. (2019a) demonstrated that the methanolic extract obtained from Paeonia kesrounansis aerial parts exhibited the highest AChE inhibition, while root extract was most effective towards BChE.

Numerous studies revealed that root extracts were more effective cholinesterases' inhibitiors compared to aerial parts. For example, the ethanolic extracts of roots of two Achillea species were rich in phenolic acids, while aerial parts were rich in flavonoids; $A$. monocephala aerial parts, with high content of luteolin and apigenin, showed the best activity against AChE and BChE (Yilmaz et al., 2018). Additionaly, Yener (2020) showed that ethanolic extract of Salvia poculata roots has stronger AChE and BChE inhibition activity in comparison with other studied plant parts, and also compared to galanthamine. In a study involving different plant parts of several Ferulago species, the root extracts demonstrated the strongest inhibition potential towards $\mathrm{AChE}$ and $\mathrm{BChE}$, containing the highest content of certain phenolic compounds (Karakaya et al., 2018; 2019b). Similar findings were obtained for Hypericum perforatum (Tusevski et al., 2018), Filago germanica (Saleem et al., 2019c), Euphorbia milii (Saleem et al., 2019c), Potentilla spp. (Sut et al., 2019a; Uysal et al., 2019b), Leiotulus dasyanthus (Karakaya et al., 2020), etc.

Also, the bulbs and roots from different monocots are shown to be a considerable source of bioactive compounds. The bulbs from the genus Allium possessed a lower AChE and BChE activity than the rest of the aerial parts (Emir et al., 2020), however, alkaloid extracts of the bulbs from the genus Phaedranassa showed considerable activity against AChE and BChE (Moreno et al., 2020), which is attributed to the presence of galanthamine-type alkaloids. Sevim and Şener (2020) demonstrated strong BChE inhibitory activity of the dichloromethane fraction of the Iris pseudoacorus bulbs. This finding is impor- 
tant because it was noticed that $\mathrm{BChE}$ activity increases along with the severity of dementia, while AChE activity declines (Lane et al., 2006), which emphasizes the importance of finding potent $\mathrm{BChE}$ inhibitory compounds.

Besides chia, the seeds of other plants are rarely tested for the enzyme inhibition analyses, so this review included only a few literature data (Table 1). Chia (S. hispanica) seeds contain healthy beneficial ingredients, displaying high potential for use in the food industry. In vitro and in vivo studies proved health beneficial effects of chia seed, and (Kobus-Cisowska et al., 2019a) examined the potential of commercially available white, gray, brown and black chia seeds from Argentina in inhibition of AChE and BChE. The ethanol extracts of colored seeds exhibited the highest inhibitory activity against AChE and BChE.

Additionally, the literature survey demonstrated that different plant preparations were used for the investigation of anticholinesterase activity, including essential oils, as well as various solvent extracts and their fractions. Solvents with different polarity are being used for extraction: methanol, ethanol, water, acetone, butanol, dichloromethane, chloroform, ethyl acetate, hexane, as well as diverse solvent mixtures (methanol/water, ethanol/water, methanol/chloroform, etc.) to make extraction process more efficient (Table 1 ). In this period, considering the total number of plant preparations tested for anticholinesterase activity, methanolic extracts (27 $\%)$ are the most frequently used, followed by aqueous (16\%), and ethyl acetate extracts (13\%), while essential oils were represented with $9 \%$. Plant preparations such as infusion, decoction, butanolic extracts, chloroform extracts, etc., which were presented with less than $3 \%$ of examined samples, are included in "other plant preparations" (Figure 4).

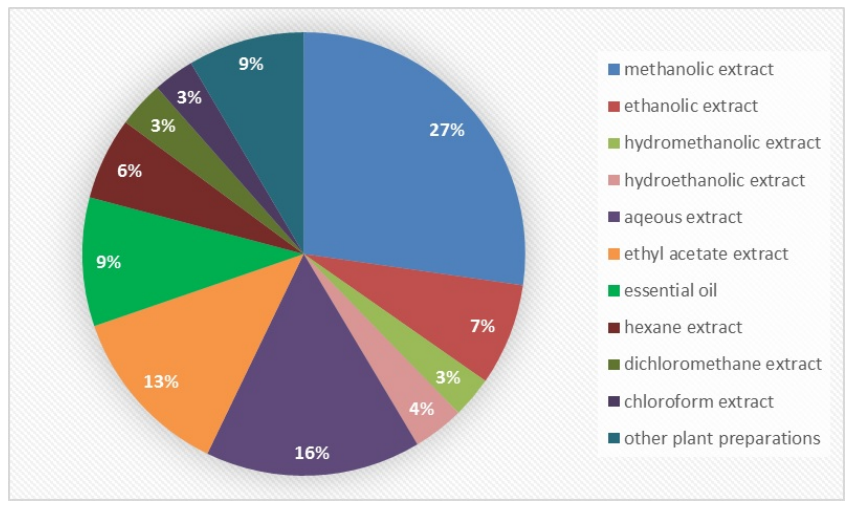

Fig. 4. Participation percentage of plant preparations tested for anticholinesterase activity regarding the total number of examined samples

Methanolic, followed by the aqueous and ethyl acetate extracts of the aerial parts of different medicinal plants are most frequently used for the investigation of phytochemistry and pharmacology including a variety of bioactivities. The methanolic extracts obtained from aerial parts of six wild edible Silene species from Turkey effectively inhibited AChE and BChE (Zengin et al., 2018f). In the study of Ceylan et al. (2021)) the methanolic extracts of aerial parts of 11 Inula species were tested, whereby I. ucheriana exhibited the highest anti-AChE activity, while I. britannica showed the strongest anti-BChE activity. The aerial parts and root methanolic extracts of six Limonium species showed that all examined samples possess anticholinesterase activity (Senizza et al., 2021). Methanolic extract of Ocimum basilicum was stronger AChE inhibitor than acetone and aqueous extracts (Duletić-Laušević et al., 2019b). Comparing AChE inhibiting potential of ethanol and aqueous extracts of sweet marjoram (Origanum majorana), Duletić-Laušević et al. (2018a) obtained better results for aqueous extracts which were less active than positive control galanthamine. Furthermore, the hydroalcoholic mixtures were proven as appropriate for the extraction of anti-AChE components. For example, $70 \%$ hydroethanolic extract showed the higher AChE inhibition than individual fractions of this extract, as previously demonstrated for Punica granatum (Šavikin et al., 2018) and Aronia melanocarpa (Zdunić et al., 2020). In addition, the ethyl acetate extracts of Potentilla recta and P. argentea expressed the highest AChE and BChE inhibitory activity in comparison with methanolic and aqeous extracts (Sut et al., 2019b). Besides extraction solvent, the extraction method significantly infuenced cholinesterase inhibiting capacity of the obtained extract. For example, Zengin et al. (2019g) have found variations of AChE and BChE inhibition of Salvia viridis ethanolic root extracts obtained by different extraction methods, achieving the best results by supercritical fluid extraction, connected with the presence of $\beta$-sitosterol.

\section{PARKINSON'S DISEASE (PD)}

\subsection{Description, symptoms, and pathophysiology of PD}

PD is one of a host of parkinsonian disorders featured by parkinsonism, primarily by prominent bradykinesia (Dickson, 2012). Described for the first time by James Parkinson in 1817, PD is second the most frequent NDDs after AD (Corti et al., 2005; Gitler et al., 2017; Jiang et al., 2018; Maiti et al., 2017; McLean et al., 2017; Váradi, 2020). Epidemiological studies have revealed that PD affects 1-2 \% of people older than 65 years, and $4-5 \%$ of those aged over 85 years, with a higher incidence in developed countries (Corti et al., 2005; Maiti et al., 2017). It is estimated that the male population is more prone to PD comparing to their female counterpart (about 1.5 times) (Maiti et al., 2017; Srivastav et al., 2017) which is attributed to the protective effect of estrogen in women (Fadaka et al., 2019; Váradi, 2020).

The most conspicuous symptoms of PD comprise motor dysfunctions including bradykinesia, rigidity, resting tremor and postural instability, and different non-motor symptoms (Balestrino and Schapira, 2020; Corti et al., 2005; Dickson, 2012; Maiti et al., 2017; McLean et al., 2017; Pathak-Gandhi and Vaidya, 2017). Although the etiology and pathogenesis of PD are not completely explained, there is evidence that both environmental risk factors and genetic predisposition can contribute to its development. Different genetic causes, i.e. familiar PD forms have been identified in approximately 5-15\% of PD cases (Balestrino and Schapira, 2020). PD may coexist with dementia and depression in over $2 \%$ of the cases (Cacabelos, 2020). Furthermore, it is reported that PD is associated with physical and mental comorbidity, particularly hypertension, constipation, coronary heart disease, painful conditions, depression, anxiety, and dementia (McLean et al., 2017). There is an increasing number of reports of neurological symptoms in COVID-19 patients, suggesting the potential for neurotropism of SARS-CoV-2 (Beauchamp et al., 2020).

Pathophysiologically, PD is characterized by dopamine (DA) deficiency resulting by loss of the dark-pigmented dopaminergic nigrostriatal neurons of the substantia nigra pars compacta (SNc) (Balestrino and Schapira, 2020; Corti et al., 2005; Hasegawa, 2010; Jiang et al., 2018; Maiti et al., 2017; Song et al., 2012; Srivastav et al., 2017; Zucca et al., 2014) and degeneration of non-dopaminergic systems such as noradrenergic, serotonergic and cholinergic systems (Maiti et al., 2017; Song et al., 2012). Neuromelanin-containing neurons of SNc are particularly susceptible to degeneration and their depigmentation is a hallmark of advanced disease (Hasegawa, 2010; Zucca et al., 2014). 
It is already known that mitochondrial dysfunction and altered oxidative stress along with aging are crucial cellular stress factors playing the most important role in PD pathogenesis (Iarkov et al., 2020; Srivastav et al., 2017; Váradi, 2020). The proposed mechanisms underlying the pathogenesis and progression of neurodegeneration in SNc include iron-catalyzed oxidative stress, toxic oxygen-free radicals during enzymatic dopamine catabolism, mitochondrial dysfunctions, trophic support, dyshomeostasis of kinase activity and intracellular calcium, neuroinflammation and disturbances of protein metabolism (Hasegawa, 2010; Maiti et al., 2017; Song et al., 2012). The neuronal damage in PD is ascribed to abnormal intracellular aggregation and accumulation of presynaptic nerve terminal protein $\alpha$-synuclein leading to Lewy bodies (LBs) formation (Balestrino and Schapira, 2020; Corti et al., 2005; Iarkov et al., 2020; Maiti et al., 2017; Pathak-Gandhi and Vaidya, 2017; Srivastav et al., 2017; Váradi, 2020).

Tyrosinase (TYR) is a key enzyme in the biosynthesis of melanin and plant polyphenols. In mammals, TYR is specifically expressed in melanocytes distributed in the skin, hair, and retina epithelium (Chang, 2009; Hasegawa, 2010; Pillaiyar et al., 2017). In the central nervous system of mammals, DAderived pigment neuromelanin is found in nigral dopaminergic cells, which suggests that TYR might play a significant role in neuromelanin formation and could be responsible for the neurodegeneration associated with PD (Hasegawa, 2010; Pillaiyar et al., 2017; Zucca et al., 2014). TYR catalyzes both the hydroxylation of tyrosine to L-DOPA and the subsequent oxidation of L-DOPA to dopaquinone in order to form melanin. In addition, under certain circumstances, TYR may oxidize DA leading to melanin, through DA quinines formation. Furthermore, DA quinones can interact with $\alpha$-synuclein and form a toxic intermediate in nigral cells (Hasegawa, 2010; Pillaiyar et al., 2017). DA-derived reactive species may interact with some key molecules in neuronal cells, leading to neuronal cell death and the concomitant neuropathological changes (Hasegawa, 2010). Neuromelanin showed a dual nature; intra neuronal neuromelanin protects the cells from toxic effects of redox-active metals, toxins, and excess of cytosolic catecholamines, while neuromelanin released by dying neurons can contribute to the activation of neuroglia triggering the neuroinflammation associated with PD (Zucca et al., 2014).

\subsection{Current therapeutic strategies for PD}

Enormous research done in this field has shown that some natural and synthetic products exhibit potential in the management of PD. Patients suffer from several motor (bradykinesia, rigidity, and resting tremor) and non-motor complications (constipation, cognitive decline, depression, fear, anxiety, weight changes, fatigue, and loss of energy, autonomic dysfunction/hypotension, dementia, hallucinations, sleep disorders, depression, psychosis, sexual problems, etc.) (Balestrino and Schapira, 2020; Corti et al., 2005; Jiang et al., 2018; Maiti et al., 2017; McLean et al., 2017; Pathak-Gandhi and Vaidya, 2017). Currently, the available treatments for PD are symptomatic and according to the mode of action drugs are divided into two categories:

1. dopaminergic drugs and

2. non-dopaminergic drugs.

Dopaminergic drugs. The main conventional strategies of PD treatment includes administration of dopaminergic drugs which actions are directed towards restoring the level of dopamine (DA), either by increasing of supply of levodopa (L3,4-dihydroxyphenylalanine/L-DOPA) or by inhibition of DA breakdown catalyzed by monoamine oxidase $\mathrm{B}$ (MAO-B) to preserve DA level (Balestrino and Schapira, 2020; Maiti et al.,
2017; Pathak-Gandhi and Vaidya, 2017; Srivastav et al., 2017; Váradi, 2020).

Dopamine is not able to pass through the blood-brain barrier, unlike its precursor L-DOPA. Administration of L-DOPA is very effective in reducing the "resting-tremors" and other primary symptoms in PD patients, but long-term benefits are not likely because L-DOPA is unable to preserve or replace degenerated DA-neurons and to stop further progression of PD. Long-term L-DOPA treatment is linked to motor complications called dyskinesias and other peripheral side effects including nausea, vomiting, low blood pressure, etc. Combined administration of L-DOPA with a peripheral DOPA decarboxylase inhibitor carbidopa prolongs the therapeutic effect of L-DOPA and helps in facilitating its side effects (Balestrino and Schapira, 2020; Iarkov et al., 2020; Maiti et al., 2017; Srivastav et al., 2017; Váradi, 2020). Another strategy for PD therapy is focused on MAO-B inhibitors used to maintain DA levels in the PD brain. The activity of the MAO-B enzyme is increased on account of DA metabolism which elevates oxidative stress and mitochondrial dysfunctions, so therapeutic approaches that optimize ROS and ameliorate mitochondrial function by inhibition of this enzyme are being considered as one of the current neuroprotective strategies (Balestrino and Schapira, 2020; Maiti et al., 2017; Srivastav et al., 2017). Although selegiline, rasagiline and safinamide show many side effects, they are currently the most commonly used MAO-B inhibitors (Jiang et al., 2018; Maiti et al., 2017). Unlike rasagiline and selegiline, safinamide is a reversible MAO-B inhibitor used in the middle and late stages of $\mathrm{PD}$, showing many additional properties, including the anti-dyskinetic effect demonstrated in animal models (Balestrino and Schapira, 2020).

When decarboxylase inhibitors are present, L-DOPA metabolism is performed by catechol-O-methyltransferase (COMT). The currently available COMT inhibitors entacapone, tolcapone, and opicapone are used in PD therapy to prolong the effects of L-DOPA, but these drugs produce serious side effects, particularly tolcapone (Balestrino and Schapira, 2020; Jiang et al., 2018; Maiti et al., 2017).

Additionally, the administration of DA agonists is used for the direct stimulation of dopamine receptors during early-stage PD. The most common DA agonists ropinirole, pramipexole, ropinirole and apomorphine (especially effective for acute "off" episodes) are used to treat PD patients during early-stage $\mathrm{PD}$, but these drugs show several potential side effects similar to L-DOPA (Balestrino and Schapira, 2020; Jiang et al., 2018; Maiti et al., 2017).

Non-dopaminergic drugs. Non-dopaminergic drugs include anticholinergic compounds, norepinephrine, serotonergic receptor- and muscarinic-receptor-related compounds, and antiviral drugs. Anticholinergic drugs (e.g. trihexyphenidyl, benztropine, orphenadrine, biperiden) can help in reducing tremors and muscle stiffness in PD but induce deficits in cognitive function (Balestrino and Schapira, 2020; Maiti et al., 2017). On the contrary, treatment with AChE inhibitors (e.g. rivastigmine, donepezil and galantamine) improves cognitive function but increases tremor (Balestrino and Schapira, 2020). NMDA (N-methyl-D-aspartate) glutamate receptor antagonists with anticholinergic activity such as amantadine activate dopamine synthesis and reduce motor symptoms, but have caused many side effects (Balestrino and Schapira, 2020; Jiang et al., 2018; Maiti et al., 2017).

Besides, there are surgical procedures, stem cell transplantation, gene therapy, as well as complementary, supportive and rehabilitation therapies that can prevent or delay the progression of this complex disease (Maiti et al., 2017). The potential therapeutic targets remain challenging keeping in mind the multifactorial heterogeneous risk factors associated with PD 


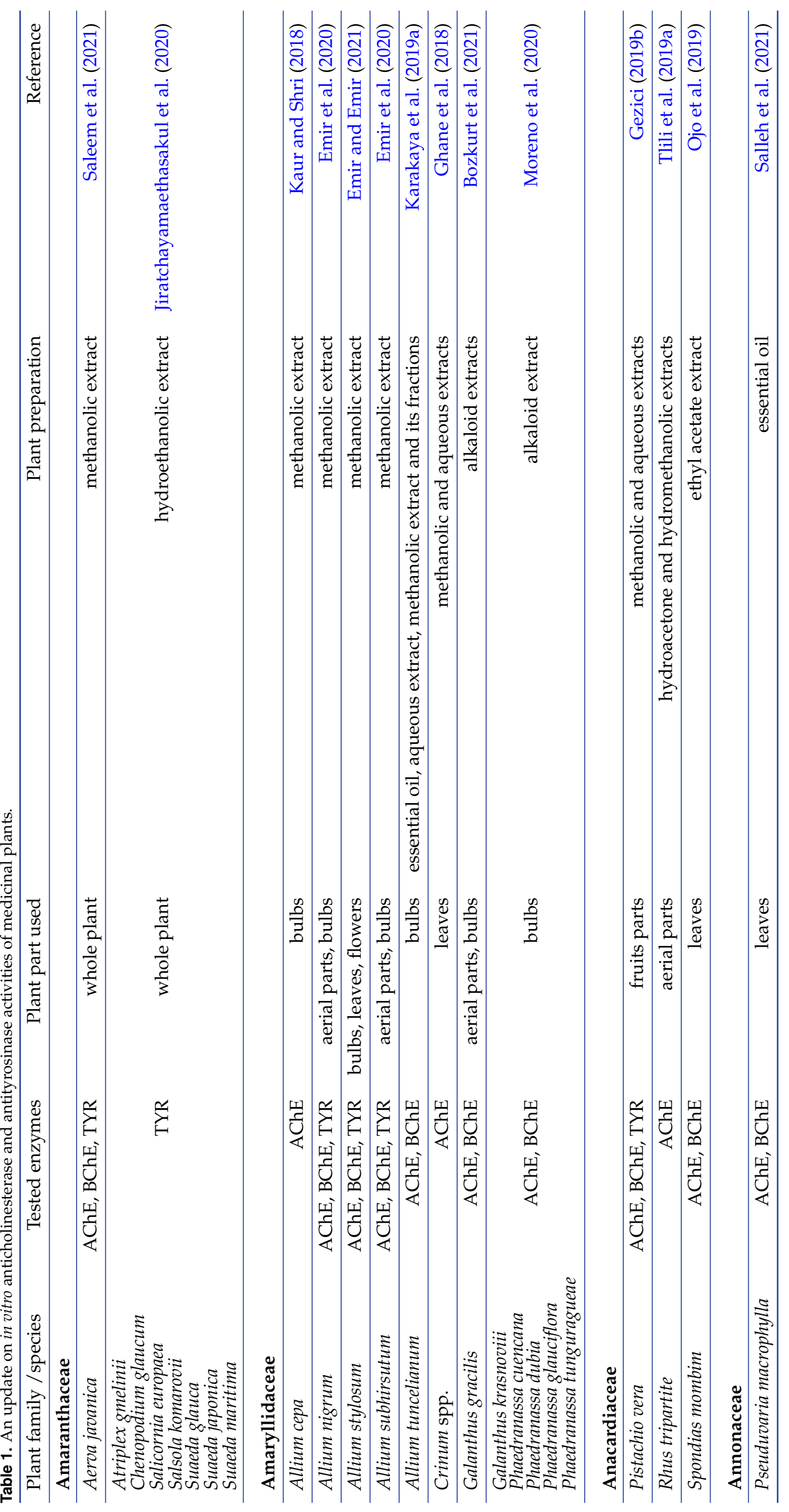




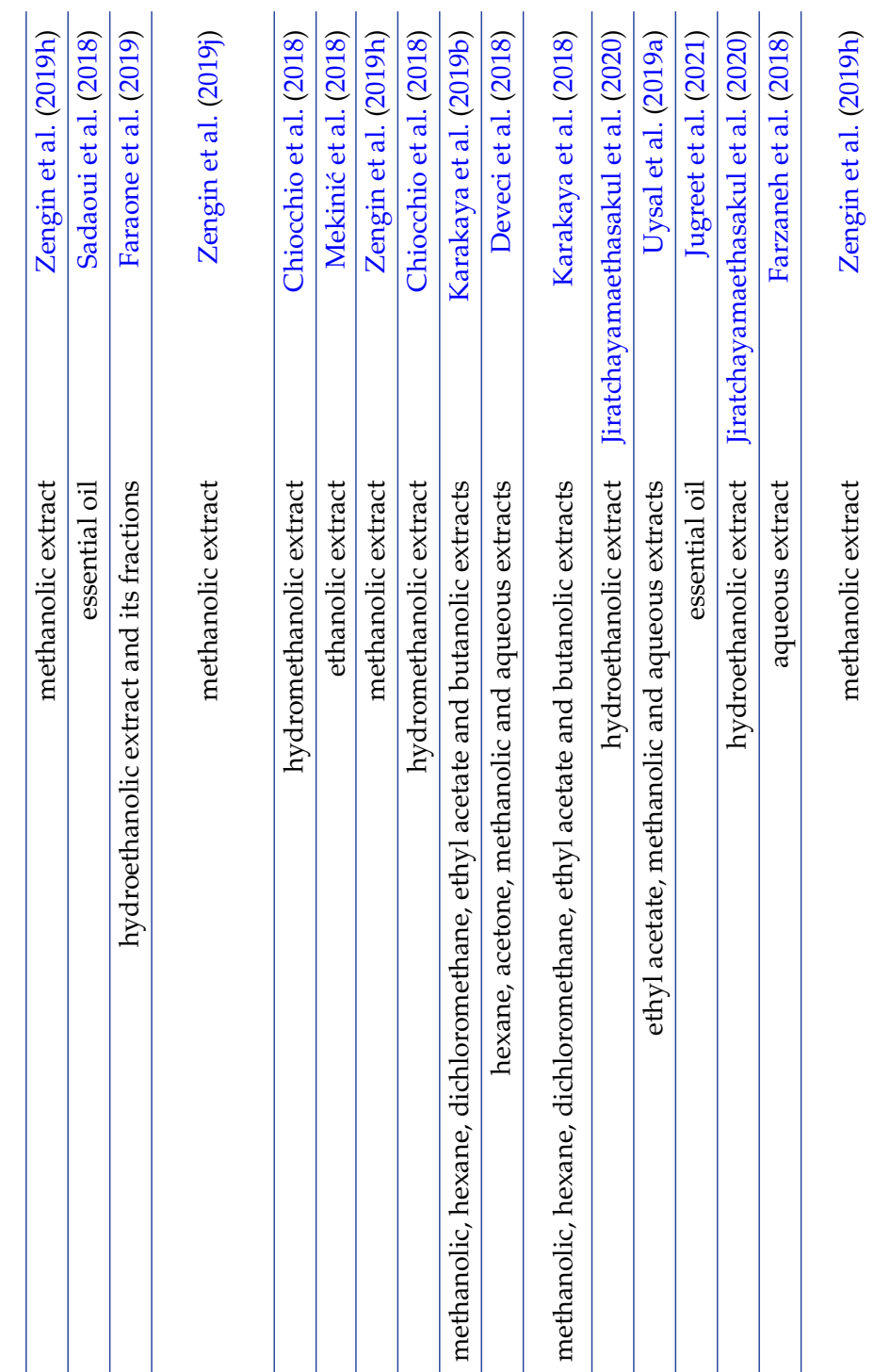

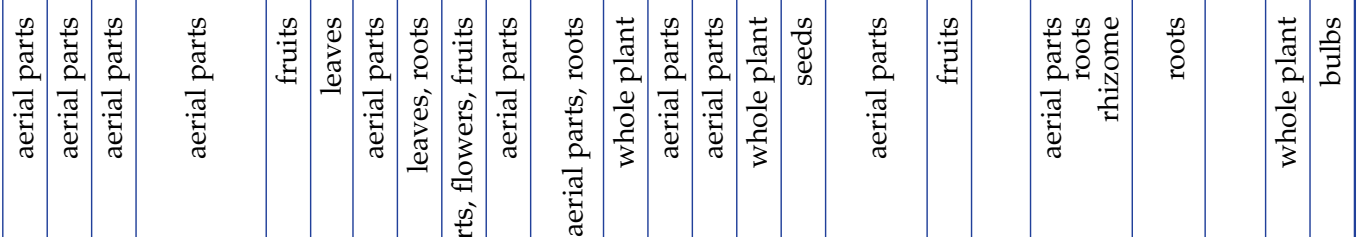

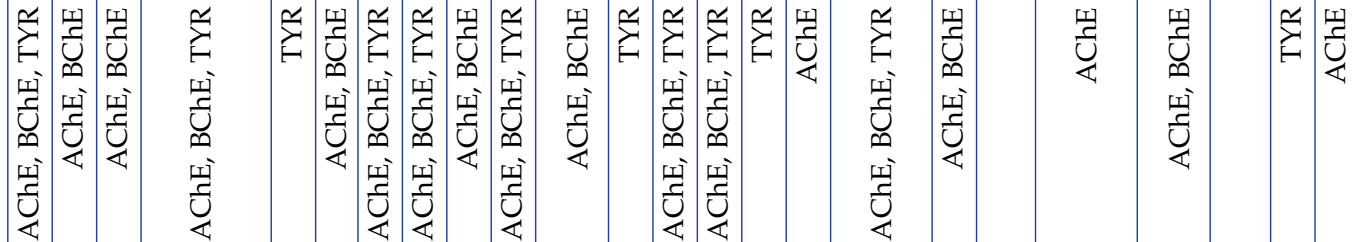

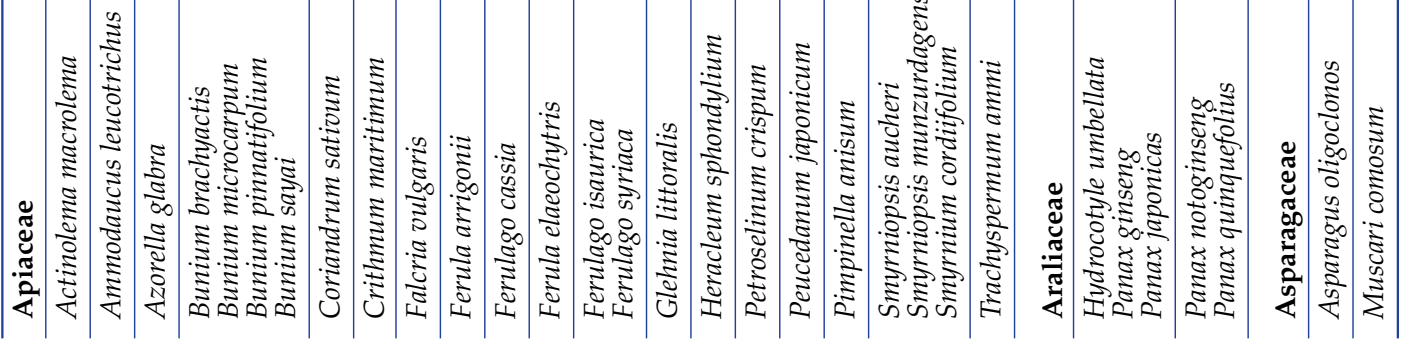




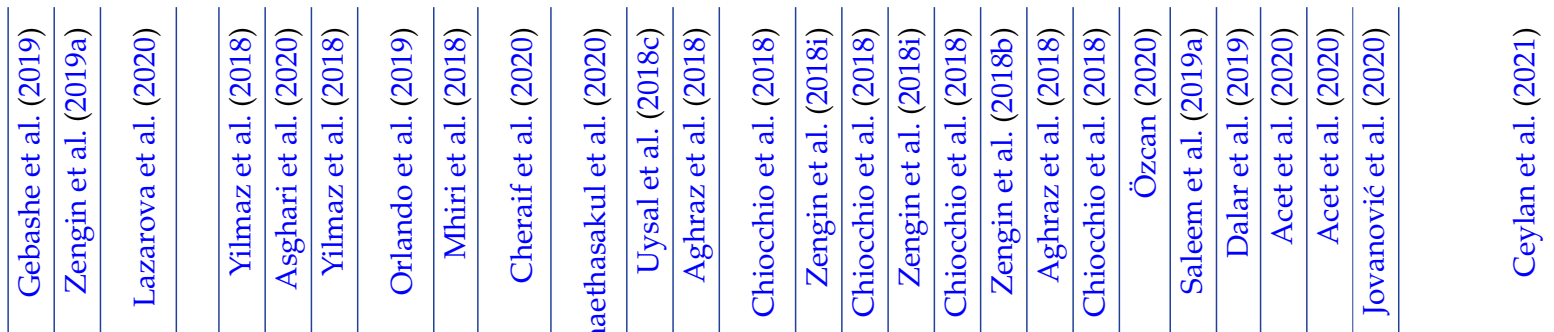

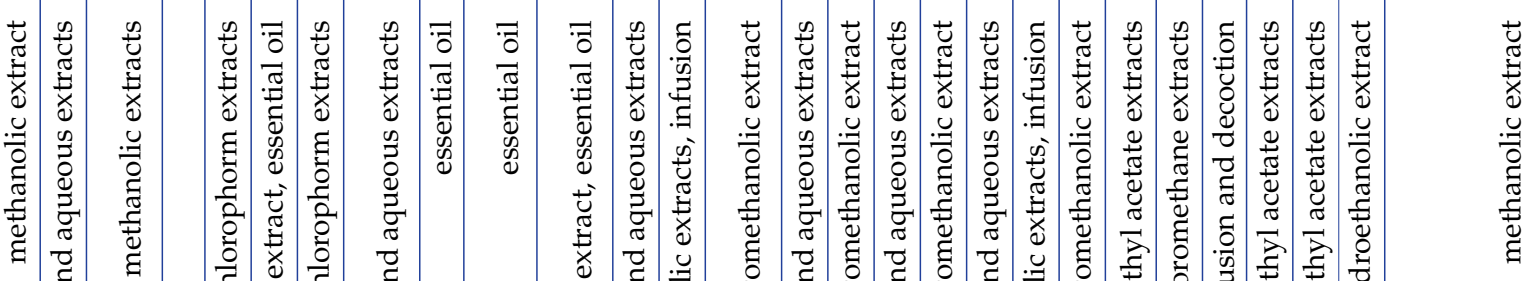
胥 


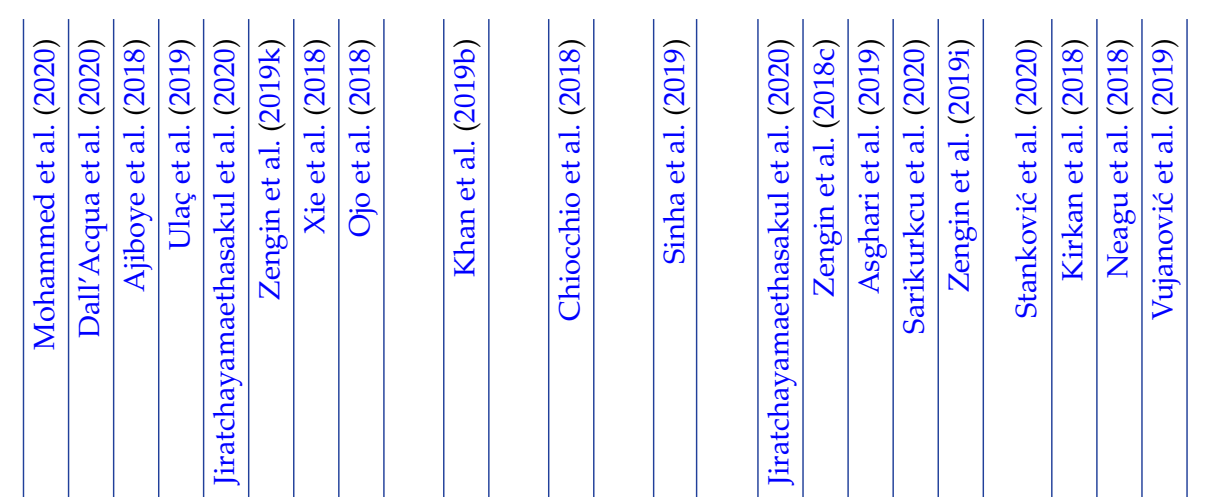

न 葛

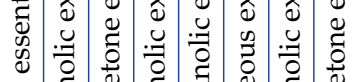

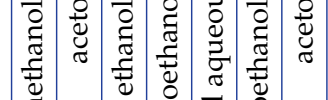

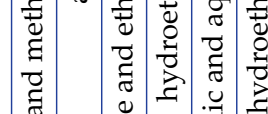

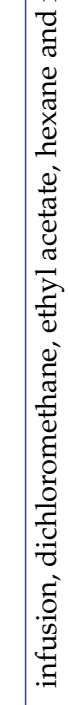

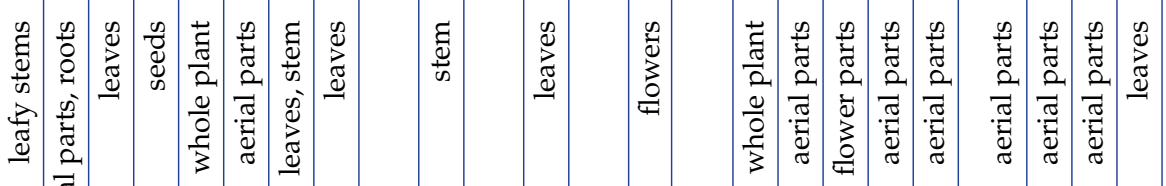
.

元苂

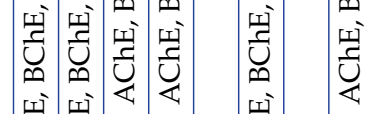

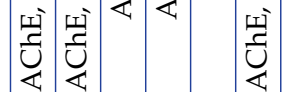

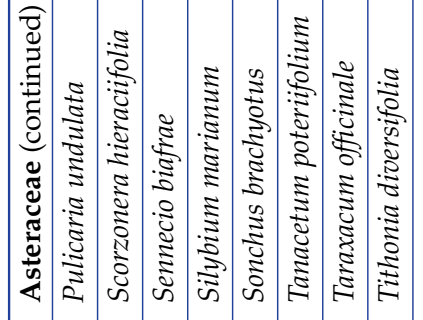

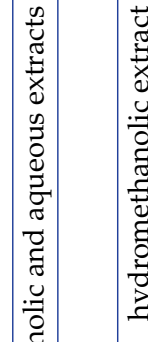

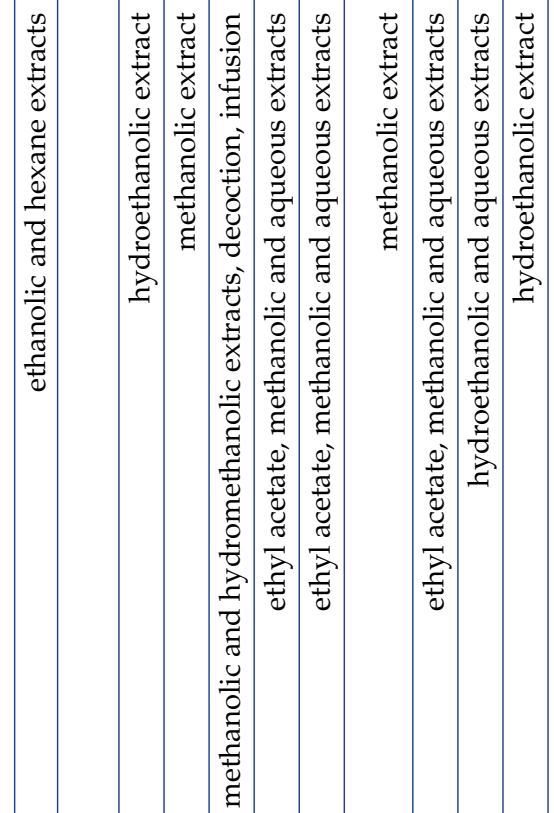

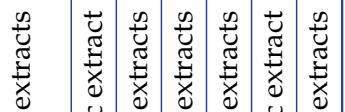

घ

穿

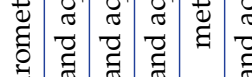

空

芯

旨

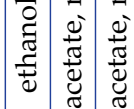

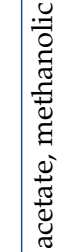

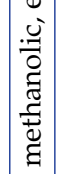

胥

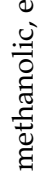

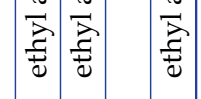

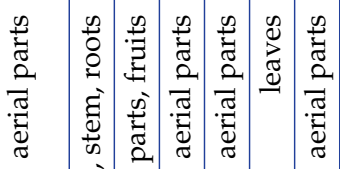

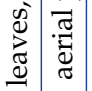

क्षे

药

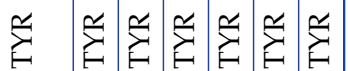

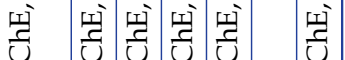

車

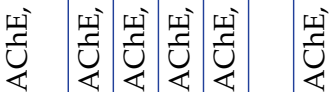

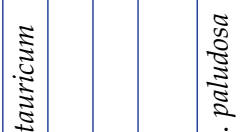

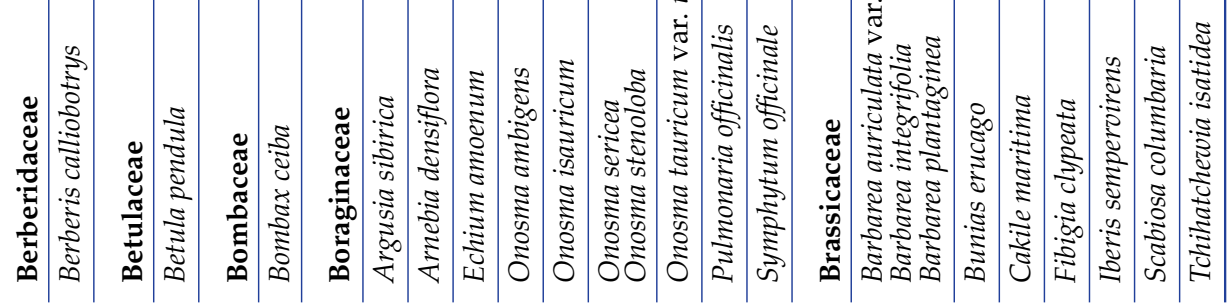




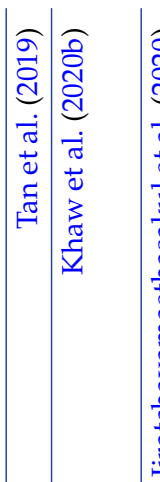

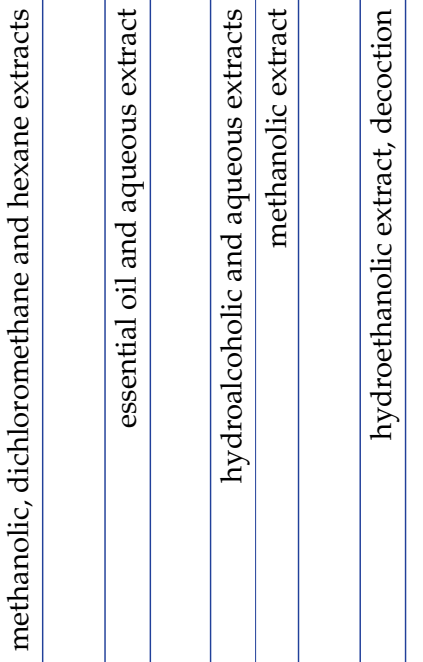

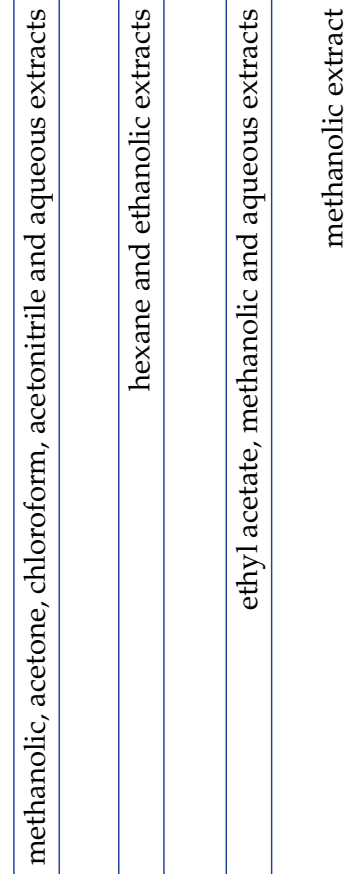

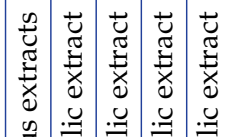

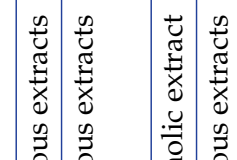

势

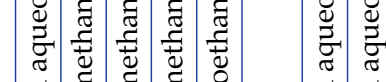

芠

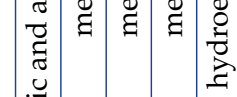

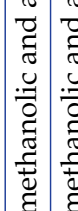

离

胥

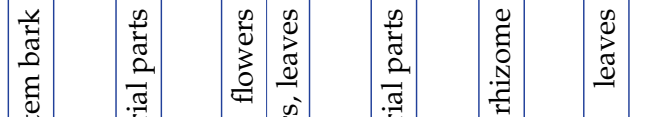

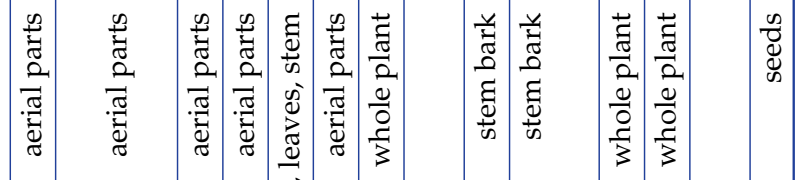

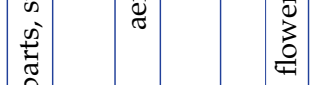

跘

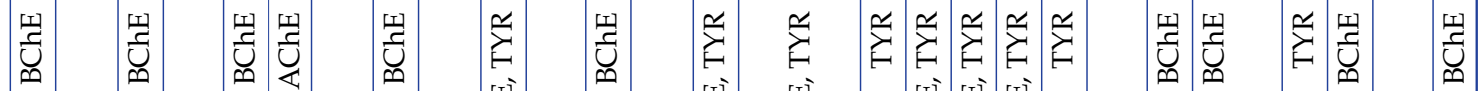

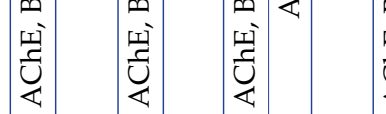

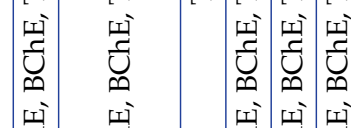

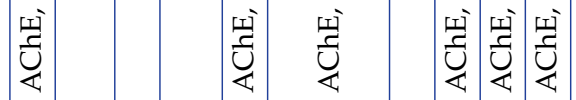

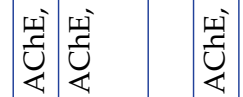

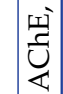

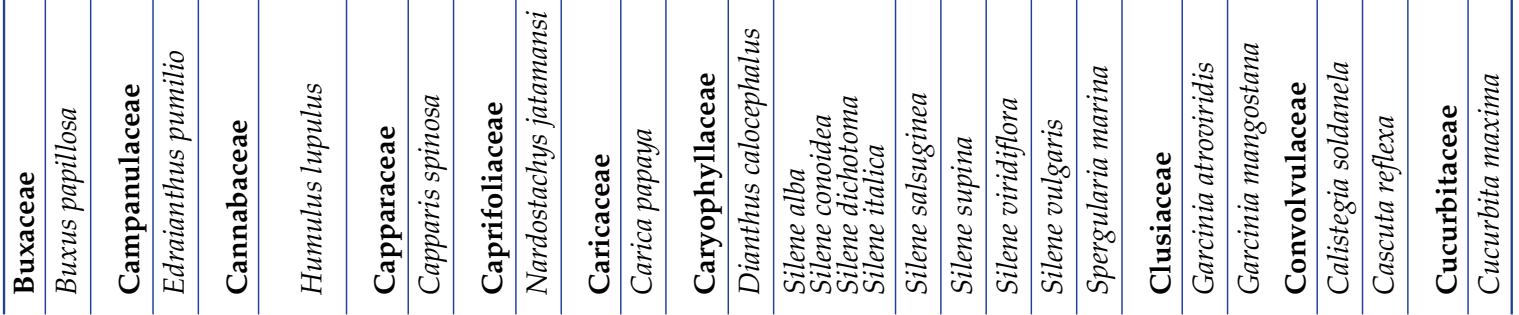




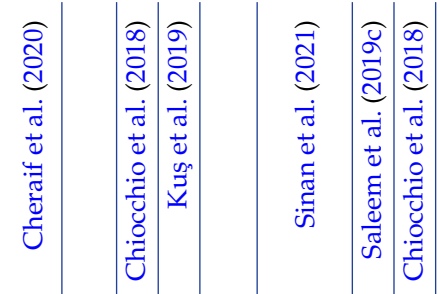

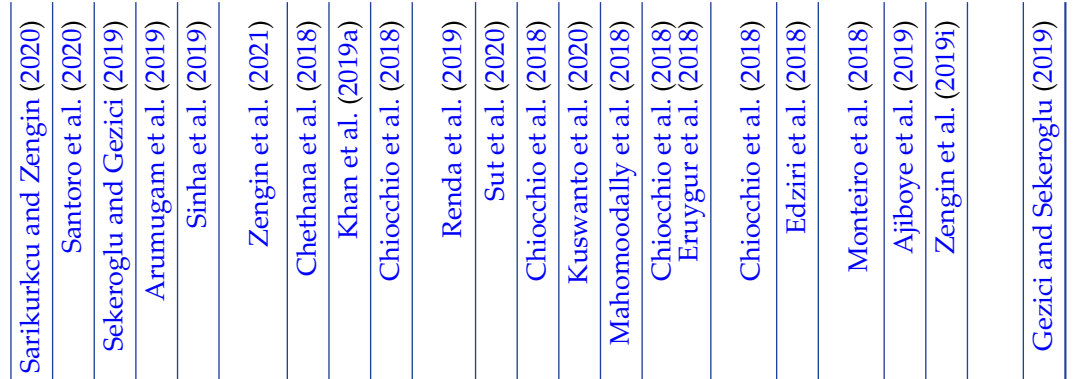

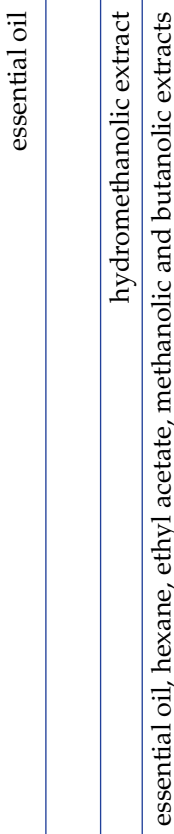

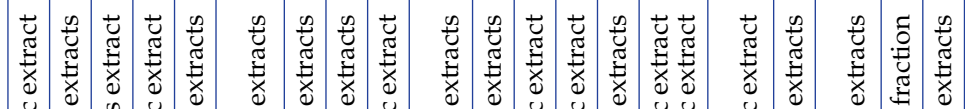

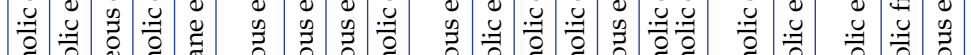

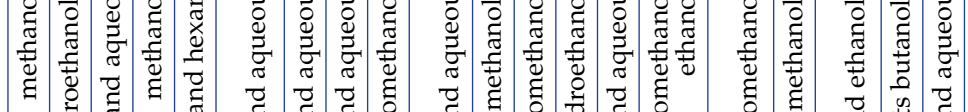

\section{苟

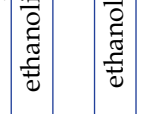

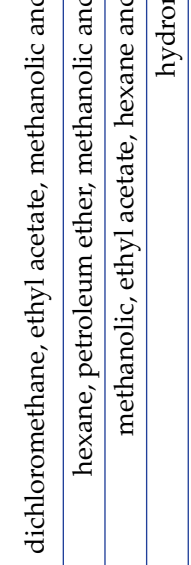

究

离

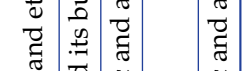

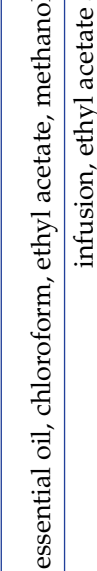

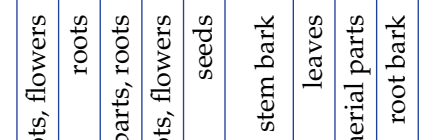

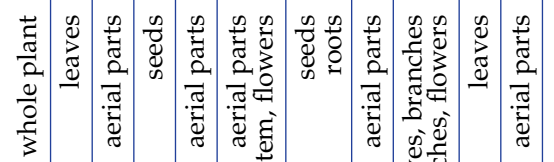

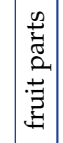

:

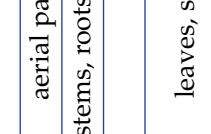

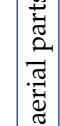

产

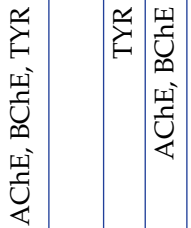

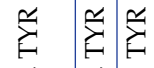

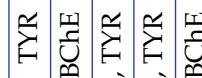

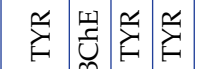

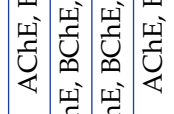

装

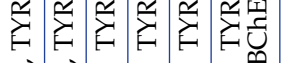

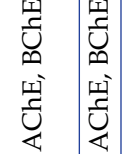

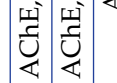

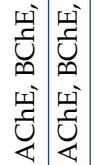

跑

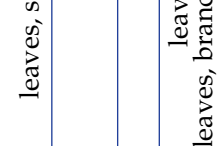

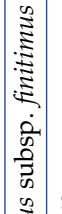

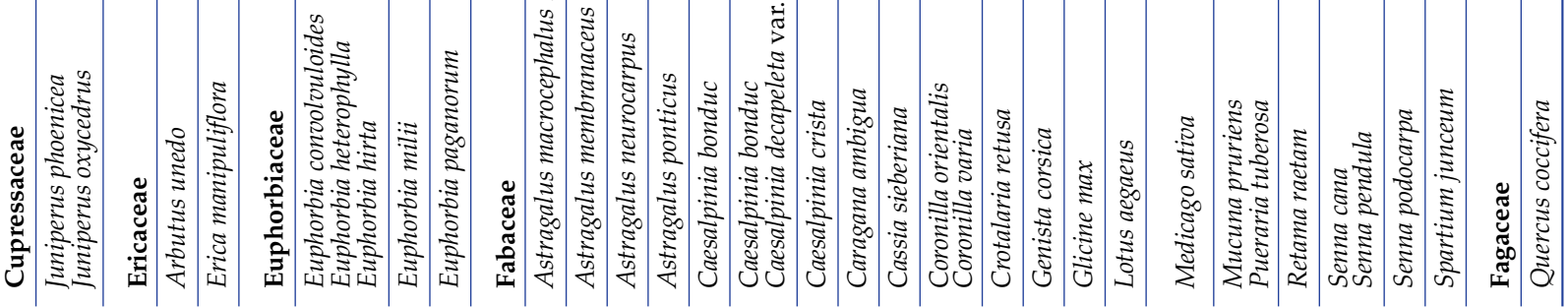




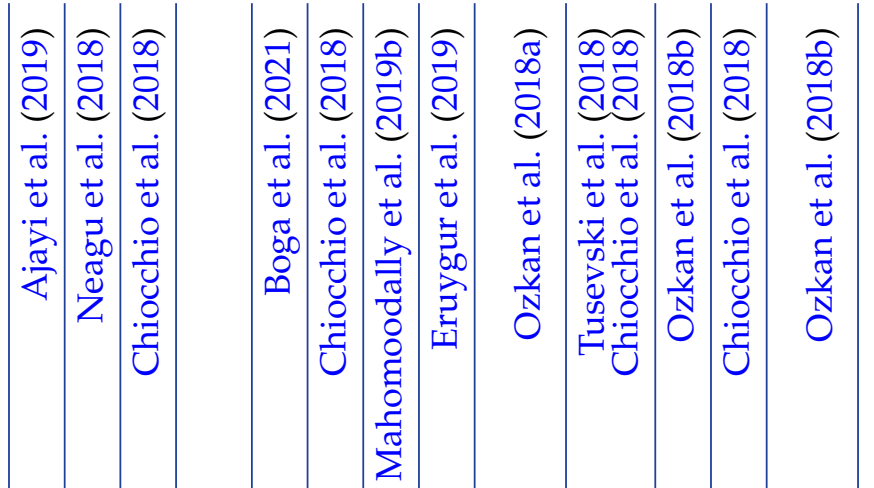

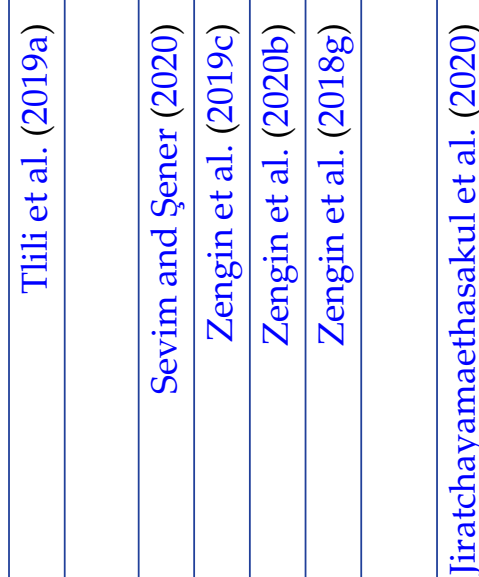

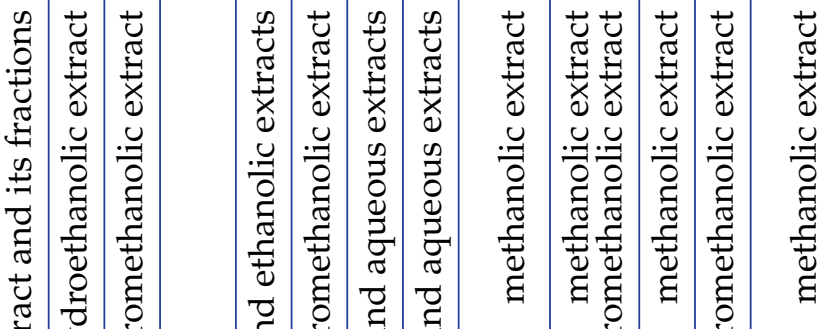

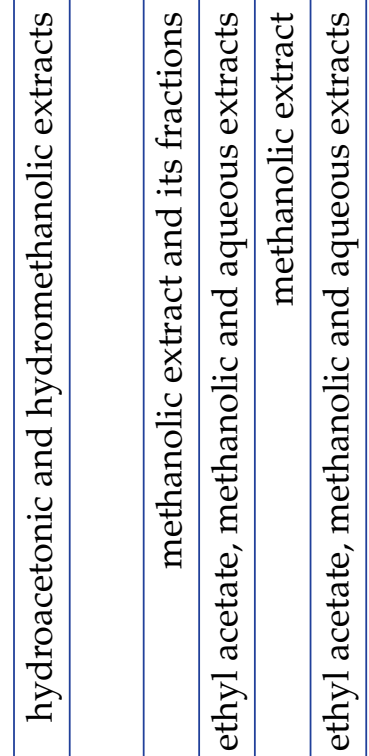

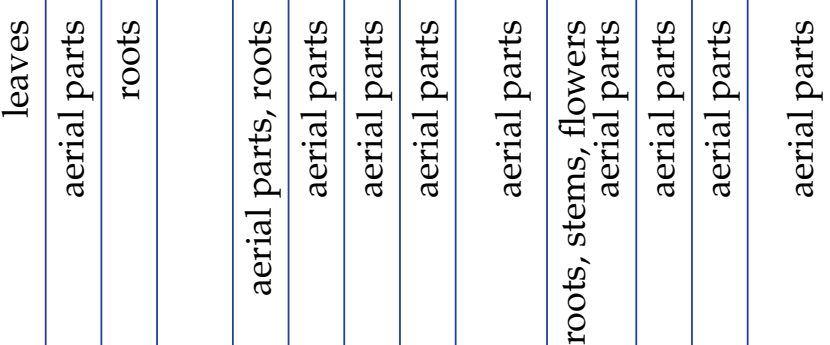

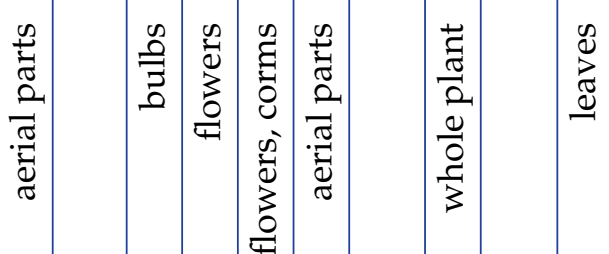

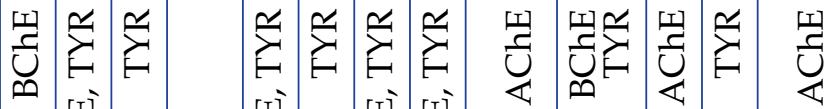

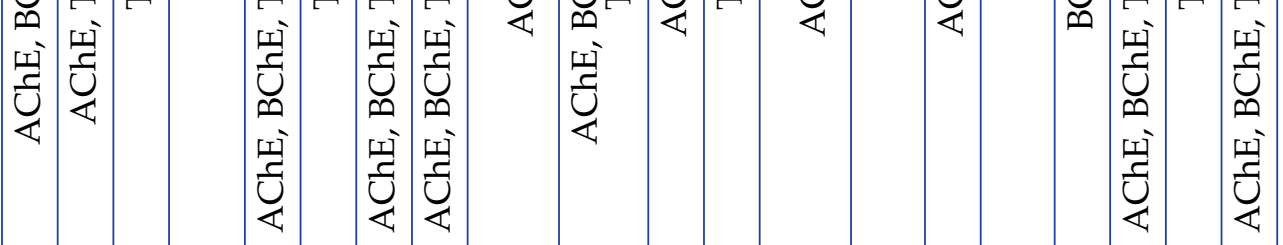

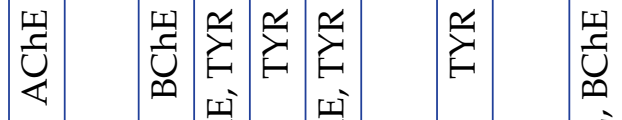

별

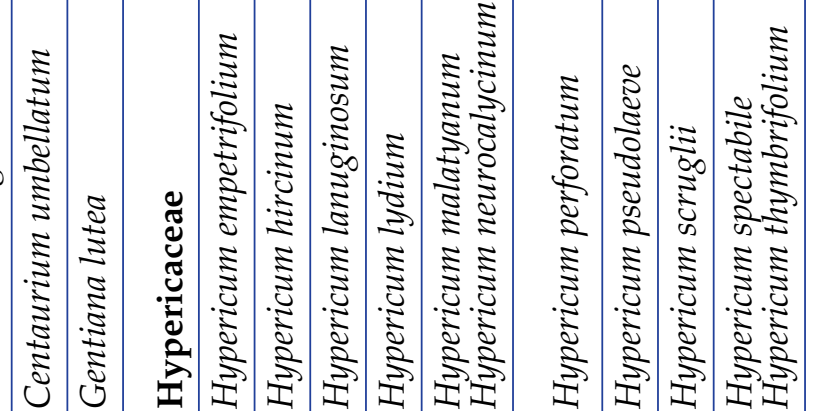

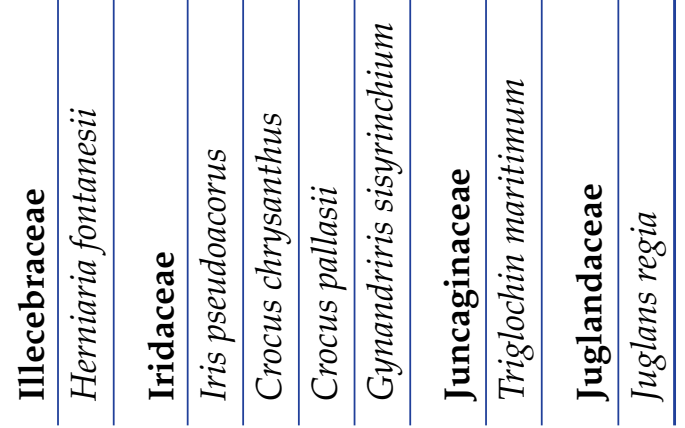




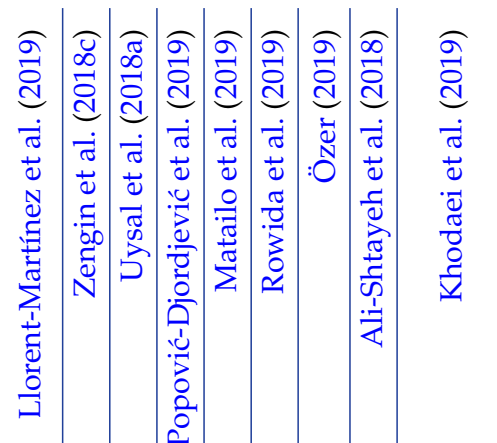

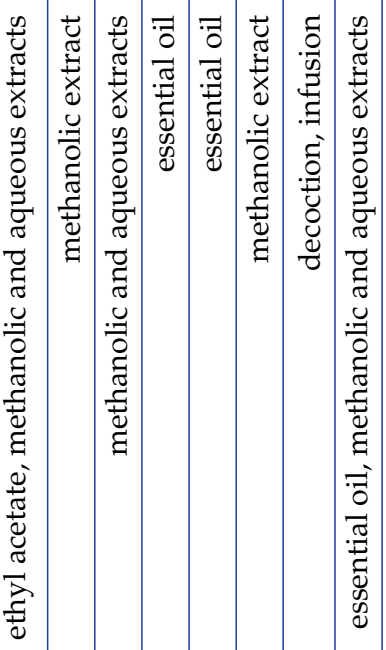

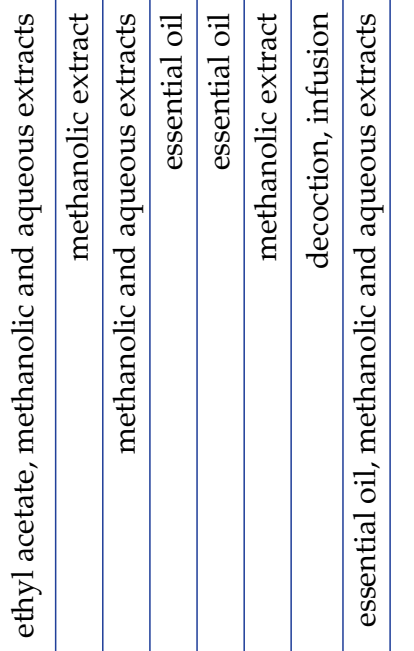

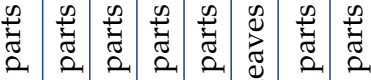

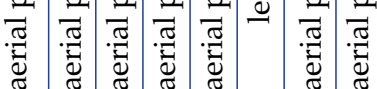

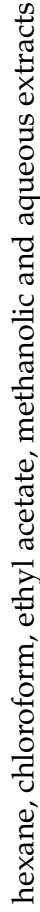

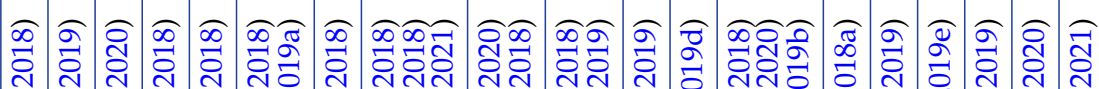

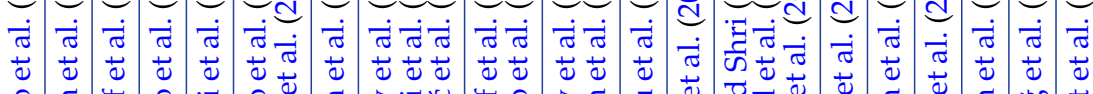

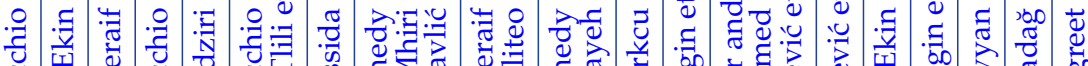

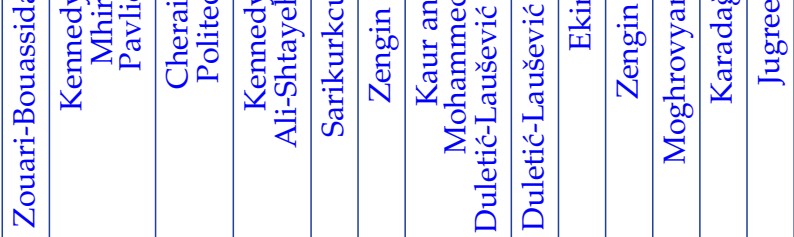

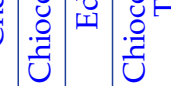

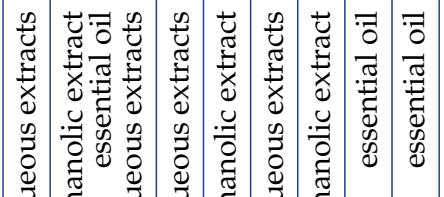

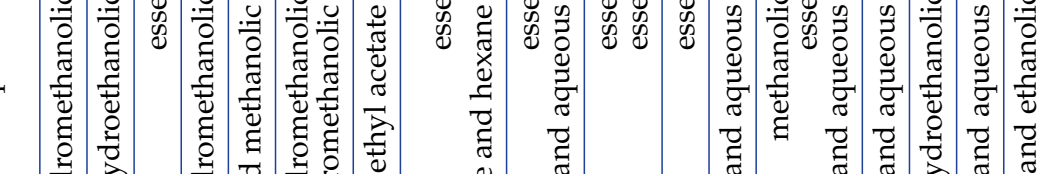
突

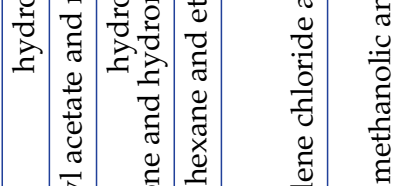

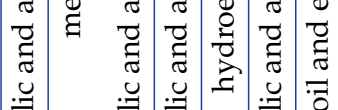
$\square$

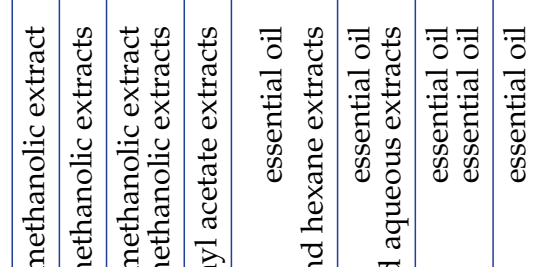

:

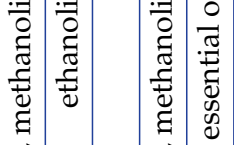

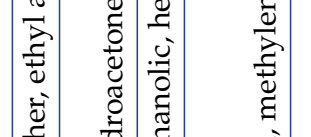

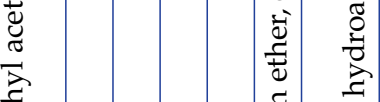

离

密

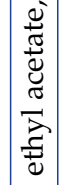

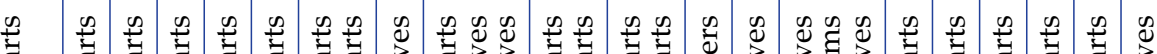

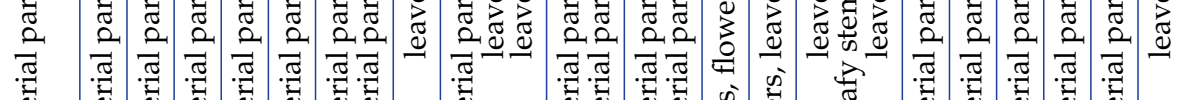

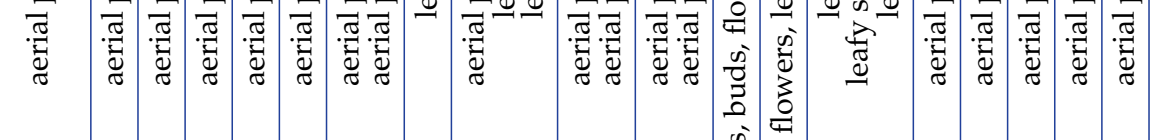
离

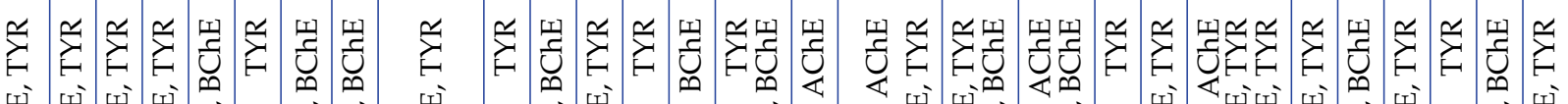

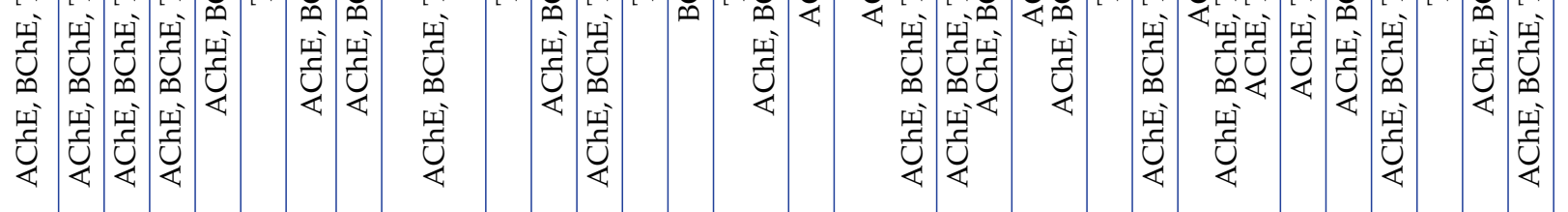

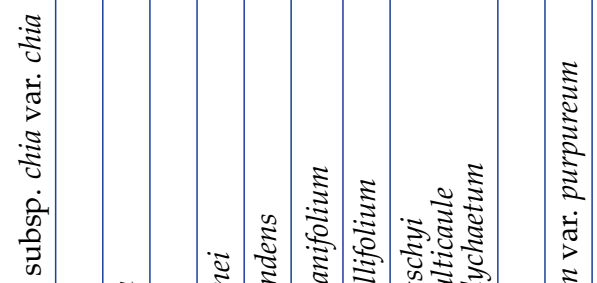

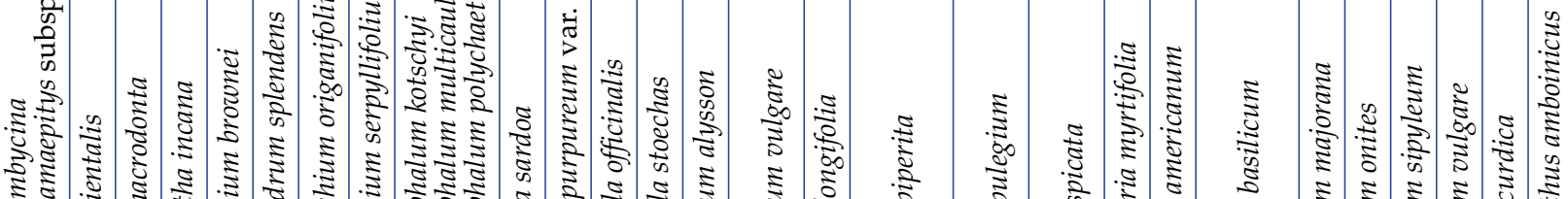

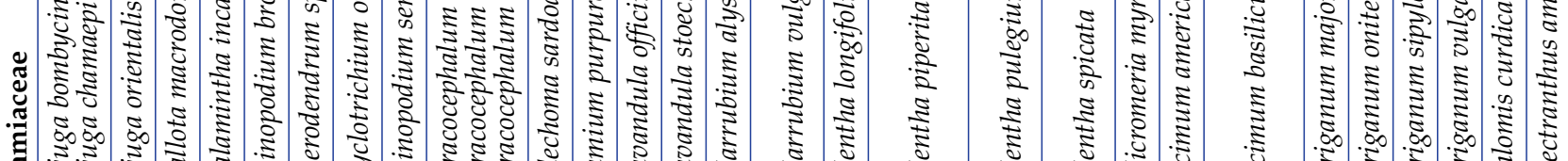

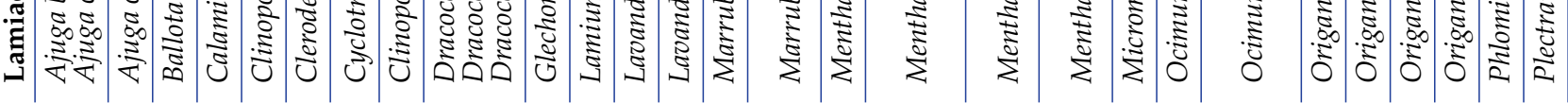




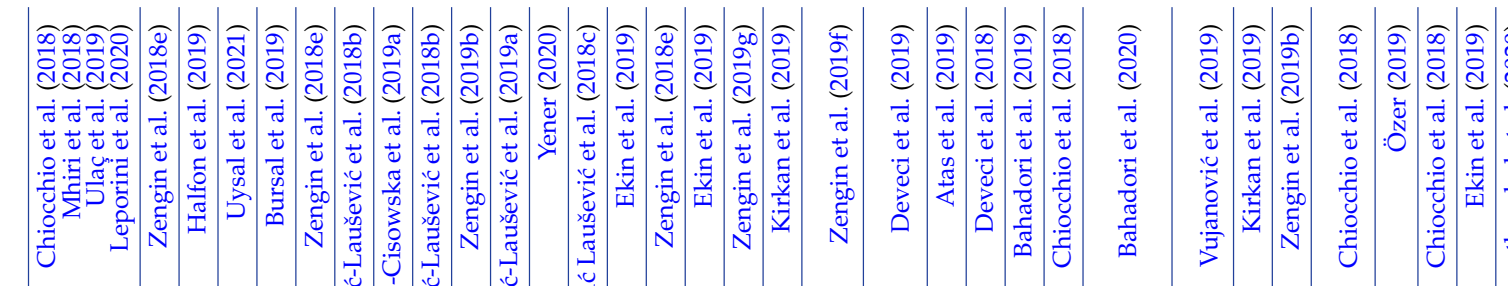

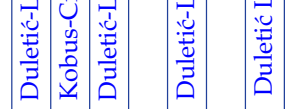

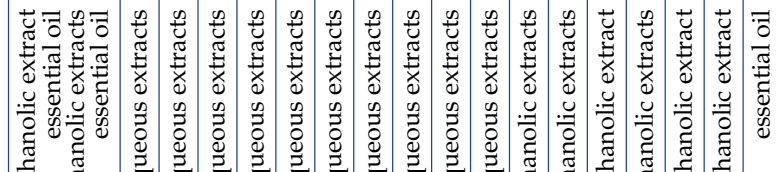

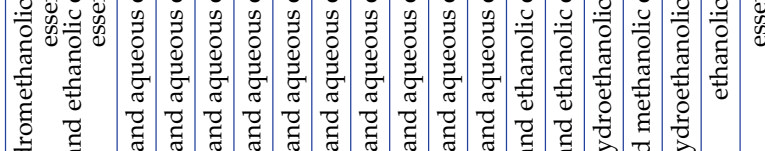

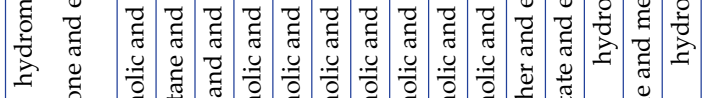

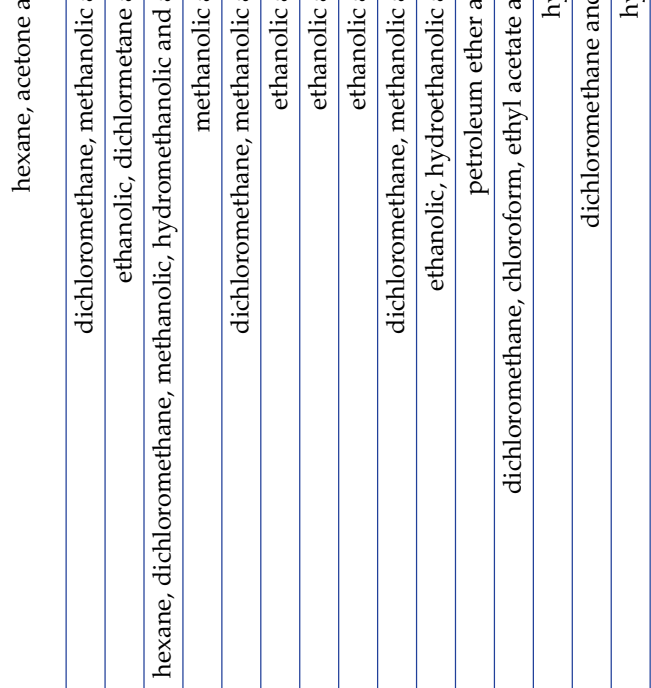

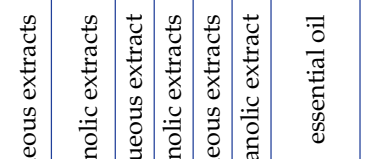

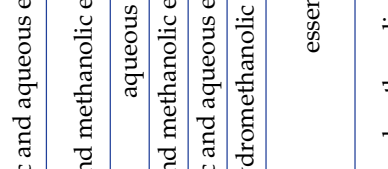

:

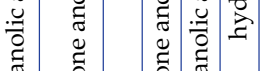

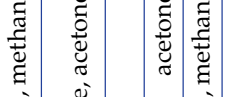

芯

衰

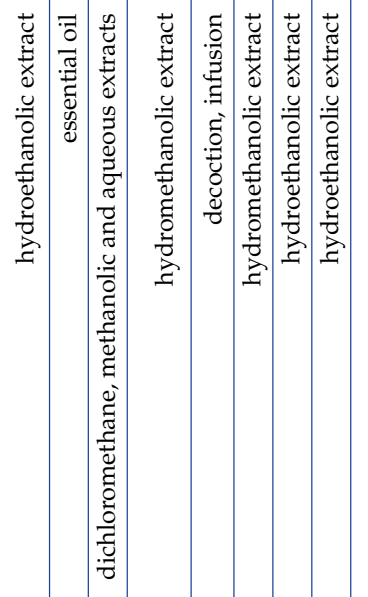

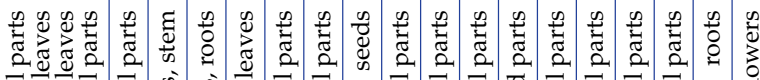

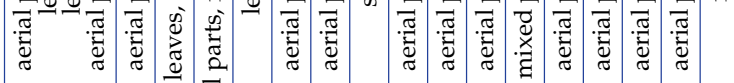
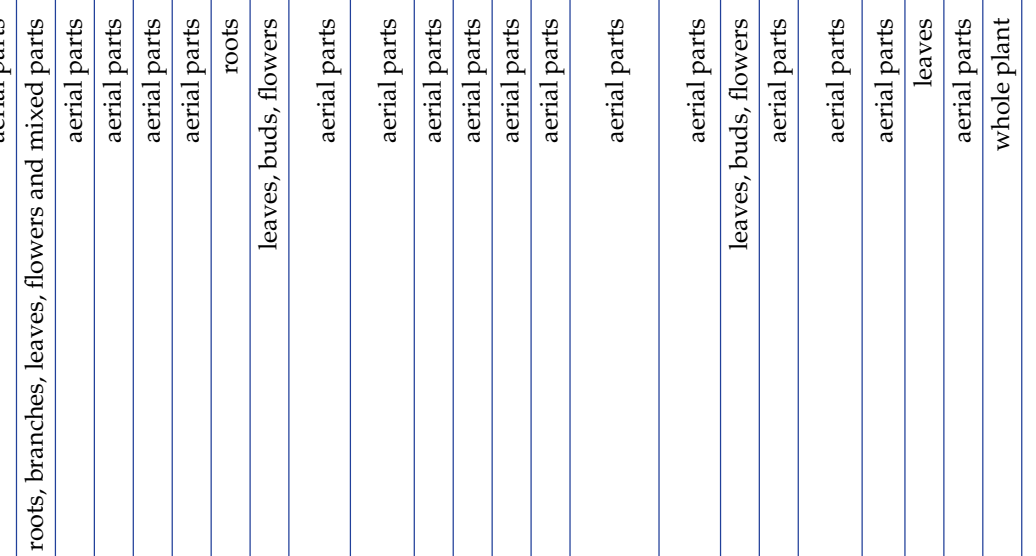

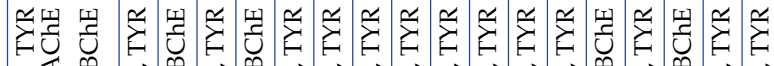
焉

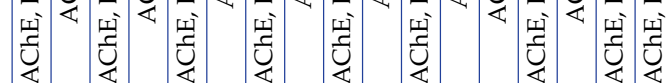

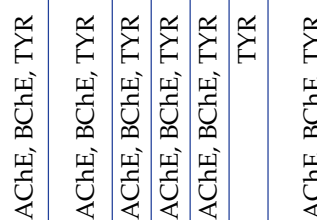

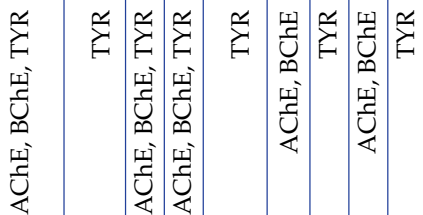

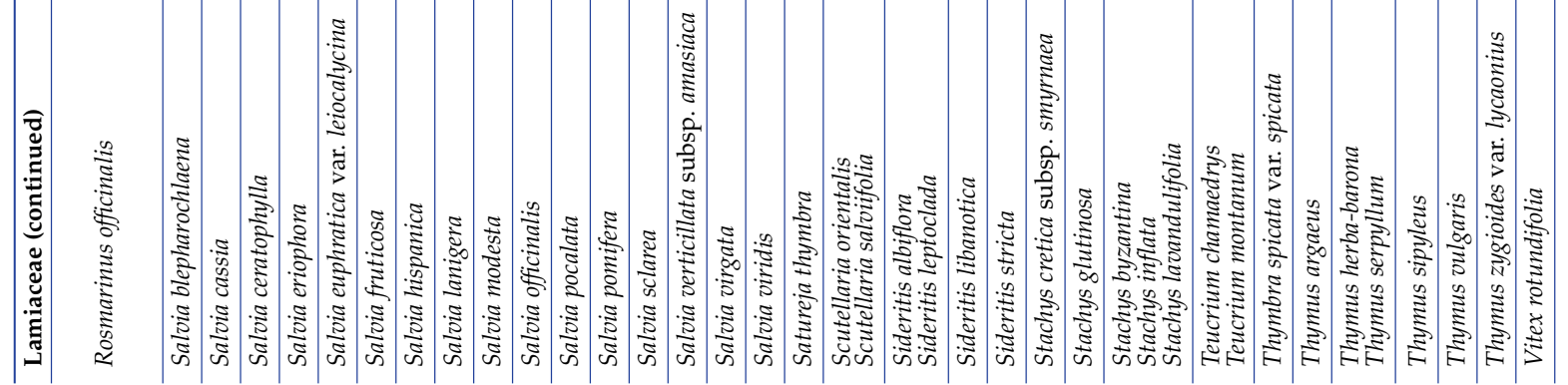




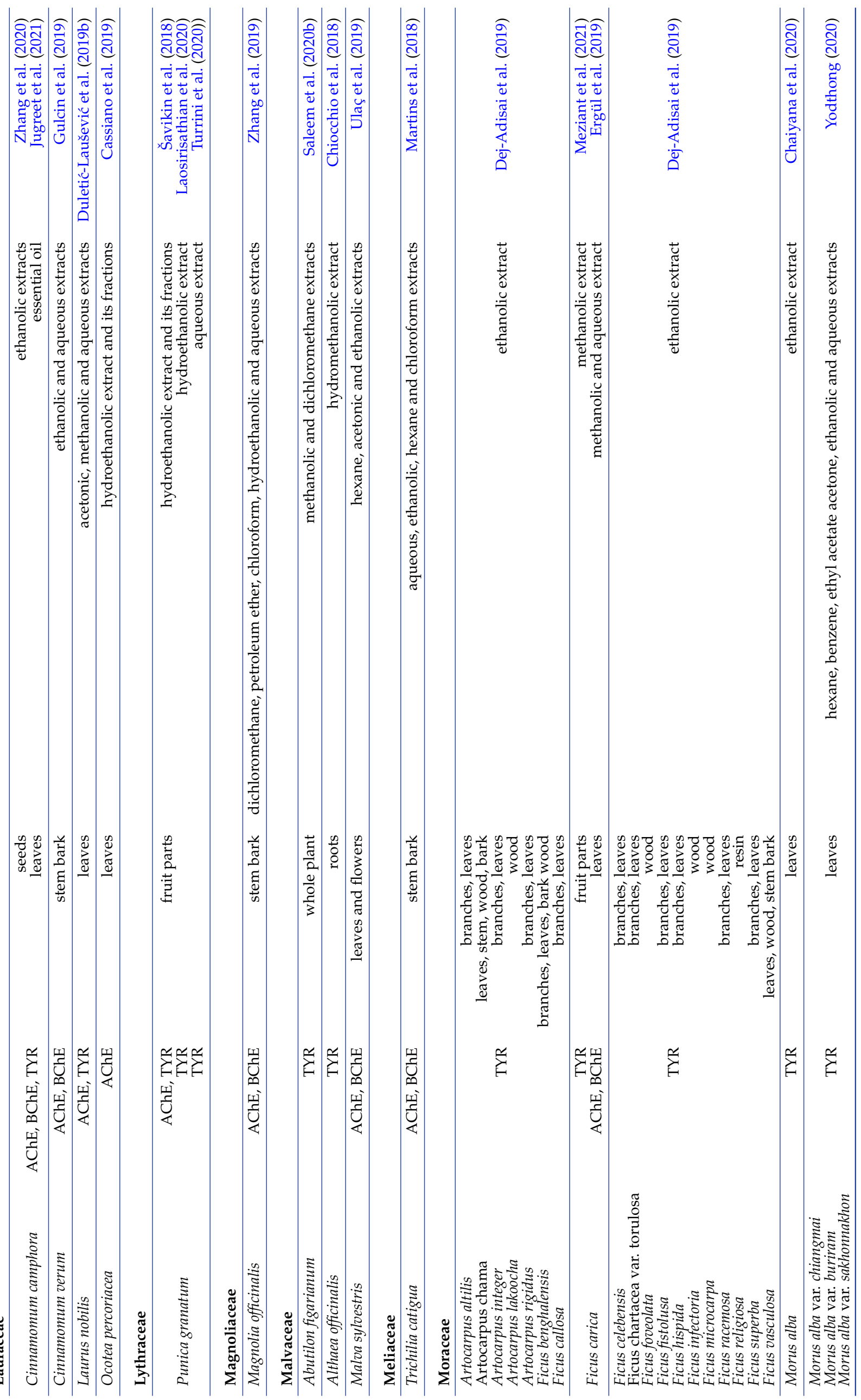




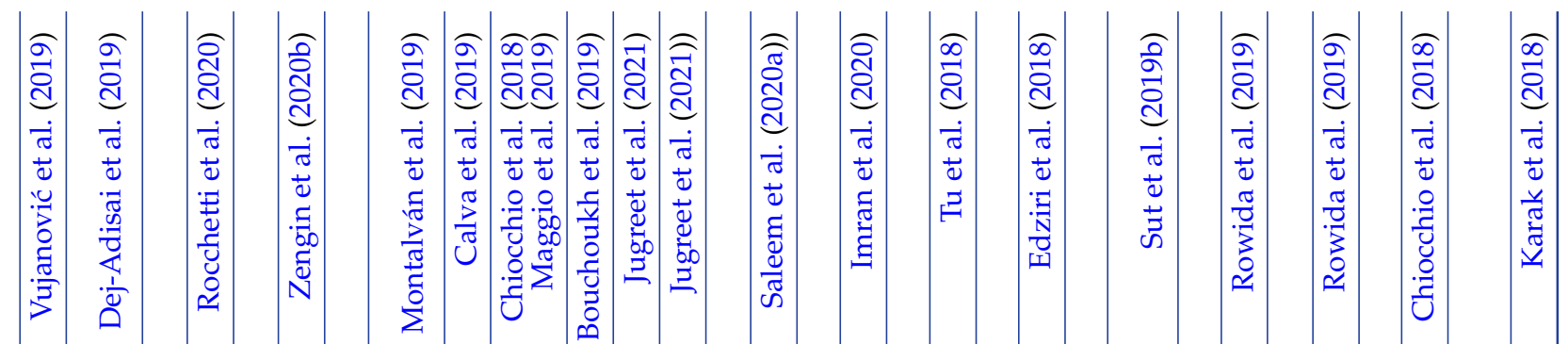

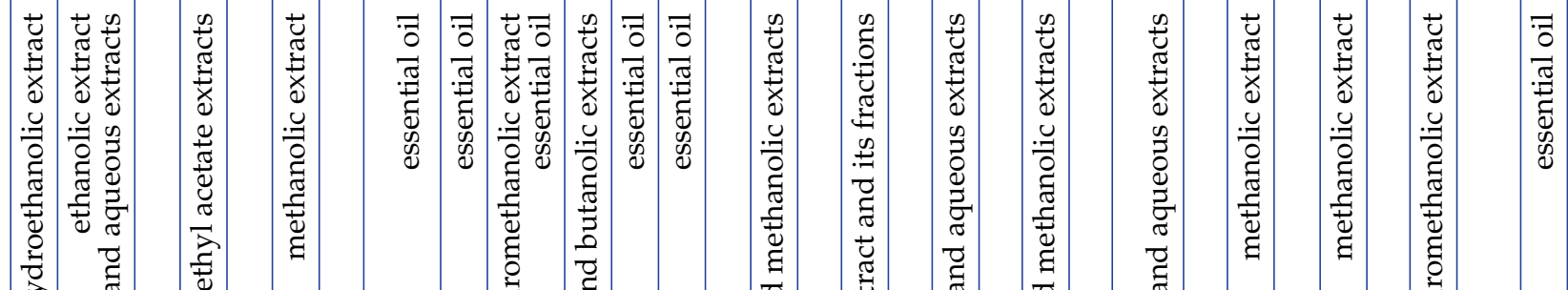

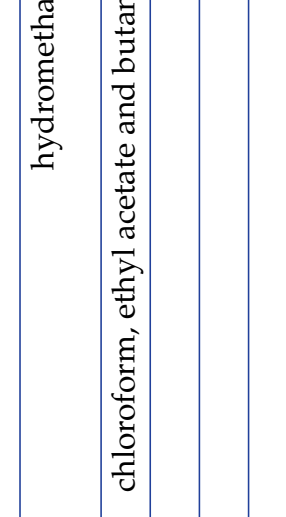

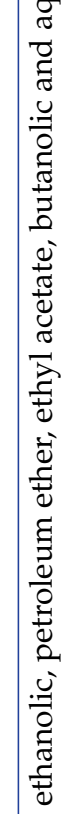

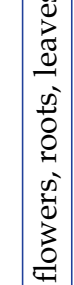

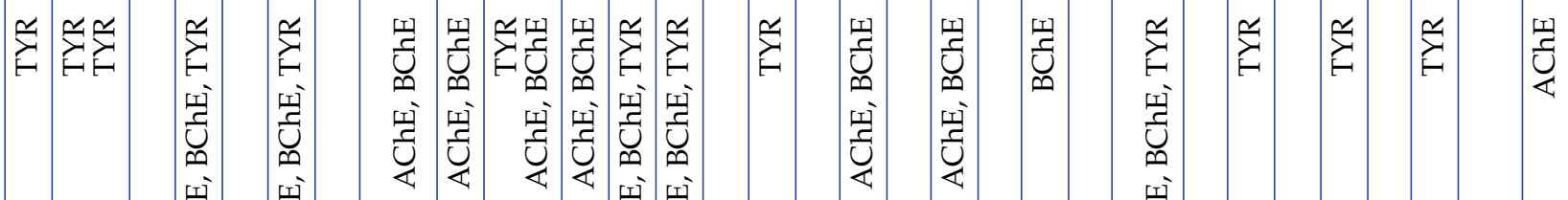
望 至 亚突 蚚

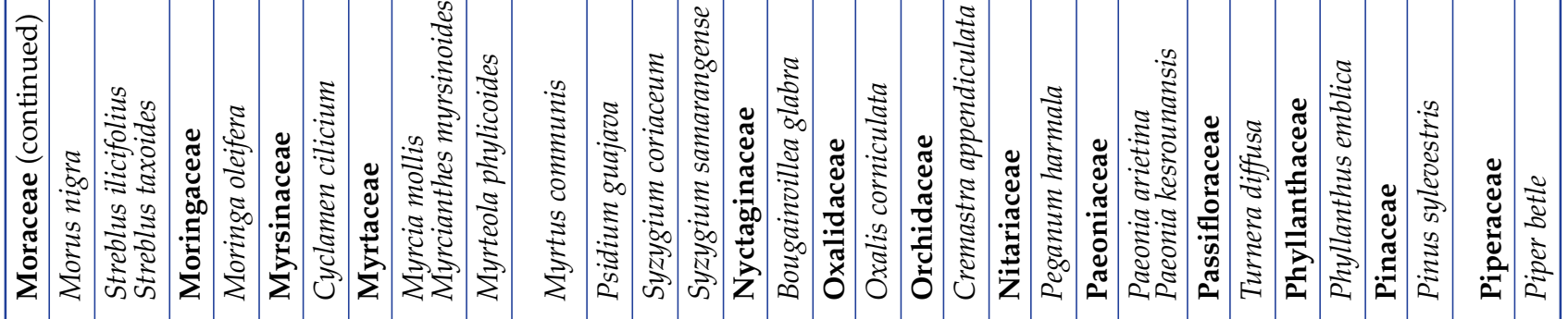




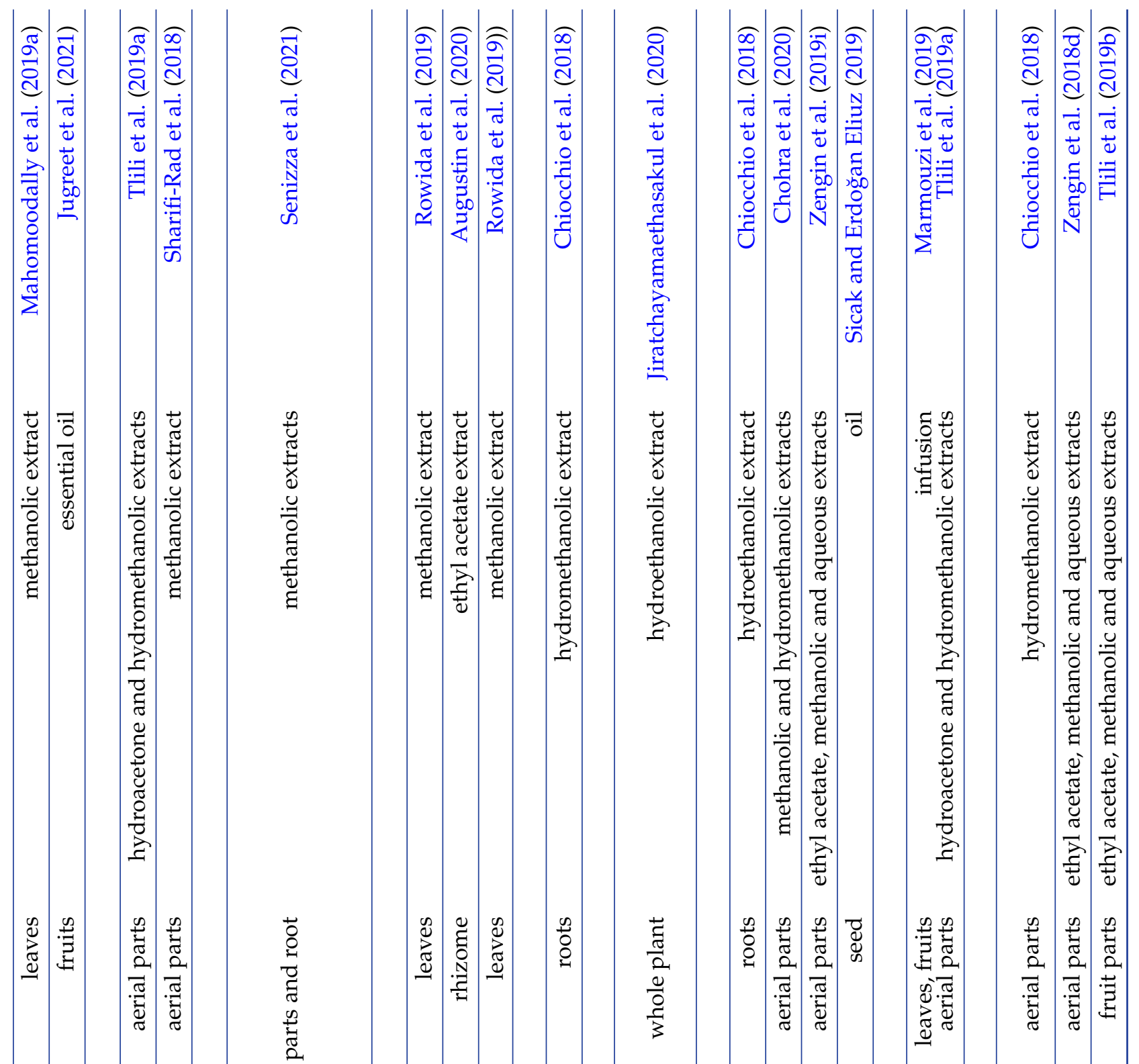

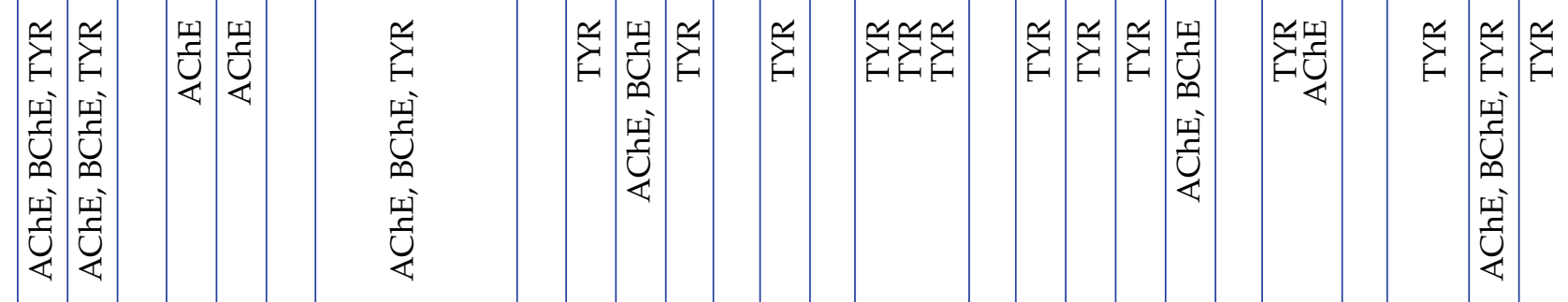

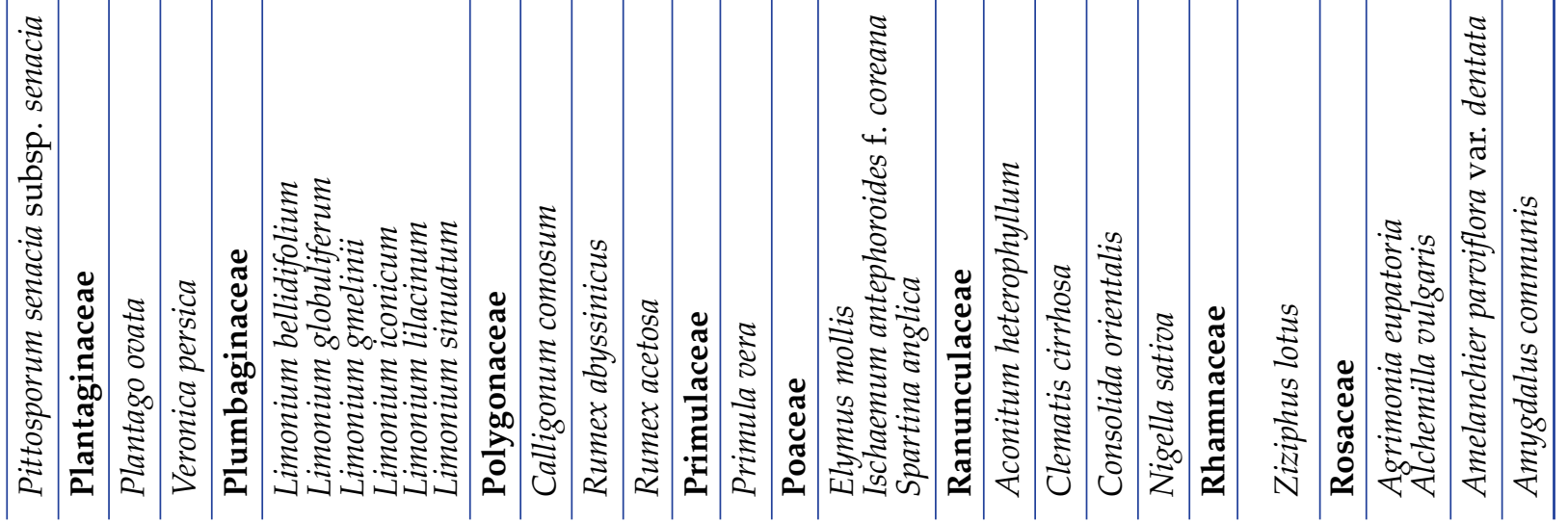




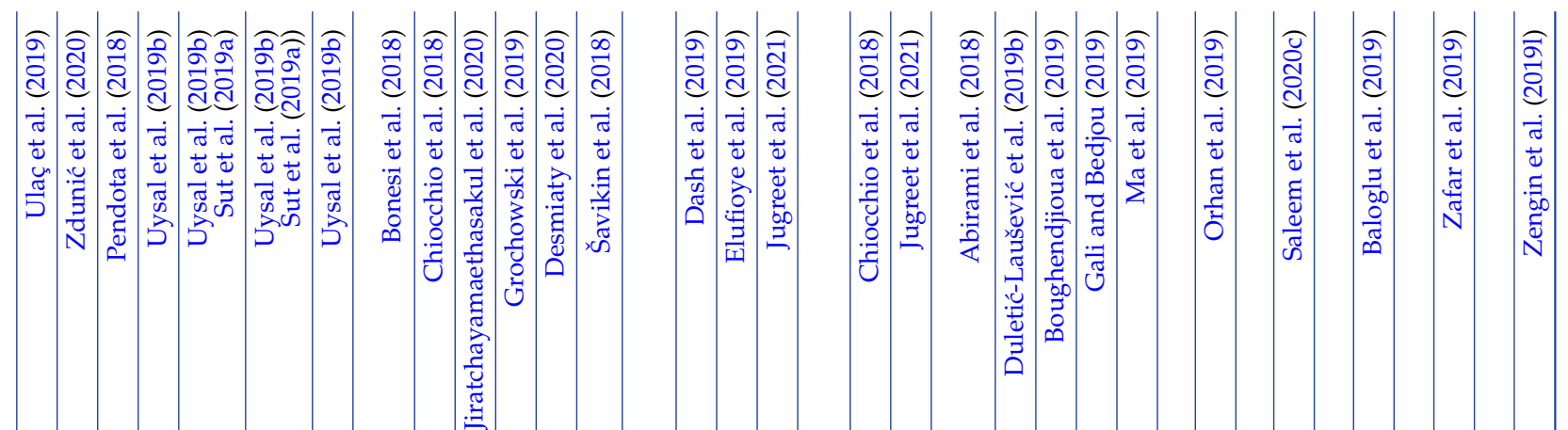

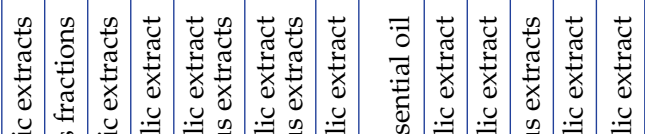

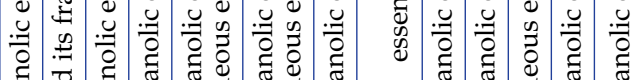

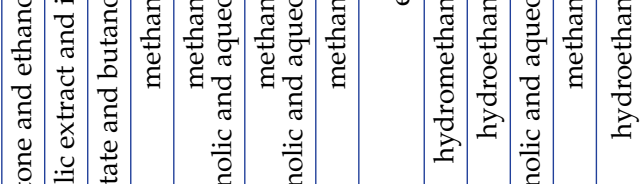

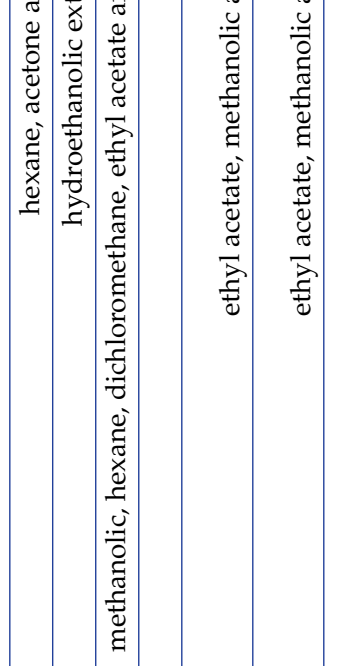

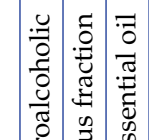

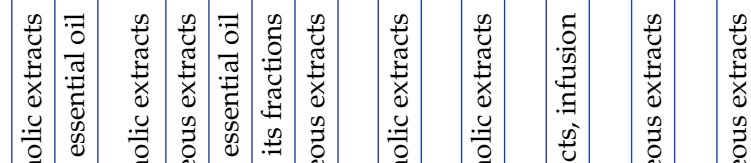
经 胥

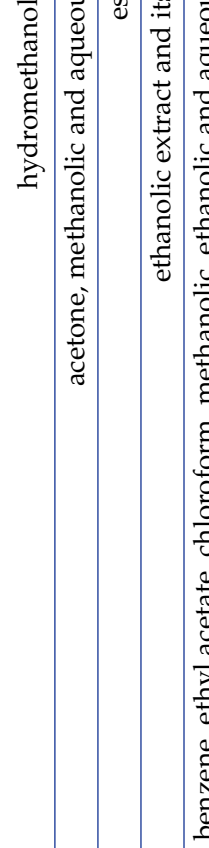
吾

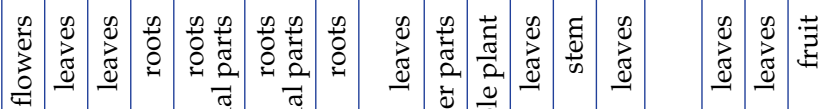

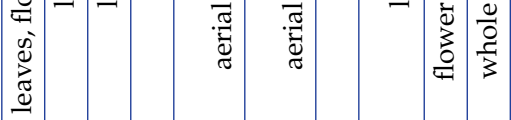

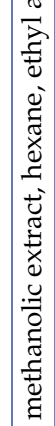

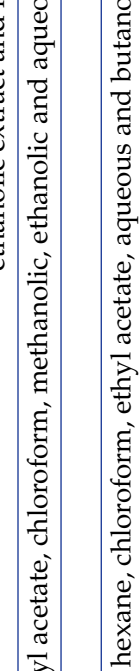

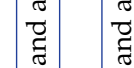
घี

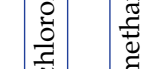

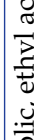

要

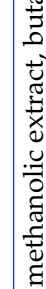

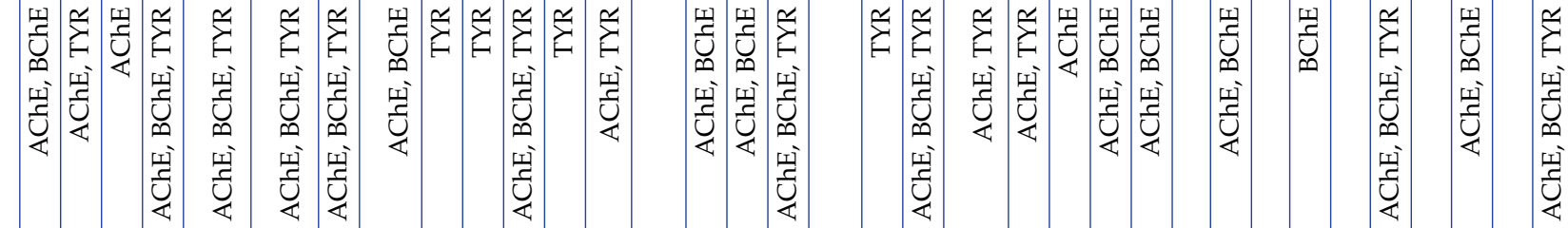

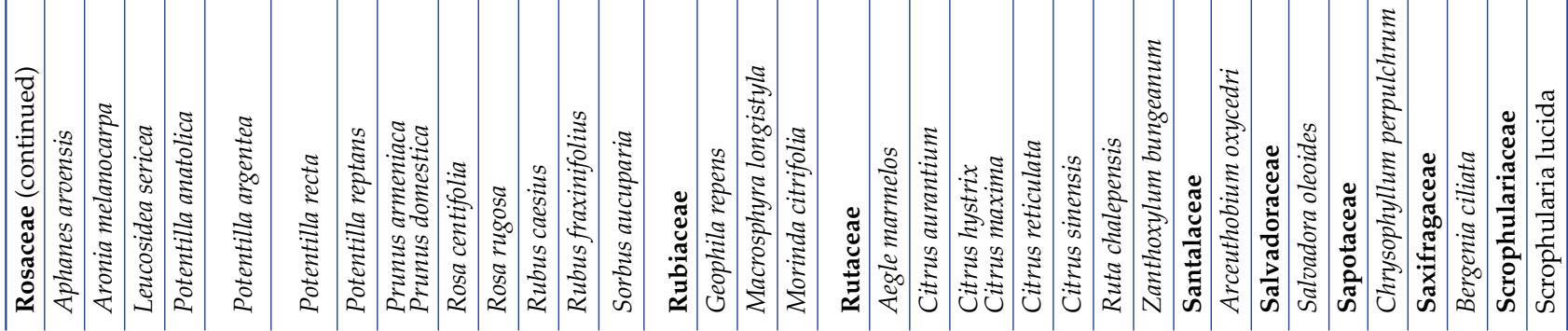




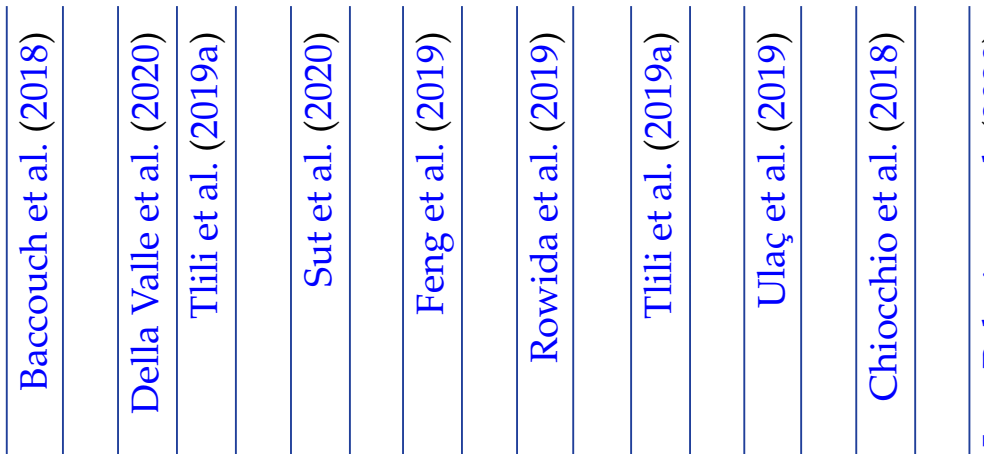

$\overline{0}$
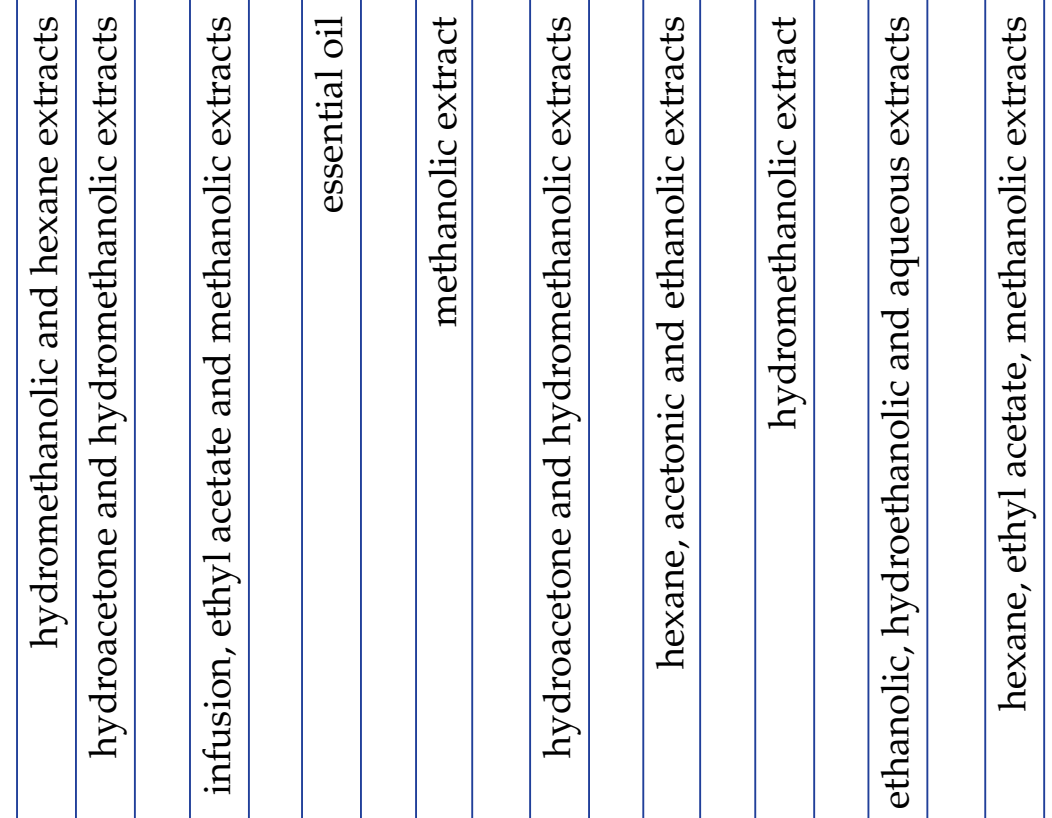

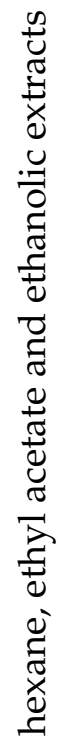

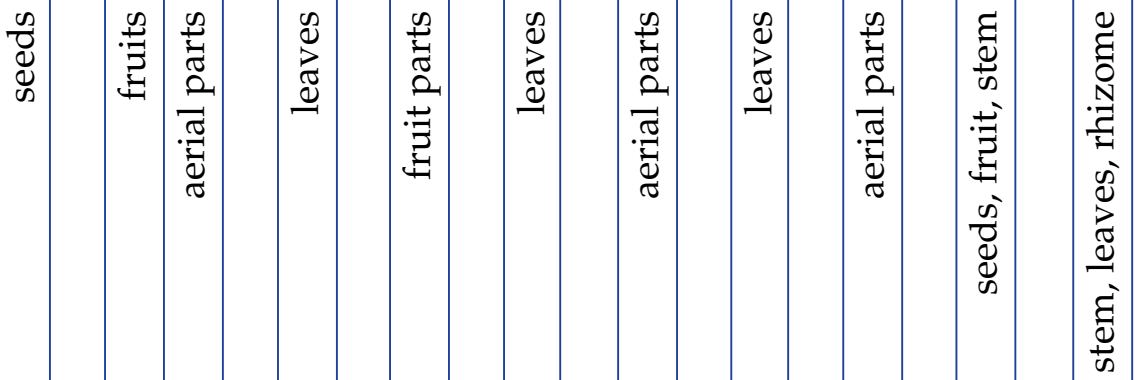

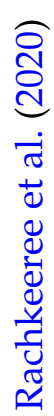

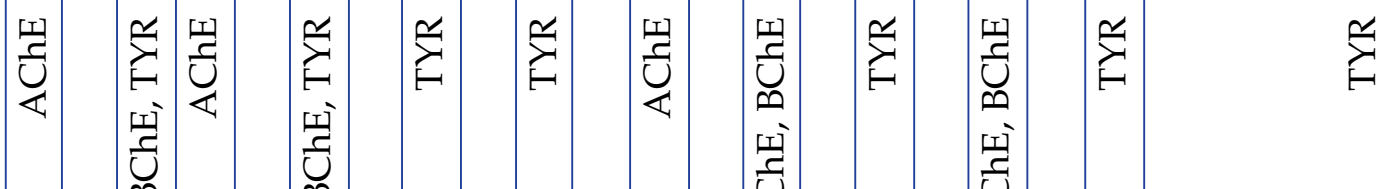

哭

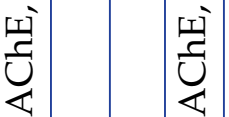

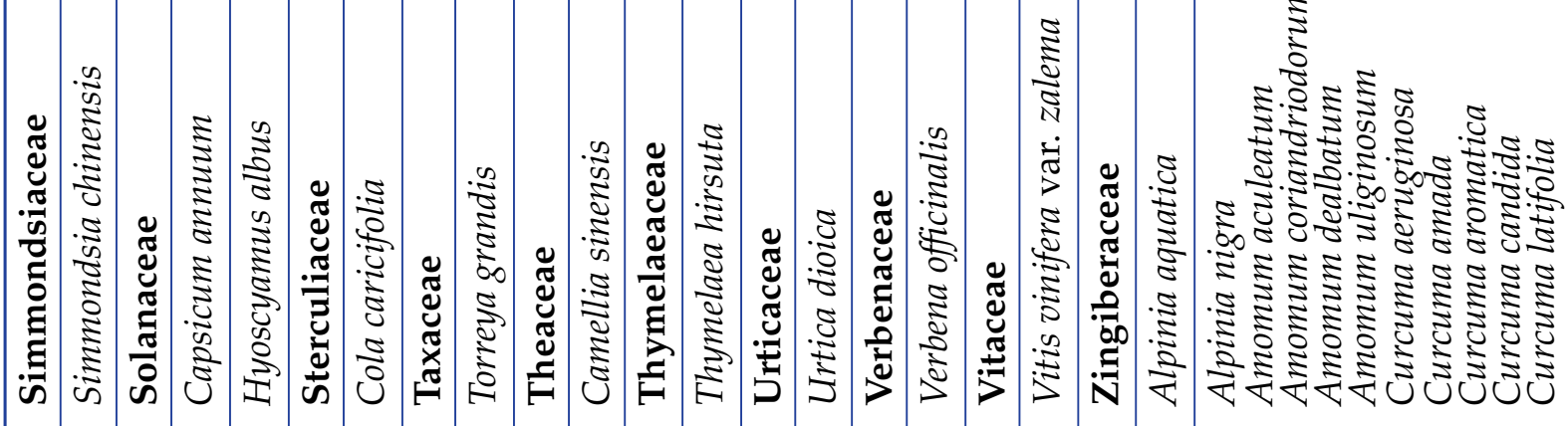




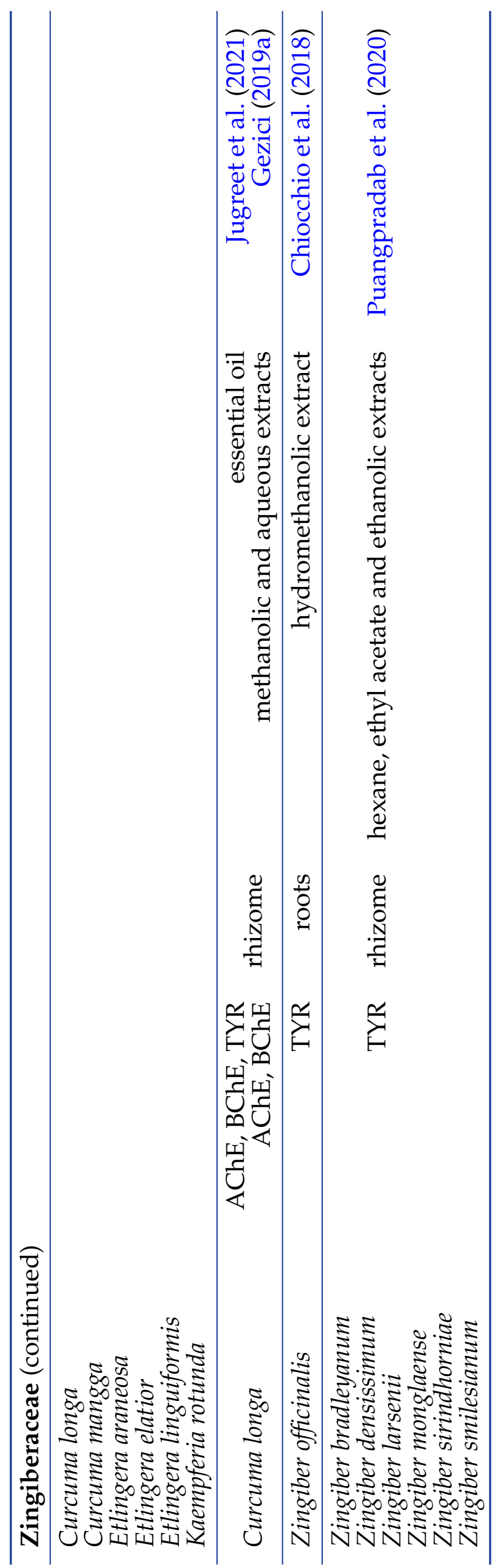


pathogenesis (Jiang et al., 2018; Srivastav et al., 2017).

In addition, several approaches for prevention and diseasemodifying treatments are extensively investigated, including substances that reduce oxidative stress and improve mitochondrial function, calcium channel blockers, and neuroprotective agents, such as nicotine (cholinergic modulator) and caffeine (adenosine receptor antagonist) (Balestrino and Schapira, 2020; Iarkov et al., 2020; Váradi, 2020). Similar to coffee, green tea could exert its effects via caffeine-induced inactivation of the adenosine receptor, while phenolic components from its leaves such as (-)-epigallocatechin-3-gallate manifested potent antioxidant and neuroprotective effects (Iarkov et al., 2020). Furthermore, increased consumption of fruits, vegetables, legumes and cereals, with minimizing consumption of red meats, typical for the Mediterranean diet, has beneficial role on the incidence of NDDs, including PD, showing positive effects on the decrease of cardiovascular and cancer mortality, lipid metabolism, blood pressure, etc. (Dohrmann et al., 2019).

One of the indirect and non-conventional strategies for the treatment of PD includes inhibition of TYR as well as reduction of oxidative stress which plays a significant role in the neurodegeneration associated with PD. The potential of medicinal plants in TYR inhibition, recognized as one of the prospective alternatives for the treatment of $\mathrm{PD}$, will be discussed in detail.

\subsection{Potential of medicinal plants in PD therapy}

The current therapeutics applied for this disorder bring forth a symptomatic relief, but strategies for slowing down or ceasing the disease progression are not developed.

There are many natural compounds, such as hydroquinone (HQ), arbutin, kojic acid, azelaicacid, L-ascorbic acid, ellagic acid, tranexamic acid, etc., which are confirmed as effective TYR inhibitors (Lee et al., 2016; Pillaiyar et al., 2017). Kojic acid, the most intensively studied inhibitor of TYR, is a fungal metabolite currently used as a cosmetic skin-whitening agent and as a food additive for preventing enzymatic browning. Kojic acid and arbutin are often used as the positive controls in the literature for comparing the inhibitory strength of the tested inhibitors (Chaiyana et al., 2020; Chang, 2009; Lee et al., 2016). Also, TYR inhibition is considered as one of alternative therapeutical strategies for PD, which acceletate the investigation of medicinal plants as natural source of TYR inhibitors. Ethnobotanical investigations and subsequent screening of medicinal plants for their biological activities represent an essential step for novel drug discovery. Literature survey showed that in vitro TYR inhibition was intensively investigated in the last two decades, mainly on different plant extracts, while the essential oils and pure bioactive compounds isolated from essential oils and extracts were investigated to a quite lesser extent.

According to the recent literature data, in the last few years TYR inhibitory activity was the most extensively investigated in Turkish medicinal plants (Bahadori et al., 2019; Bozkurt et al., 2021; Emir and Emir, 2021; Khan et al., 2019a; Sarikurkcu and Zengin, 2020; Ulaç et al., 2019; Uysal et al., 2018a;b;c; 2021; Zengin et al., 2018a; 2019a;b;c; 2018b;c;d; 2019d;e; 2018e; 2019f;g; 2018f;g;h)). Besides, a number of traditionally used medicinal plants from South Korea (Jiratchayamaethasakul et al., 2020), Thailand (Chaiyana et al., 2020; Laosirisathian et al., 2020; Puangpradab et al., 2020; Rachkeeree et al., 2020; Yodthong, 2020), Sudan (Dirar et al., 2019; Mohammed et al., 2020), Algeria (Cheraif et al., 2020), India (Abirami et al., 2018, Chiocchio et al., 2018; Mukherjee et al., 2018; Pathak-Gandhi and Vaidya, 2017; Srivastav et al., 2017), China (Xie et al., 2018; Zhang et al., 2020)), Iran (Asghari et al., 2019; Dall'Acqua et al., 2020) also showed significant anti-TYR potential.
In the examined 40 months-period, selected papers on the antiTYR activity of 300 taxa belonging to 53 families are displayed in Table 1. In the Figure 5, the percentage of representatives of families regarding the total number of taxa encompassed within this study is presented. The highest number of examined taxa belongs to the families Lamiaceae (18\%), Asteraceae (12\%), Moraceae (9\%), Zingiberaceae (8\%), Fabaceae, Apiaceae, Rosaceae, etc. (Table 1, Figure 5). Some of the plant families comprising less than $3 \%$ are Brassicaceae, Plumbaginaceae, Amaranthaceae, Euphorbiaceae, etc.

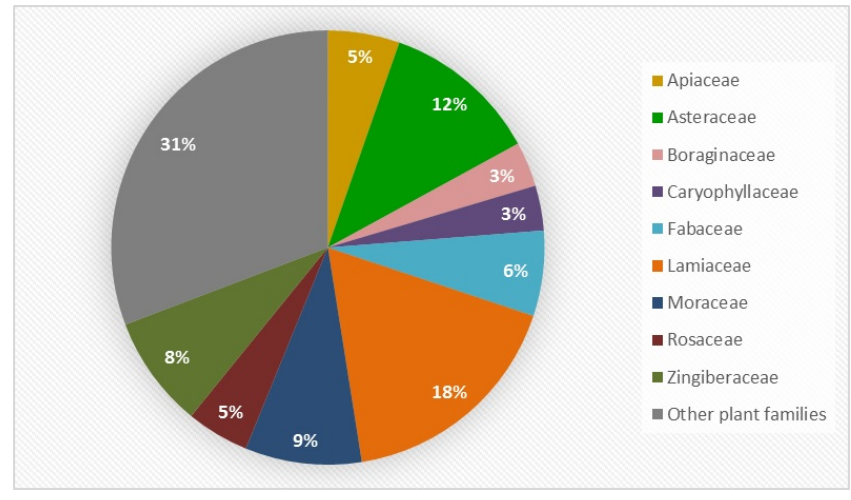

Fig. 5. Participation percentage plant families' representatives examined for anti-TYR activity regarding the total number of taxa

The diverse solvent extracts and essential oils of numerous Lamiaceae herbs were extensively evaluated for their TYR inhibition potential. Among them, the most frequently examined taxa belong to the genus Salvia. The genus Salvia comprises nearly 1000 species, many of which are proved for their bioactivities, including enzyme inhibiting effects. Methanolic, ethanolic and aqueous extracts, mainly obtained from aerial parts of different Salvia species, showed high anti-TYR capacity in numerous studies (Ekin et al., 2019; Halfon et al., 2019; Yener, 2020; Zengin et al., 2018b;c;e) (Table 1) Previous investigation on TYR inhibition of Salvia spp. showed high potential of different extracts of examined species, including Libyan $S$. fruticosa, S. lanigera, Cretan S. pomifera and S. officinalis from Montenegro (Duletić-Laušević et al., 2019a; Duletić Laušević et al., 2018c). It is worth-mentioning that the ethanolic and aqueous extracts of Salvia species from Libya (DuletićLaušević et al., 2018b) and ethanolic extract of S. officinalis Duletić-Laušević et al. (2019a) showed stronger anti-TYR effects than kojic acid used as positive control. Additionaly, the dichloromethane extracts were frequently found as the most efficient TYR inhibitors compared to other extracts, as Uysal et al. (2021) demonstrated in the study of S. ceratophylla aerial parts and roots.

To isolate active components, whole plants and separated plant parts (roots, rhizomes, leaves, flowers, fruits, different fruits parts) have been exploited (Table 1). During the investigated period, considering the total number of samples examined for anti-TYR activity, whole plant/aerial parts (45 $\%)$ were most frequently used for plant preparations, followed by leaves $(19 \%)$, stems $(9 \%)$, roots $(8 \%)$, rhizomes $(7 \%)$, etc. Among "other plant parts", bulbs and seeds comprised only 2 $\%$ regarding the total number of samples (Figure 6).

For the investigation of TYR inhibition potential of medicinal plants, essential oils and various solvent extracts have been isolated and tested. Polar and non-polar solvents such as methanol, ethanol, water, acetone, butanol, dichloromethane, chloroform, ethyl acetate, hexane, and especially different solvent mixtures are applied for the extractions (Table 1). In the studied period, in view of total number of plant preparations tested for anti-TYR activity, methanolic extracts $(24 \%)$ are 


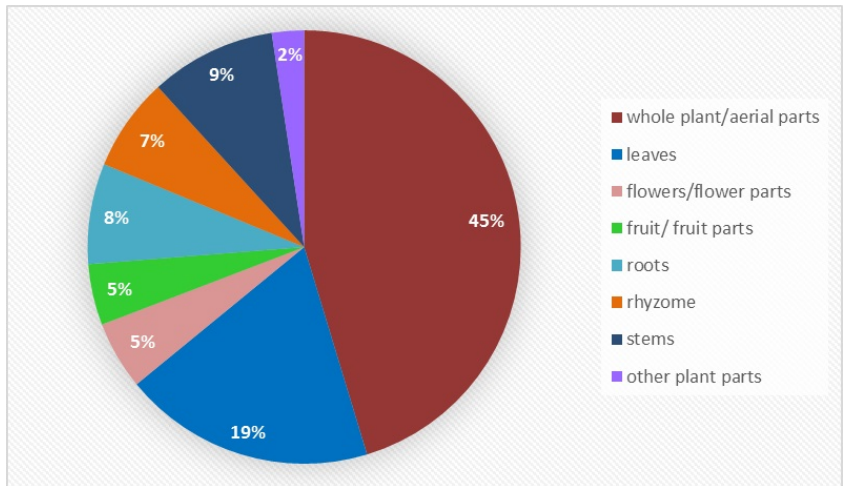

Fig. 6. Participation percentage of plant parts used for anti-TYR activity regarding the total number of examined samples

the most frequently used, followed by ethyl acetate (14\%), aqueous $(13 \%)$ and ethanolic extracts $(12 \%)$, while essential oils were represented with only $6 \%$. Infusion, decoction, dichloromethane, acetone extracts, etc., were present with less than $3 \%$ of examined samples, and included in "other plant preparations" (Figure 7).

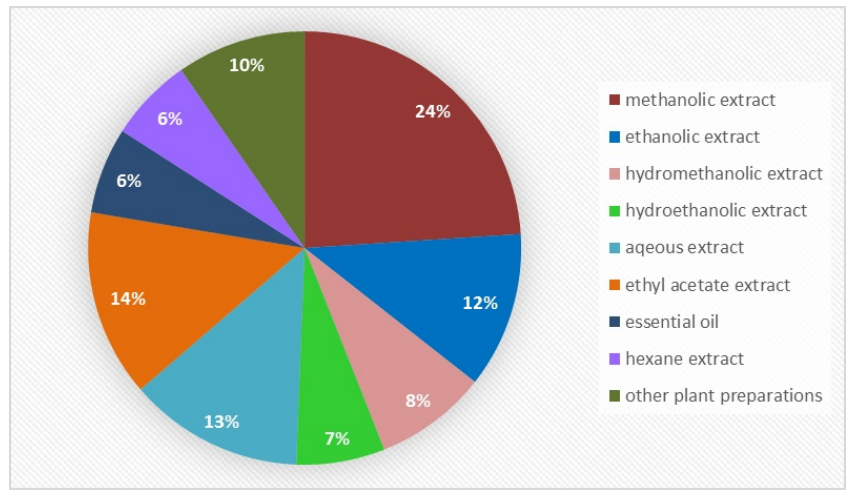

Fig. 7. Participation percentage of plant preparations tested for anti-TYR activity regarding the total number of examined samples

Different plant preparations and extraction procedures were applied to optimize the extraction process and to achieve maximal inhibition of medicinal herbs. Also, tested plant preparations are obtained using whole aerial parts and/or separated plant parts such as roots, rhizomes, leaves, flowers, etc. (Aghraz et al., 2018; Asghari et al., 2019; Chaiyana et al., 2020; Dej-Adisai et al., 2019; Turrini et al., 2020; Uysal et al., 2018a; 2021; Zengin et al., 2019e; 2020a; Zhang et al., 2020). As can be seen in the Table 1 and Figures 6-7, the methanolic extracts of whole aerial parts were the most frequently prepared for the investigation of TYR inhibition. Many aerial parts of the Apiaceae taxa displayed prominent anti-TYR effects (Deveci et al., 2018; Uysal et al., 2019a; Zengin et al., 2019f;g). Sarikurkcu and Zengin (2020) showed that all methanolic extracts from different plant parts of Astragalus macrocephalus subsp. finitimus are comparable with positive control kojic acid and the most active was the extract of the leaves. Many Asteraceae species, mostly from genus Inula, are shown to be potent inhibitors of TYR activity. Ceylan et al. (2021) showed that Inula viscidula exhibited the strongest anti-TYR activity among 11 tested methanolic extracts of aerial parts of Inula species. Chohra et al. (2020) recorded that two methanolic extracts of Clematis cirrhosa aerial parts showed noticeable anti-TYR activity compared to kojic acid.

The mixture of water and alcohols, such as ethanol and methanol, was frequently applied to improve extraction of bioactive components (about $15 \%$ of all tested samples, Ta- ble 1 and Figure 7). Hydroethanolic extracts of Punica granatum (Šavikin et al., 2018) and Aronia melanocarpa (Zdunić et al., 2020) displayed the stronger TYR inhibition than individual fractions of this extract. Testing 100 plant extracts for anti-TYR potential, Chiocchio et al. (2018) found that hydromethanolic extracts of Mediterranean plants collected in Sardinia, such as aerial parts of Cytinus hypocistis and Limonum morisianum, as well as leaves of Pistacia lentiscus and P. terrebinthus, have prominent inhibiting effects. In the study of Jiratchayamaethasakul et al. (2020), hydroethanolic extracts of 22 South Korean species aerial parts were tested and Spartina anglica showed the highest anti-TYR activity. Furthermore, methanolic extracts of six halophyte Limonium species roots and aerial parts also showed considerable anti-TYR activity (Senizza et al., 2021).

Additionaly, it is worth mentioning that Artocarpus spp. and Ficus spp. belonging to family Moraceae, as well as Curcuma spp. and Zingiber spp. belonging to family Zingiberaceae, were extensively examined for anti-TYR activities (Table 1) Among 15 Sri Lankan medicinal plants, the bark ethanolic extracts of Artocarpus altilis and A. nobilis were stronger TYR inhibitors than kojic acid (Liyanaarachchi et al., 2018). Moreover, the ethanolic extracts of 48 taxa belonging to Moraceae family were tested by Dej-Adisai et al. (2019). This study showed that the extracts of Artocrpus chama stem and Streblus taxoides wood exhibited the highest anti-TYR activity, in both enzymatic and intracellular assays. Morus spp. (mulberry) belonging to the same family contain various polyphenols (Chang, 2009; Mukherjee et al., 2018; Pillaiyar et al., 2017; Zolghadri et al., 2019), including oxyresveratrol which exhibited 32-fold stronger inhibitory activity than kojic acid and 50-fold higher TYR inhibiting potential than resveratrol isolated from grapes (Chang, 2009).

Camelia sinensis is the rich source of polyphenols and catechins (green tea) with antioxidant activity, and theaflavins (black tea) which showed neuroprotective effects (Srivastav et al., 2017). It is shown that catechins reduce tyrosine hydroxylase and interfere with the $\alpha$-synuclein aggregation (Jiang et al., 2018). The flavonoid rich extracts of several members of Fabaceae family were also proved as promising anti-TYR agents, including Glycyrrhiza spp. and Glycine max (Mukherjee et al., 2018). The root extracts of Glycyrrhiza species showed melanogenesis inhibitory activity due to the presence of isoflavonoids glabridine and glabrene (Chang, 2009), and chalcones with anti-TYR activity (Lee et al., 2016). A member of the Fabaceae family, Mucuna pruriens, has been used in traditional Ayurvedic medicine to manage neurodegenerative diseases like PD, because its seeds represent a natural source of levodopa (PathakGandhi and Vaidya, 2017; Srivastav et al., 2017). The studies performed by Puangpradab et al. (2020) and Rachkeeree et al (2020) have showed that plants of family Zingiberaceae, especially Curcuma spp. and Zingiber spp., represent an immerse source of compounds with anti-TYR potential, which are frequently accumulated in the rhizomes. The hexane extract of Zingiber denisissimum rhizome exhibited the highest anti-TYR potential among six Zingiber species (Puangpradab et al., 2020). Additionaly, Rachkeeree et al. (2020) revealed that among 16 Zingiberaceae plant species, using different solvents, the most prominent activity had the hexane extracts of Curcuma spp. rhizomes. It is previously reported that Curcuma longa contains curcumin and other curcuminoids which demonstrated significant TYR inhibition potential and neuroprotective effects (Jiang et al., 2018; Mukherjee et al., 2018; Song et al., 2012; Srivastav et al., 2017).

Diverse monocots also exhibited potent anti-TYR effects, as was shown for methanolic extracts obtained from diverse plant parts of Turkish Allium species (Emir et al., 2020; Emir 
and Emir, 2021), which could be explained by high content of polyphenolics, especially catechol (Emir and Emir, 2021). Moreover, Lazarova et al. (2020) found that roots extracts of two Asphodelus species, particularly A. aestivus exhibited strong TYR inhibition.

Several studies have demonstrated that essential oils and their individual components isolated from medicinal herbs of Lamiaceae, Asteraceae, Myrtaceae, Lauraceae, Rutaceae and Cupressaceae, also possess TYR inhibition effects (Table 1). The considerable anti-TYR activity was shown by Ocimum basilicum and Pulicaria undulata essential oils (Mohammed et al., 2020). Citral and myrcene from citrus fruits essential oils and flavonoids nobiletin, hesperidin, neohesperidin and naringin from the citrus peel are proved as TYR inhibitors (Chang, 2009; Mukherjee et al., 2018). Among nine investigated species from Mauritius, essential oils of two Syzigium species and Morinda citrifolia showed the highest TYR inhibition potential (Jugreet et al., 2021; 2020). In the study including six Algerian plants, the most prominent anti-TYR effects displayed the essential oils of Juniperus oxycedrus and Artemisia campestris (Cheraif et al., 2020).

Herbal medicines can be an alternative and valuable source for anti-PD drug discovery. Some well-studied compounds such as baicalein, puerarin, resveratrol, curcumin, and ginsenosides deserve further consideration in clinical trials (Jiang et al., 2018; Lee et al., 2016; Song et al., 2012; Zolghadri et al., 2019). Furthermore, the mixtures of some TYR inhibitors such as glabridin/resveratrol, glabridin/oxyresveratrol, resveratrol/oxyresveratrol, aloesin/arbutin and several other combinations have shown the synergistic effect on TYR inhibition, which can be a useful strategy for the improvement of their inhibitory activities (Zolghadri et al., 2019).

\section{SYNERGISM AMONG MEDICINAL PLANTS AS A NEW PROMISING STRATEGY IN AD AND PD TREAT- MENT}

Synergy is a process in which some substances cooperate to reach a combined effect that is greater than the sum of their separate effects (Pezzani et al., 2019). In Traditional Chinese Medicine (TCM) different herbs can be used together as paired herbs to increase drug efficiency (Kong et al., 2019). In the last few decades, one of the promising approaches in the investigation of natural products therapeutic potential is searching for possible synergistic interactions, which are documented between/among:

- plants and/or mushrooms in their mixtures,

- components of single plant/mushroom extracts,

- isolated components of plant/mushroom extracts,

- plants/mushrooms extracts or their isolated components and commercial drugs.

According to the available literature data, different combinations of herbs, as well as individual metabolites isolated from herbs performed synergistic effects in inhibition of enzymes involved in neurodegeneration.

For example, synergistic effects in AChE inhibition were shown for 1,8-cineole- $\alpha$-pinene/caryophyllene oxide in Salvia lavandulaefolia essential oil (Savelev et al., 2004), for combinations of essential oils obtained from Lavandula stoechas and Mentha pulegium (2:1) and for Laurus nobilis and Mentha pulegium oils (1:1) (Yakoubi et al., 2021), the mixture of Acacia nilotica and Rhamnus prinoides roots aqueous extracts (Crowch and Okello, 2009), aqueous and ethanolic extracts of Ganoderma lucidum and Salvia officinalis (Ćilerdžić et al.,
2019), acetone extracts of Hypoxis colchicifolia and H. hemerocallidea corns (Ndhlala et al., 2013), berberine-coptisinepalmatine from TCM herbs Berberis bealei, Coptis chinensis and Phellodendron chinense (Kaufmann et al., 2016), fangchinolinecoptisine/berberine (Kong et al., 2019), palmatine and berberine (Balkrishna et al., 2019; Ma et al., 2019), curcumin-piperine (Abdul Manap et al., 2019). The several results published from January 2018 until present, showed that research on this topic was mainly focused on alkaloid-containing herbs traditionally used to treat dementia and/or due to their neuroprotective properties. Kong et al. (2019) reviewed the potential of naturally derived alkaloids as therapeutics or even nutraceuticals for managing neurodgenerative disorders. They emphasized harmine and berberine chloride, among 61 alkaloids listed, as potential modulators in the management of the progression of $\mathrm{AD}$ and $\mathrm{PD}$, but also mentioned the limitations of application, such as dosage, penetration into the brain, low extraction yields, etc.

In the study of TCM herbs, it was reported that fangchinoline isolated from the dried root of Stephania tetrandra and its combinations with coptisine/berberine isolated from the dried bark of $P h$. chinense and/or dried rhizome of $C$. chinensis synergistically inhibited AChE. As stated by Kong et al. (2019) these alkaloid-containing herbs are usually paired for dementia treatment in TCM. The results of the study encompassing fractions of five herbs used in the Ayurvedic medicine showed the highest AChE inhibition of Tinospora cordifolia, resulting from synergistic effects of palmatine and berberine. AChE inhibition mode of these alkaloids was non-competitive, unlike galantamine acting by competitive mode (Balkrishna et al., 2019). According to results obtained by Abdul Manap et al. (2019), the combination of curcumin and piperine in lower concentrations exhibited greater AChE inhibition than treatment with individual compounds and additionally showed significant neuroprotective effects.

In comparison to $\mathrm{AChE}$, synergistic effects of combinations of herbs and/or individual components in TYR inhibition were less extensively studied up to date. To our knowledge, only a few studies are available on this topic. Liang et al. (2012) discovered a synergistic TYR inhibitor from Smilax china root. Namely, a mixture of oxyresveratrol and dioscin highly increased the inhibition of TYR activity as compared to single components. Sindhuja et al. (2014) found that synergistic effects of the mixture of herbal extracts of four Malaysian plants (Tridax procumbens, Lantana camara, Euphorbia hirta and Thevetia peruviana) on TYR inhibition were not observed. In the mixture containing Phyllanthus emblica extract, L-ascorbic acid and kojic acid, Wangkananon et al. (2018) found an optimal ratio of ingredients providing the highest level of TYR inhibition. Wang et al. (2018) studied TYR inhibiting potential of four antioxidants (glabridin, resveratrol, oxyresveratrol and phenylethylresorcinol) and found out synergistic interactions for combinations of glabridin/resveratrol, glabridin/oxyresveratrol, oxyresveratrol/resveratrol and phenylethylresorcinol/resveratrol.

Our previous research work on this topic (Ćilerdžić et al., 2019) was aimed to investigate the possible synergistic AChE and TYR inhibiting effects of combined Ganoderma lucidum and Salvia officinalis ethanol and aqueous extracts, as highly valued species in traditional medicine. In the AChE inhibition assay, the ethanolic and aqueous extracts obtained from mixture of dried G. lucidum and S. officinalis materials (70:30) as well as the mixture of their liquid extracts obtained by extraction with ethanol and water (30:70) showed the strongest synergistic effects. In the TYR inhibition assay, the ethanolic and aqueous extracts obtained from the mixture of equal dried materials showed the most prominent synergism comparing to others. 


\section{CONCLUSIONS AND PERSPECTIVES}

As the literature survey for the examined period showed, majority of the tested plants exhibited in vitro inhibition of cholinesterases and tyrosinase, however, their effects varied in a broad range, depending on plant species, plant part used to obtain the preparation, choice of the extraction solvent, extraction technique, etc. In this review, almost 300 taxa belonging to about 70 plant families were selected. Data analysis showed that families with the highest number of tested representatives were Lamiaceae (comprising up to $20 \%$ of the investigated taxa), followed by Asteraceae (12\% of the investigated taxa), while other families were represented with percentage below $10 \%$. Among them, the high number of representatives selected for the investigation of cholinesterase inhibition belongs to the families Apiaceae and Fabaceae, while tyrosinase inhibition was extensively studied for numerous Moraceae and Zingiberaceae members. Regarding the plant parts used to obtain preparations, almost half of the samples tested for enzymes inhibition was prepared from whole plant/aerial plant parts, followed by leaves (about $20 \%$ ), while other individual plant parts participated with less than $10 \%$. The most frequently tested preparations were methanolic extracts (about a quarter of the samples examined), followed by aqueous, ethanolic and ethyl acetate extracts. The essential oils were tested to quite lesser extent compared to the extracts, as well as infusions, decoctions and hydroethanolic extracts, although these preparations are more suitable for human consumption. Additionally, a great deal of literature data was found on the effects of synergistic interactions between different herbs, mushrooms and/or isolated compounds. The presented data showed that medicinal plants represent an immense source of diverse compounds which could be further tested as potent inhibitors of the enzymes involved in the neurodegeneration processes.

\section{FUNDING}

This work was supported by the Ministry of Education, Science and Technological Development of the Republic of Serbia [Grant No. 451-03-9/2021-14/200178]

\section{REFERENCES}

Abdul Manap, A., Wei Tan, A., Leong, W., Yin Chia, A., Vijayabalan, S., Arya, A., Wong, E., Rizwan, F., Bindal, U., Koshy, S. and Madhavan, P. (2019). Synergistic effects of curcumin and piperine as potent acetylcholine and amyloidogenic inhibitors with significant neuroprotective activity in SH-SY5Y cells via computational molecular modeling and in vitro assay, Frontiers in Aging Neuroscience 11: 206.

Abirami, A., Srinivasan, G., Nagarani, G., Saipriya, V. and Siddhuraju, P. (2018). Antioxidant activity, type II diabetes related enzymes, cholinesterase and tyrosinase inhibition properties of methanolic extracts of peel, pulp and peel fiber from underutilized fruits of Citrus hystrix and C. maxima, International Journal of Food Science and Nutrition 3(6): 136-144.

Acet, T., Ozcan, K. and Zengin, G. (2020). An assessment of phenolic profiles, fatty acid compositions, and biological activities of two $\mathrm{He}$ lichrysum species: $H$. plicatum and $H$. chionophilum, Journal of Food Biochemistry 44(2): e13128.

ADI (2021). Alzheimer's disease international. [Accessed date: 09/20/2021].

URL: www.alzint.org/about/dementia-facts-figures/

Aghraz, A., Gonçalves, S., Rodríguez-Solana, R., Ait Dra, L., Di Stefano, V., Dugo, G., Cicero, N., Larhsini, M., Markouk, M. and Romano, A. (2018). Antioxidant activity and enzymes inhibitory properties of several extracts from two Moroccan Asteraceae species, South African Journal of Botany 118: 58-64.

Ajayi, O., Aderogba, M., Obuotor, E. and Majinda, R. (2019). Acetylcholinesterase inhibitor from Anthocleista vogelii leaf extracts, Journal of Ethnopharmacology 231: 503-506.
Ajiboye, B., Ojo, O., Fatoba, B., Afolabi, O., Olayide, I., Okesola, M. and Oyinloye, B. (2019). In vitro antioxidant and enzyme inhibitory properties of the $n$-butanol fraction of Senna podocarpa (Guill. and Perr.) leaf, Journal of Basic and Clinical Physiology and Pharmacology 31(1): 1-13.

Ajiboye, B., Ojo, O., Okesola, M., Akinyemi, A., Talabi, J., Idowu, O., Fadaka, A., Boligon, A. and Anraku de Campos, M. (2018). In vitro antioxidant activities and inhibitory effects of phenolic extract of Senecio biafrae (Oliv and Hiern) against key enzymes linked with type II diabetes mellitus and Alzheimer's disease, Food Science \& Nutrition 6(7): 1803-1810.

Akhtar, M., Akbar, S., Erum, A. and Bhatti, S. (2019). In vitro evaluation of anticholinesterase and antioxidant activities of Cascuta reflexa, Journal of Herbs, Spices \& Medicinal Plants 25(3): 181-191.

Ali-Shtayeh, M., Jamous, R., Abu-Zaitoun, S., Akkawi, R., Kalbouneh, S., Bernstein, N. and Dudai, N. (2018). Chemical profile and bioactive properties of the essential oil isolated from Clinopodium serpyllifolium (M. Bieb.) Kuntze growing in Palestine, Industrial Crops and Products 124: 617-625.

Ali-Shtayeh, M., Jamous, R., Abu-Zaitoun, S., Khasati, A. and Kalbouneh, S. (2019). Biological properties and bioactive components of Mentha spicata L. essential oil: focus on potential benefits in the treatment of obesity, Alzheimer's disease, dermatophytosis, and drug-resistant infections, Evidence-Based Complementary and Alternative Medicine 2019: 1-11.

Arumugam, R., Kirkan, B. and Sarikurkcu, C. (2019). Phenolic profile, antioxidant and enzyme inhibitory potential of methanolic extracts from different parts of Astragalus ponticus Pall., South African Journal of Botany 120: 268-273.

Asghari, B., Mafakheri, S., Zarrabi, M., Erdem, S., Orhan, I. and Bahadori, M. (2019). Therapeutic target enzymes inhibitory potential, antioxidant activity, and rosmarinic acid content of Echium amoenum, South African Journal of Botany 120: 191-197.

Asghari, B., Mafakheri, S., Zengin, G., Dinparast, L. and Bahadori, M. B. (2020). In-depth study of phytochemical composition, antioxidant activity, enzyme inhibitory and antiproliferative properties of Achillea filipendulina: a good candidate for designing biologically-active food products, Journal of Food Measurement and Characterization 14(4): 2196-2208.

Atas, M., Eruygur, N., Sozmen, F., Ergul, M., Ergul, M., Akpulat, H. and Ucar, E. (2019). Evaluation of various biological activities of endemic Sideritis libanotica extracts, Notulae Scientia Biologicae 11(2): 210 217

Augustin, N., Nuthakki, V., Abdullaha, M., Hassan, Q., Gandhi, S. and Bharate, S. (2020). Discovery of helminthosporin, an anthraquinone isolated from Rumex abyssinicus Jacq as a dual cholinesterase inhibitor, ACS Omega 5(3): 1616-1624.

Baccouch, N., Salah, H., Belhaj, S., Hentati, O., Abdennabi, R., Gharsallah, N., Elfeki, A., Ayedi, M. and Allouche, N. (2018). Chemical characterization and biological activities of Simmondsia chinensis (Link) CK Schneid seeds oil, Cellular and Molecular Biology 64(4): 11-16.

Badem, M., Sener, S., Korkmaz, N., Kanbolat, S., Yildirmiş, S., Ozgen, U., Aliyazicioglu, R. and Kandemir, A. (2020). Phenolic content and enzyme inhibition activities Barbarea auriculata var. paludosa, B. integrifolia and B. plantaginea Brassicaceae's, Journal of Pharmaceutical Research International pp. 86-93.

Bahadori, M., Kirkan, B. and Sarikurkcu, C. (2019). Phenolic ingredients and therapeutic potential of Stachys cretica subsp. smyrnaea for the management of oxidative stress, Alzheimer's disease, hyperglycemia, and melasma, Industrial Crops and Products 127: 82-87.

Bahadori, M., Maggi, F., Zengin, G., Asghari, B. and Eskandani, M. (2020). Essential oils of hedgenettles (Stachys inflata, S. lavandulifolia, and $S$. byzantina) have antioxidant, anti-Alzheimer, antidiabetic, and antiobesity potential: a comparative study, Industrial Crops and Products 145: 112089

Balestrino, R. and Schapira, A. (2020). Parkinson disease, European Journal of Neurology 27(1): 27-42.

Balkrishna, A., Pokhrel, S., Tomer, M., Verma, S., Kumar, A., Nain, P., Gupta, A. and Varshney, A. (2019). Anti-acetylcholinesterase activities of mono-herbal extracts and exhibited synergistic effects of the phytoconstituents: a biochemical and computational study, Molecules 24(22): 4175.

Baloglu, M., Llorent-Martínez, E., Aumeeruddy, M., Mahomoodally, M., Altunoglu, Y., Ustaoglu, B., Ocal, M., Gürel, S., Bene, K., Sinan, K. and Zengin, G. (2019). Multidirectional insights on Chrysophyllum 
perpulchrum leaves and stem bark extracts: HPLC-ESI-MSn profiles, antioxidant, enzyme inhibitory, antimicrobial and cytotoxic properties, Industrial Crops and Products 134: 33-42.

Beauchamp, L., Finkelstein, D., Bush, A., Evans, A. and Barnham, K. (2020). Parkinsonism as a third wave of the COVID-19 pandemic? Journal of Parkinson's Disease 10(4): 1343-1353.

Blažević, I., Đulović, A., Čikeš Čulić, V., Burčul, F., Ljubenkov, I., Ruščić, M. and Generalić Mekinić, I. (2019). Bunias erucago L.: glucosinolate profile and in vitro biological potential, Molecules 24(4): 741.

Boga, M., Ersoy, E., Ozkan, E., Cinar, E., Kara, E., Canturk, Y. and Zengin, G. (2021). Volatile and phenolic profiling of a traditional medicinal plant Hypericum empetrifolium with in vitro biological activities, Journal of Ethnopharmacology 272: 113933.

Bonesi, M., Tenuta, M., Loizzo, M., Sicari, V. and Tundis, R. (2018). Potential application of Prunus armeniaca $\mathrm{L}$. and $P$. domestica $\mathrm{L}$. leaf essential oils as antioxidant and of cholinesterases inhibitors, Antioxidants 8(1): 2

Bose, B., Tripathy, D., Chatterjee, A., Tandon, P. and Kumaria, S. (2019) Secondary metabolite profiling, cytotoxicity, anti-inflammatory potential and in vitro inhibitory activities of Nardostachys jatamansi on key enzymes linked to hyperglycemia, hypertension and cognitive disorders, Phytomedicine 55: 58-69.

Bouchoukh, I., Hazmoune, T., Boudela, M., Bensouici, C. and Zellagui, A. (2019). Anticholinesterase and antioxidant activities of foliar extract from a tropical species: Psidium guajava L. (Myrtaceae) grown in Algeria, Current Issues in Pharmacy and Medical Sciences 32(3): 160167.

Boughendjioua, H., Hafsa, A. and Kadach, A. (2019). Antiacetylcholinesterase activitie of sweet orange Citrus sinensis essential oil from Algeria, Algerian Journal of Natural Products 7(2): 701-705. Publisher: Zenodo.

Bozkurt, B., Kaya, G., Onur, M. and Unver-Somer, N. (2021). Chemoprofiling of some turkish Galanthus L. (Amaryllidaceae) species and their anticholinesterase activity, South African Journal of Botany 136: 65-69.

Bui, T. and Nguyen, T. (2017). Natural product for the treatment of Alzheimer's disease, Journal of Basic and Clinical Physiology and Pharmacology 28(5): 413-423.

Bursal, A., Aras, A., Kılıç, O., Taslimi, P., Gören, A. and Gülçin, I. (2019). Phytochemical content, antioxidant activity, and enzyme inhibition effect of Salvia eriophora Boiss. \& Kotschy against acetylcholinesterase, $\alpha$ amylase, butyrylcholinesterase, and $\alpha$-glycosidase enzymes, Journal of Food Biochemistry 43(3): e12776.

Cacabelos, R. (2020). Pharmacogenomics of Alzheimer's and Parkinson's diseases, Neuroscience Letters 726: 133807.

Calva, J., Castillo, J., Bec, N., Ramírez, J., Andrade, J., Larroque, C and Armijos, C. (2019). Chemical composition, enantiomeric distribution and AChE-BChE activities of the essential oil of Myrteola phylicoides (Benth) Landrum from Ecuador, Records of Natural Products 13(4): 355-362.

Cassiano, D., Reis, I., de Oliveira Estrela, I., de Freitas, H., da Rocha Pita, S., David, J. and Branco, A. (2019). Acetylcholinesterase inhibitory activities and bioguided fractionation of the Ocotea percoriacea extracts: HPLC-DAD-MS/MS characterization and molecular modeling of their alkaloids in the active fraction, Computational Biology and Chemistry 83: 107-129.

Ceylan, R., Zengin, G., Mahomoodally, M., Sinan, K., Ak, G., Jugreet, S. Cakır, O., Ouelbani, R., Paksoy, M. and Yılmaz, M. (2021). Enzyme inhibition and antioxidant functionality of eleven Inula species based on chemical components and chemometric insights, Biochemical Systematics and Ecology 95: 104225.

Chaiyana, W., Sirithunyalug, J., Somwongin, S., Punyoyai, C., Laothaweerungsawat, N., Marsup, P., Neimkhum, W. and Yawootti, A. (2020). Enhancement of the antioxidant, anti-tyrosinase, and antihyaluronidase activity of Morus alba L. leaf extract by pulsed electric field extraction, Molecules 25(9): 2212.

Chang, T.-S. (2009). An updated review of tyrosinase inhibitors, International Journal of Molecular Sciences 10(6): 2440-2475.

Cheraif, K., Bakchiche, B., Gherib, A., Bardaweel, S., Çol Ayvaz, M. Flamini, G., Ascrizzi, R. and Ghareeb, M. (2020). Chemical composition, antioxidant, anti-tyrosinase, anti-cholinesterase and cytotoxic activities of essential oils of six Algerian plants, Molecules 25(7): 1710.

Chethana, K., Sasidhar, B., Naika, M. and Keri, R. (2018). Phytochemical composition of Caesalpinia crista extract as potential source for inhibiting cholinesterase and $\beta$-amyloid aggregation: significance to Alzheimer's disease, Asian Pacific Journal of Tropical Biomedicine 8(10): 500

Chiocchio, I., Mandrone, M., Sanna, C., Maxia, A., Tacchini, M. and Poli, F. (2018). Screening of a hundred plant extracts as tyrosinase and elastase inhibitors, two enzymatic targets of cosmetic interest, Industrial Crops and Products 122: 498-505.

Chohra, D., Ferchichi, L., Cakmak, Y., Zengin, G. and Alsheikh, S. (2020). Phenolic profiles, antioxidant activities and enzyme inhibitory effects of an Algerian medicinal plant Clematis cirrhosa L., South African Journal of Botany 132: 164-170.

Corti, O., Hampe, C., Darios, F., Ibanez, P., Ruberg, M. and Brice, A. (2005). Parkinson's disease: from causes to mechanisms, Comptes Rendus Biologies 328(2): 131-142.

Crowch, C. M. and Okello, E. J. (2009). Kinetics of acetylcholinesterase inhibitory activities by aqueous extracts of Acacia nilotica L. and Rhamnus prinoides L'Her., African Journal of Pharmacy and Pharmacology 3(10): 469-475. Publisher: Newcastle University.

Dalar, A., Zengin, G., Mukemre, M., Bengu, A. and İşler, S. (2019) Gundelia rosea seed: evaluation of biopharmaceutical potential and bioactive composition, South African Journal of Botany 125: 505-510.

Dall'Acqua, S., Ak, G., Sut, S., Zengin, G., Yıldıztugay, E., Fawzi Mahomoodally, M., Ibrahime Sinan, K. and Lobine, D. (2020). Comprehensive bioactivity and chemical characterization of the endemic plant Scorzonera hieraciifolia Hayek extracts: a promising source of bioactive compounds, Food Research International 137: 109371

Damuka, N., Kammari, K., Potshangbam, A. M., Rathore, R. S., Kondapi, A. and Vindal, V. (2020). Discovery of dual cation- $\pi$ inhibitors of acetylcholinesterase: design, synthesis and biological evaluation, Pharmacological Reports 72(3): 705-718.

Dash, U., Kanhar, S., Dixit, A., Dandapat, J. and Sahoo, A. (2019). Isolation, identification, and quantification of pentylcurcumene from Geophila repens: a new class of cholinesterase inhibitor for Alzheimer's disease, Bioorganic Chemistry 88: 102947.

Dej-Adisai, S., Parndaeng, K., Wattanapiromsakul, C., Nuankaew, W. and Kang, T. (2019). Effects of selected Moraceae plants on tyrosinase enzyme and melanin content, Pharmacognosy Magazine 15(65): 708

Della Valle, A., Dimmito, M., Zengin, G., Pieretti, S., Mollica, A., Locatelli, M., Cichelli, A., Novellino, E., Ak, G., Yerlikaya, S. and Baloglu, M. (2020). Exploring the nutraceutical potential of dried pepper Capsicum annuum L. on market from Altino in Abruzzo region, Antioxidants 9(5): 400

Desmiaty, Y., Saputri, F., Hanafi, M., Prastiwi, R. and Elya, B. (2020). Anti-elastase, anti-tyrosinase and anti-oxidant of Rubus fraxinifolius stem methanolic extract, Pharmacognosy Journal 12(2): 271-275.

Deveci, E., Tel-Çayan, G. and Duru, M. E. (2018). Phenolic profile, antioxidant, anticholinesterase, and anti-tyrosinase activities of the various extracts of Ferula elaeochytris and Sideritis stricta, International Journal of Food Properties 21(1): 771-783.

Deveci, E., Tel-Çayan, G., Duru, M. and Öztürk, M. (2019). Phytochemical contents, antioxidant effects, and inhibitory activities of key enzymes associated with alzheimer's disease, ulcer, and skin disorders of Sideritis albiflora and Sideritis leptoclada, Journal of Food Biochemistry 43(12): e13078

Dickson, D. W. (2012). Parkinson's disease and parkinsonism: neuropathology, Cold Spring Harbor Perspectives in Medicine 2(8): a009258.

Dirar, A., Alsaadi, D., Wada, M., Mohamed, M., Watanabe, T. and Devkota $H$. (2019). Effects of extraction solvents on total phenolic and flavonoid contents and biological activities of extracts from Sudanese medicinal plants, South African Journal of Botany 120: 261-267.

Dohrmann, D., Putnik, P., Kovačević, D., Simal-Gandara, J., Lorenzo, J. and Barba, F. (2019). Japanese, Mediterranean and Argentinean diets and their potential roles in neurodegenerative diseases, Food Research International 120: 464-477.

D’Onofrio, G., Sancarlo, D., Ruan, Q., Yu, Z., Panza, F., Daniele, A. Greco, A. and Seripa, D. (2017). Phytochemicals in the treatment of Alzheimer's disease: a systematic review, Current Drug Targets 18(13): 1487-1498.

Duletić-Laušević, S., Alimpić Aradski, A., Šavikin, K., Knežević, A., Milutinović, M., Stević, T., Vukojević, J., Marković, S. and Marin, P. (2018b). Composition and biological activities of libyan Salvia fruticosa Mill. and S. lanigera Poir. extracts., South African Journal of Botany 117: 101109 
Duletić-Laušević, S., Alimpić Aradski, A., Živković, J., Gligorijević, N., Šavikin, K., Radulović, S., Ćoćić, D. and Marin, P. (2019a). Evaluation of bioactivities and phenolic composition of extracts of Salvia officinalis L. (lamiaceae) collected in montenegro, Botanica Serbica 43(1): 47-58.

Duletić-Laušević, S., Alimpić Aradski, A., Kolarević, S., Vuković-Gačić, B., Oalđe, M., Živković, J., Šavikin, K. and Marin, P. (2018a). Antineurodegenerative, antioxidant and antibacterial activities and phenolic components of Origanum majorana L. (Lamiaceae) extracts of different origin, Journal of Applied Botany and Food Quality 91: 126-134.

Duletić Laušević, S., Alimpić Aradski, A., Kolarević, S., Vuković Gačić, B., Oalđe, M. and Marin, P. (2018c). Biological activities of Cretan Salvia pomifera extracts, Botanica Serbica 42(2): 209-216. Accepted: 2019-09-19T11:52:19Z.

Duletić-Laušević, S., Oalđe, M. and Alimpić Aradski, A. (2019b). In vitro evaluation of antioxidant, antineurodegenerative and antidiabetic activities of Ocimum basilicum L., Laurus nobilis L. leaves and Citrus reticulata Blanco peel extracts, Lekovite sirovine 39: 60-68.

Edwards III, G., Gamez, N., Escobedo Jr, G., Calderon, O. and MorenoGonzalez, I. (2019). Modifiable risk factors for Alzheimer's disease, Frontiers in Aging Neuroscience 11: 146.

Edziri, H., Marzouk, B., Mabrouk, H., Garreb, M., Douki, W., Mahjoub, A., Verschaeve, L., Najjar, F. and Mastouri, M. (2018). Phytochemical screening, butyrylcholinesterase inhibitory activity and antiinflammatory effect of some Tunisian medicinal plants, South African Journal of Botany 114: 84-88.

Ekin, H., Deliorman Orhan, D., Erdoğan Orhan, I., Orhan, N. and Aslan, M. (2019). Evaluation of enzyme inhibitory and antioxidant activity of some Lamiaceae plants, Journal of Research in Pharmacy 23(4): 749-58.

Elufioye, T., Chinaka, C. and Oyedeji, A. (2019). Antioxidant and anticholinesterase activities of Macrosphyra longistyla (DC) Hiern relevant in the management of Alzheimer's disease, Antioxidants 8(9): 400.

Emir, A., Emir, C. and Yıldırım, H. (2020). Characterization of phenolic profile by LC-ESI-MS/MS and enzyme inhibitory activities of two wild edible garlic: Allium nigrum L. and Allium subhirsutum L., Journal of Food Biochemistry 44(4): e13165.

Emir, C. and Emir, A. (2021). Phytochemical analyses with LC-MS/MS and in vitro enzyme inhibitory activities of an endemic species Allium stylosum O. Schwarz (Amaryllidaceae), South African Journal of Botany 136: 70-75.

Ergül, M., Ergül, M., Eruygur, N., Ataş, M. and Ucar, E. (2019). In vitro evaluation of the chemical composition and various biological activities of Ficus carica leaf extracts, Turkish Journal of Pharmaceutical Sciences 16(4): 401-409.

Eruygur, N., Dincel, B., Dincel, N. and Ucar, E. (2018). Comparative study of in vitro antioxidant, acetylcholinesterase and butyrylcholinesterase activity of alfalfa (Medicago sativa L.) collected during different growth stages, Open Chemistry 16(1): 963-967.

Eruygur, N., Ucar, E., Akpulat, H., Shahsavari, K., Safavi, S. and Kahrizi, D. (2019). In vitro antioxidant assessment, screening of enzyme inhibitory activities of methanol and water extracts and gene expression in Hypericum lydium, Molecular Biology Reports 46(2): 2121-2129.

Fadaka, A., Ajiboye, B., Adewale, I., Ojo, O., Oyinloye, B. and Okesola, M. (2019). Significance of antioxidants in the treatment and prevention of neurodegenerative diseases, The Journal of Phytopharmacology 8(2): 75-83.

Faraone, I., Rai, D., Russo, D., Chiummiento, L., Fernandez, E., Choudhary, A. and Milella, L. (2019). Antioxidant, antidiabetic, and anticholinesterase activities and phytochemical profile of Azorella glabra Wedd., Plants 8(8): 265.

Farjadmand, F., Khanavi, M., Eftekhari, M., Hosseinsalari, A., Akbarzadeh, T., Safavi, M., Asatouri, R., Mirabzadeh, M. and Ardekani, M. R. S. (2018). The effect of extraction method on the major constituents and biological effects of Trachyspermum ammi L. fruits, Research Journal of Pharmacognosy 5(1): 55-61.

Farzaneh, V., Gominho, J., Pereira, H. and Carvalho, I. (2018). Screening of the antioxidant and enzyme inhibition potentials of portuguese Pimpinella anisum I. seeds by GC-MS, Food Analytical Methods 11(10): 2645-2656.

Feng, T., Hu, Z., Song, S., Yao, L., Sun, M., Zhu, X. and Lu, J. (2019). The antioxidant and tyrosinase inhibition properties of essential oil from the peel of Chinese Torreya grandis Fort., RSC Advances 9(72): 4236042366.

Folch, J., Petrov, D., Ettcheto, M., Abad, S., Sánchez-López, E., García, M., Olloquequi, J., Beas-Zarate, C., Auladell, C. and Camins, A.
(2016). Current research therapeutic strategies for Alzheimer's disease treatment, Neural Plasticity 2016: 1-15.

Gali, L. and Bedjou, F. (2019). Antioxidant and anticholinesterase effects of the ethanol extract, ethanol extract fractions and total alkaloids from the cultivated Ruta chalepensis, South African Journal of Botany 120: 163-169.

Gebashe, F., Baskaran, P. and Van Staden, J. (2019). Pharmacology and polyphenolic contents of in vitro propagated Aloe pruinosa Reynolds grown ex vitro, South African Journal of Botany 122: 504-509.

Gezici, S. (2019a). A study on Turmeric (Curcuma longa L.): Multifunctional agents for the management of oxidative damage, neurodegeneration and cancer, Current Research in Pharmaceutical Sciences 9(3): 46-53

Gezici, S. (2019b). Cancer preventive and neuroprotective potentials of red hulls, kernels and oleo-gum resins from pistachio, International Journal of Agriculture, Environment and Food Sciences 3(3): 137-143.

Gezici, S. and Sekeroglu, N. (2019). Neuroprotective potential and phytochemical composition of acorn fruits, Industrial Crops and Products 128: 13-17.

Ghane, S., Attar, U., Yadav, P. and Lekhak, M. (2018). Antioxidant, anti-diabetic, acetylcholinesterase inhibitory potential and estimation of alkaloids (lycorine and galanthamine) from Crinum species: an important source of anticancer and anti-Alzheimer drug, Industrial Crops and Products 125: 168-177.

Gitler, A. D., Dhillon, P. and Shorter, J. (2017). Neurodegenerative disease: models, mechanisms, and a new hope, Disease Models \& Mechanisms 10(5): 499-502.

Grochowski, D., Uysal, S., Zengin, G. and Tomczyk, M. (2019). In vitro antioxidant and enzyme inhibitory properties of Rubus caesius L, International Journal of Environmental Health Research 29(3): 237-245.

Gulcin, I., Kaya, R., Goren, A., Akincioglu, H., Topal, M., Bingol, Z., Cetin Çakmak, K., Ozturk Sarikaya, S., Durmaz, L. and Alwasel, S. (2019). Anticholinergic, antidiabetic and antioxidant activities of cinnamon (Cinnamomum verum) bark extracts: polyphenol contents analysis by LC-MS/MS, International Journal of Food Properties 22(1): 15111526.

Halfon, B., Çetin, Ö., Kökdil, G. and Topçu, G. (2019). Chemical investigation and bioactivity screening of Salvia cassia extracts, Records of Natural Products 13(2): 156-166.

Hamdy, S., El Hefnawy, H., Azzam, S. and Aboutabl, E. (2018). Chemical profiling, volatile oil analysis and anticholinesterase activity of Hydrocotyle umbellata L. aerial parts cultivated in Egypt, South African Journal of Botany 115: 108-112.

Hampel, H., Mesulam, M., Cuello, A., Farlow, M., Giacobini, E., Grossberg, G., Khachaturian, A., Vergallo, A., Cavedo, E., P.J., S. and Khachaturian, Z. (2018). The cholinergic system in the pathophysiology and treatment of Alzheimer's disease, Brain 141(7): 1917-1933.

Hasegawa, T. (2010). Tyrosinase-expressing neuronal cell line as in vitro model of Parkinson's disease, International Journal of Molecular Sciences 11(3): 1082-1089.

Howes, M. and E., P. (2011). The role of phytochemicals in the treatment and prevention of dementia, Drugs \& Aging 28(6): 439-468.

larkov, A., Barreto, G., Grizzell, J. and Echeverria, V. (2020). Strategies for the treatment of Parkinson's disease beyond dopamine, Frontiers in Aging Neuroscience 12: 4

Ćilerdžić, J., Alimpić Aradski, A., Stajić, M., Vukojević, J. and DuletićLaušević, S. (2019). Do Ganoderma lucidum and Salvia officinalis extracts exhibit synergistic antioxidant and antineurodegenerative ef fects?, Journal of Food Measurement and Characterization 13(4): 33573365.

Imran, M., Irfan, A., Ibrahim, M., Assiri, M. A., Khalid, N., Ullah, S. and AlSehemi, A. (2020). Carbonic anhydrase and cholinesterase inhibitory activities of isolated flavonoids from Oxalis corniculata L. and their firstprinciples investigations, Industrial Crops and Products 148: 112285.

Jagust, W. (2018). Imaging the evolution and pathophysiology of Alzheimer disease, Nature Reviews Neuroscience 19(11): 687-700.

Jara-Palacios, M., Gonçalves, S., Heredia, F., Hernanz, D. and Romano, A. (2020). Extraction of antioxidants from winemaking byproducts: effect of the solvent on phenolic composition, antioxidant and anticholinesterase activities, and electrochemical behaviour, Antioxidants 9(8): 675.

Jiang, X., Ganesan, P., Rengarajan, T., Choi, D.-K. and Arulselvan, P. (2018). Cellular phenotypes as inflammatory mediators in Parkinson's disease: interventional targets and role of natural products, 
Biomedicine \& Pharmacotherapy 106: 1052-1062.

Jiratchayamaethasakul, C., Ding, Y., Hwang, O., Im, S., Jang, Y., Myung, S., Lee, J., Kim, H., Ko, S. and Lee, S. (2020). In vitro screening of elastase, collagenase, hyaluronidase, and tyrosinase inhibitory and antioxidant activities of 22 halophyte plant extracts for novel cosmeceuticals, Fisheries and Aquatic Sciences 23(1): 1-9.

Jovanović, M., Drinić, Z., Bigović, D., Alimpić-Aradski, A., Duletić-Laušević, S. and Šavikin, K. (2020). In vitro antineurodegenerative activity and in silico predictions of blood-brain barrier penetration of Helichrysum plicatum flower extract, Lekovite sirovine 40: 45-51.

Jugreet, B. S., Kouadio Ibrahime, S., Zengin, G., Abdallah, H. H. and Fawzi Mahomoodally, M. (2021). GC/MS profiling, in vitro and in silico pharmacological screening and principal component analysis of essential oils from three exotic and two endemic plants from Mauritius, Chemistry \& Biodiversity 18(3): e2000921.

Jugreet, B. S., Mahomoodally, M. F., Sinan, K. I., Zengin, G. and Abdallah, H. H. (2020). Chemical variability, pharmacological potential, multivariate and molecular docking analyses of essential oils obtained from four medicinal plants, Industrial Crops and Products 150: 112394.

Kamal, M., Naz, M., Jawaid, T. and Arif, M. (2019). Natural products and their active principles used in the treatment of neurodegenerative diseases: a review, Oriental Pharmacy and Experimental Medicine 19(4): 343-365.

Karadağ, A. E., Demirci, B., Kültür, k., Demirci, F. and Başer, K. H. C (2020). Antimicrobial, anticholinesterase evaluation and chemical characterization of essential oil Phlomis kurdica Rech. Fil growing in Turkey, Journal of Essential Oil Research 32(3): 242-246.

Karak, S., Acharya, J., Begum, S., Mazumdar, I., Kundu, R. and De, B (2018). Essential oil of Piper betle L. leaves: chemical composition, antiacetylcholinesterase, anti- $\beta$-glucuronidase and cytotoxic properties, Journal of Applied Research on Medicinal and Aromatic Plants 10: 8592.

Karakaya, S., Bingol, Z., Koca, M., Demirci, B., Gulcin, I. and Baser, K. H. C. (2020). Screening of non-alkaloid acetylcholinesterase and carbonic anhydrase isoenzymes inhibitors of Leiotulus dasyanthus (K. Koch) Pimenov \& Ostr. (Apiaceae), Journal of Essential Oil Research 32(3): 227-241.

Karakaya, S., Eksi, G., Koca, M., Demirci, B., Kaymak, H. C., Kaplan, M. E. and Aksakal, O. (2019a). Chemical and morphological characterization of Allium tuncelianum Amaryllidaceae and its antioxidant and anticholinesterase potentials, Anales del Jardín Botánico de Madrid 76(2): 085.

Karakaya, S., Koca, M., Kılıc, C. S. and Coskun, M. (2018). Antioxidant and anticholinesterase activities of Ferulago syriaca Boiss. and F. isaurica Peșmen growing in Turkey, Medicinal Chemistry Research 27(7): 1843-1850.

Karakaya, S., Koca, M., Sytar, O., Dursunoglu, B., Ozbek, H., Duman, H., Guvenalp, Z. and Kılıc, C. (2019b). Antioxidant and anticholinesterase potential of Ferulago cassia with farther bio-guided isolation of active coumarin constituents, South African Journal of Botany 121: 536-542.

Karakaya, S., Koca, M., Yeşilyurt, F. and Hacımüftüoğlu, A. (2019c). Antioxidant and anticholinesterase activities of Juglans regia L. growing in Turkey., Journal of Faculty of Pharmacy of Ankara University 43(3): 230-238.

Kaufmann, D., Kaur Dogra, A., Tahrani, A., Herrmann, F. and Wink, M. (2016). Extracts from traditional Chinese medicinal plants inhibit acetylcholinesterase, a known Alzheimer's disease target, Molecules 21(9): 1161.

Kaur, R. and Shri, R. (2018). Evaluation of two culinary plant species for anticholinesterase, antioxidant and cytotoxic activity, Pharmacognosy Communications 8(1): 25-28.

Kawamoto, H., Takeshita, F. and Murata, K. (2019). Inhibitory effects of essential oil extracts from Panax plants against $\beta$-secretase, cholinesterase, and amyloid aggregation, Natural Product Communications 14(10): 1-7.

Kennedy, D., Okello, E., Chazot, P., Howes, M.-J., Ohiomokhare, S., Jackson, P., Haskell-Ramsay, C., Khan, J., Forster, J. and Wightman, E. (2018). Volatile terpenes and brain function: investigation of the cognitive and mood effects of Mentha $\times$ piperita L. essential oil with in vitro properties relevant to central nervous system function, Nutrients 10(8): 1029.

Keskin, Ş., Şirin, Y., Çakir, H. and Keskin, M. (2019). An investigation of Humulus lupulus L.: phenolic composition, antioxidant capacity and inhibition properties of clinically important enzymes, South African
Journal of Botany 120: 170-174.

Khan, A., Ikram, M., Hahm, J. R. and Kim, M. O. (2020). Antioxidant and anti-inflammatory effects of citrus flavonoid hesperetin: special focus on neurological disorders, Antioxidants 9(7): 609.

Khan, S., Nazir, M., Raiz, N., Saleem, M., Zengin, G., Fazal, G., Saleem, H., Mukhtar, M., Tousif, M. I., Tareen, R. B., Abdallah, H. H. and Mahomoodally, F. M. (2019a). Phytochemical profiling, in vitro biological properties and in silico studies on Caragana ambigua stocks (Fabaceae): a comprehensive approach, Industrial Crops and Products 131: 117-124.

Khan, S., Nazir, M., Saleem, H., Raiz, N., Saleem, M., Anjum, S. M. M., Zengin, G., Mukhtar, M., Tousif, M. I., Mahomoodally, F. M. and Ahemad, N. (2019b). Valorization of the antioxidant, enzyme inhibition and phytochemical propensities of Berberis calliobotrys Bien. ex Koehne: a multifunctional approach to probe for bioactive natural products, Industrial Crops and Products 141: 111693.

Khaw, K.-Y., Chear, N. J. Y., Maran, S., Yeong, K. Y., Ong, Y. S. and Goh, B. H. (2020a). Butyrylcholinesterase inhibitory activity and GC-MS analysis of Carica papaya leaves, Natural Product Sciences 26(2): 165170. Publisher: The Korean Society of Pharmacognosy.

Khaw, K. Y., Chong, C. W. and Murugaiyah, V. (2020b). LC-QTOF-MS analysis of xanthone content in different parts of Garcinia mangostana and its influence on cholinesterase inhibition, Journal of Enzyme Inhibition and Medicinal Chemistry 35(1): 1433-1441.

Khodaei, M., Yaghob, A., Ali, F. M., Morteza, P. H. and Reza, A. H. (2019). Cholinesterase inhibitory, anti-oxidant and anti-tyrosinase activities of three Iranian species of Dracocephalum, Research Journal of Pharmacognosy 6(3): 25-31. Publisher: RESEARCH JOURNAL OF PHARMACOGNOSY

Kirkan, B., Sarikurkcu, C. and Amarowicz, R. (2019). Composition, and antioxidant and enzyme-inhibition activities, of essential oils from Satureja thymbra and Thymbra spicata var. spicata, Flavour and Fragrance Journal 34(6): 436-442.

Kirkan, B., Sarikurkcu, C., Ozer, M. S., Cengiz, M., Atılgan, N., Ceylan O. and Tepe, B. (2018). Phenolic profile, antioxidant and enzyme inhibitory potential of Onosma tauricum var. tauricum, Industrial Crops and Products 125: 549-555.

Kobus-Cisowska, J., Szymanowska, D., Maciejewska, P., Kmiecik, D., Gramza-Michałowska, A., Kulczyński, B. and Cielecka-Piontek, J. (2019a). In vitro screening for acetylcholinesterase and butyrylcholinesterase inhibition and antimicrobial activity of chia seeds (Salvia hispanica), Electronic Journal of Biotechnology 37: 1-10.

Kobus-Cisowska, J., Szymanowska-Powałowska, D., Szczepaniak, O., Kmiecik, D., Przeor, M., Gramza-Michałowska, A., Cielecka-Piontek J., Smuga-Kogut, M. and Szulc, P. (2019b). Composition and in vitro effects of cultivars of Humulus lupulus L. hops on cholinesterase activity and microbial growth, Nutrients 11(6): 1377.

Kong, Q., Jiang, R., Li, M., Xu, F., Zhang, Y., Tang, Z. and Dong, J. (2019). A retrospective database analysis of traditional Chinese medicine syndromes in patients with chronic obstructive pulmonary disease and asthma, European Journal of Integrative Medicine 32: 101001.

Kuş, Ç., Taş, M., Küçükaydin, S., Tel-Çayan, G. and Duru, M. E. (2019). Chemical analysis and in vitro antioxidant and anticholinesterase activities of essential oils and extracts from different parts of Erica manipuliflora, Journal of Research in Pharmacy 23(6): 1098-1105.

Kumar, A., Singh, A. and Ekavali, E. (2015). A review on Alzheimer's disease pathophysiology and its management: an update, Pharmacological Reports 67(2): 195-203.

Kuswanto, D., Lister, I. N. E., Girsang, E., Nasution, A. N. and Widowati, W. (2020). Comparison of antioxidant and anti-tyrosinase activity between black soybean Glycine max (L). Merr. and daidzein, Buletin Farmatera 5(1): 163.

Lane, R. M., Potkin, S. G. and Enz, A. (2006). Targeting acetylcholinesterase and butyrylcholinesterase in dementia, The International Journal of Neuropsychopharmacology 9: 101-124.

Laosirisathian, N., Saenjum, C., Sirithunyalug, J., Eitssayeam, S., Sirithunyalug, B. and Chaiyana, W. (2020). The chemical composition, antioxidant and anti-tyrosinase activities, and irritation properties of Sripanya Punica granatum peel extract, Cosmetics 7(1): 1-13.

Larocca, M., Di Marsico, M., Riccio, P. and Rossano, R. (2018). The in vitro antioxidant properties of Muscari comosum bulbs and their inhibitory activity on enzymes involved in inflammation, post-prandial hyperglycemia, and cognitive/neuromuscular functions, Journal of Food Biochemistry 42(5): e12580. 
Lazarova, I., Zengin, G., Sinan, K. I., Aneva, I., Uysal, S., Picot-Allain, M. C. N., Aktumsek, A., Bouyahya, A. and Mahomoodally, M. F. (2020). Metabolomics profiling and biological properties of root extracts from two Asphodelus species: A. albus and A. aestivus, Food Research International 134: 109277.

Lee, S. Y., Baek, N. and Nam, T.-g. (2016). Natural, semisynthetic and synthetic tyrosinase inhibitors, Journal of Enzyme Inhibition and Medicinal Chemistry 31(1): 1-13.

Leporini, M., Bonesi, M., Loizzo, M. R., Passalacqua, N. G. and Tundis, R. (2020). The essential oil of Salvia rosmarinus Spenn. from Italy as a source of health-promoting compounds: chemical profile and antioxidant and cholinesterase inhibitory activity, Plants 9(6): 798.

Liang, C., Lim, J.-H., Kim, S.-H. and Kim, D.-S. (2012). Dioscin: a synergistic tyrosinase inhibitor from the roots of Smilax china, Food Chemistry 134(2): 1146-1148.

Libro, R., Giacoppo, S., Soundara Rajan, T., Bramanti, P. and Mazzon, E. (2016). Natural phytochemicals in the treatment and prevention of dementia: an overview, Molecules 21(4): 518.

Liyanaarachchi, G. D., Samarasekera, J. K. R. R., Mahanama, K. R. R. and Hemalal, K. D. P. (2018). Tyrosinase, elastase, hyaluronidase, inhibitory and antioxidant activity of Sri Lankan medicinal plants for novel cosmeceuticals, Industrial Crops and Products 111: 597-605.

Llorent-Martínez, E. J., Zengin, G., Ortega-Barrales, P., Zakariyyah Aumeeruddy, M., Locatelli, M., Mollica, A. and Mahomoodally, M. F. (2019). Characterization of the phytochemical profiles and biological activities of Ajuga chamaepitys subsp. chia var. chia and Ajuga bombycina by high-performance liquid chromatography-electrospray ionization-tandem mass spectrometry (HPLC-ESI-MSn), Analytical Letters 52(5): 852-868.

Lopresti, A. L. (2017). Salvia (sage): a review of its potential cognitiveenhancing and protective effects, Drugs in R\&D 17(1): 53-64.

Ma, Y., Li, X., Hou, L.-X. and Wei, A.-Z. (2019). Extraction solvent affects the antioxidant, antimicrobial, cholinesterase and HepG2 human hepatocellular carcinoma cell inhibitory activities of Zanthoxylum bungeanum pericarps and the major chemical components, Industrial Crops and Products 142: 111872.

Magalingam, K. B., Radhakrishnan, A., Ping, N. S. and Haleagrahara, N. (2018). Current concepts of neurodegenerative mechanisms in Alzheimer's disease, BioMed Research International 2018: 3740461.

Maggio, A., Loizzo, M. R., Riccobono, L., Bruno, M., Tenuta, M. C., Leporini, M., Falco, T., Leto, C., Tuttolomondo, T., Cammalleri, I., La Bella, S. and Tundis, R. (2019). Comparative chemical composition and bioactivity of leaves essential oils from nine Sicilian accessions of Myrtus communis L., Journal of Essential Oil Research 31(6): 546-555.

Mahomoodally, M. F., Picot-Allain, C., Hosenally, M., Ugurlu, A., Mollica, A., Stefanucci, A., Llorent-Martínez, E., Baloglu, M. C. and Zengin, G. (2019a). Multi-targeted potential of Pittosporum senacia Putt.: HPLCESI-MSn analysis, in silico docking, DNA protection, antimicrobial, enzyme inhibition, anti-cancer and apoptotic activity, Computational Biology and Chemistry 83: 107114.

Mahomoodally, M. F., Vlaisavljevic, S., Berezni, S., Abdallah, H. H., Zengin, G., Atanasov, A. G., Mollica, A., Lobine, D. and Aktumsek, A. (2018). Lotus aegaeus (Gris.) Boiss and Iberis sempervirens L.: chemical fingerprints, antioxidant potential, and inhibition activities and docking on key enzymes linked to global health problems, Industrial Crops and Products 120: 271-278.

Mahomoodally, M. F., Zengin, G., Zheleva-Dimitrova, D., Mollica, A., Stefanucci, A., Sinan, K. I. and Aumeeruddy, M. Z. (2019b). Metabolomics profiling, bio-pharmaceutical properties of Hypericum lanuginosum extracts by in vitro and in silico approaches, Industrial Crops and Products 133: 373-382.

Maiti, P., Manna, J. and Dunbar, G. L. (2017). Current understanding of the molecular mechanisms in Parkinson's disease: targets for potential treatments, Translational Neurodegeneration 6(1): 28.

Mamadalieva, N. Z., Böhmdorfer, S., Zengin, G., Bacher, M., Potthast, A., Akramov, D. K., Janibekov, A. and Rosenau, T. (2019). Phytochemical and biological activities of Silene viridiflora extractives. Development and validation of a HPTLC method for quantification of 20-hydroxyecdysone, Industrial Crops and Products 129: 542-548.

Marmouzi, I., Kharbach, M., El Jemli, M., Bouyahya, A., Cherrah, Y., Bouklouze, A., Vander Heyden, Y. and Faouzi, M. E. A. (2019). Antidiabetic, dermatoprotective, antioxidant and chemical functionalities in Zizyphus lotus leaves and fruits, Industrial Crops and Products 132: 134-139.

Martins, N. O., de Brito, I. M., Araújo, S. S. O., Negri, G., Carlini, E. d. A. and Mendes, F. R. (2018). Antioxidant, anticholinesterase and antifatigue effects of Trichilia catigua (catuaba), BMC Complementary and Alternative Medicine 18(1): 172.

Matailo, A., Bec, N., Calva, J., Ramírez, J., Andrade, J. M., Larroque, C., Vidari, G. and Armijos, C. (2019). Selective BuChE inhibitory activity, chemical composition, and enantiomer content of the volatile oil from the Ecuadorian plant Clinopodium brownei, Revista Brasileira de Farmacognosia 29(6): 749-754.

McLean, G., Hindle, J. V., Guthrie, B. and Mercer, S. W. (2017). Comorbidity and polypharmacy in Parkinson's disease: insights from a large Scottish primary care database, BMC Neurology 17(1): 126

Mekinić, I., Šimat, V., Ljubenkov, I., Burčul, F., Grga, M., Mihajlovski, M., Lončar, R., Katalinić, V. and Skroza, D. (2018). Influence of the vegetation period on sea fennel, Crithmum maritimum L. (Apiaceae), phenolic composition, antioxidant and anticholinesterase activities, Industrial Crops and Products 124: 947-953.

Meziant, L., Bachir-bey, M., Bensouici, C., Saci, F., Boutiche, M. and Louaileche, H. (2021). Assessment of inhibitory properties of flavonoidrich fig (Ficus carica L.) peel extracts against tyrosinase, $\alpha$-glucosidase, urease and cholinesterases enzymes, and relationship with antioxidant activity, European Journal of Integrative Medicine 43: 101272.

Mhiri, R., Kchaou, M., Belhadj, S., El Feki, A. and Allouche, N. (2018). Characterization of aromatic compounds and biological activities of essential oils from Tunisian aromatic plants, Journal of Food Measurement and Characterization 12(2): 839-847.

Moghrovyan, A., Sahakyan, N., Babayan, A., Chichoyan, N., Petrosyan, M. and Trchounian, A. (2019). Essential oil and ethanol extract of oregano (Origanum vulgare L.) from Armenian flora as a natural source of terpenes, flavonoids and other phytochemicals with antiradical, antioxidant, metal chelating, tyrosinase inhibitory and antibacterial activity, Current Pharmaceutical Design 25(16): 1809-1816.

Mohammed, A. B., Yagi, S., Tzanova, T., Schohn, H., Abdelgadir, H., Stefanucci, A., Mollica, A., Mahomoodally, M. F., Adlan, T. A. and Zengin, G. (2020). Chemical profile, antiproliferative, antioxidant and enzyme inhibition activities of Ocimum basilicum L. and Pulicaria undulata (L.) C.A. Mey. grown in Sudan, South African Journal of Botany 132: 403-409.

Mollica, A., Stefanucci, A., Macedonio, G., Locatelli, M., Luisi, G., Novellino, E. and Zengin, G. (2019). Chemical composition and biological activity of Capparis spinosa L. from Lipari island, South African Journal of Botany 120: 135-140.

Montalván, M., Peñafiel, M. A., Ramírez, J., Cumbicus, N., Bec, N., Larroque, C., Bicchi, C. and Gilardoni, G. (2019). Chemical composition, enantiomeric distribution, and sensory evaluation of the essential oils distilled from the ecuadorian species Myrcianthes myrsinoides (Kunth) Grifo and Myrcia mollis (Kunth) DC. (Myrtaceae), Plants 8(11): 511.

Monteiro, J. A., Ferreira Júnior, J. M., Oliveira, I. R., Batista, F. L. A., Pinto, C. C. C., Silva, A. A. S., Morais, S. M. and Silva, M. G. V. (2018) Bioactivity and toxicity of Senna cana and Senna pendula extracts, Biochemistry Research International 2018: 074-306.

Moreno, R., Tallini, L. R., Salazar, C., Osorio, E. H., Montero, E., Bastida, J., Oleas, N. H. and Acosta León, K. (2020). Chemical profiling and cholinesterase inhibitory activity of five Phaedranassa Herb. (Amaryllidaceae) species from Ecuador, Molecules 25(9): 2092.

Mukherjee, P. K., Biswas, R., Sharma, A., Banerjee, S., Biswas, S. and Katiyar, C. (2018). Validation of medicinal herbs for anti-tyrosinase potential, Journal of Herbal Medicine 14: 1-16.

Mukherjee, P. K., Kumar, V., Mal, M. and Houghton, P. J. (2007). Acetylcholinesterase inhibitors from plants, Phytomedicine 14(4): 289-300.

Murray, A., Faraoni, M., Castro, M., Alza, N. and Cavallaro, V. (2013). Natural AChE inhibitors from plants and their contribution to Alzheimer's disease therapy, Current Neuropharmacology 11(4): 388-413.

Naughton, S. X., Raval, U. and Pasinetti, G. M. (2020). Potential novel role of COVID-19 in Alzheimer's disease and preventative mitigation strategies, Journal of Alzheimer's Disease 76(1): 21-25.

Ndhlala, A., Stafford, G. and Van Staden, J. (2013). Phytosynergy in some Hypoxis species and pharmacological properties of a Hypoxisbased phytopharmaceutical formula, Journal of Ethnopharmacology 150(2): 492-500.

Neagu, E., Radu, G. L., Albu, C. and Paun, G. (2018). Antioxidant activity, acetylcholinesterase and tyrosinase inhibitory potential of Pulmonaria officinalis and Centarium umbellatum extracts, Saudi Journal of Biological Sciences 25(3): 578-585.

Ojo, O. A., Afon, A. A., Ojo, A. B., Ajiboye, B. O., Okesola, M. A., Aruleba, 
R. T., Adekiya, T. A. and Oyinloye, B. E. (2019). Spondias mombim L. (Anacardiaceae): chemical fingerprints, inhibitory activities, and molecular docking on key enzymes relevant to erectile dysfunction and alzheimer's diseases, Journal of Food Biochemistry 43(3): e12772.

Ojo, O. A., Ojo, A. B., Ajiboye, B. O., Olaiya, O., Okesola, M. A., Boligon, A. A., de Campos, M. M. A., Oyinloye, B. E. and Kappo, A. P. (2018) HPLC-DAD fingerprinting analysis, antioxidant activities of Tithonia diversifolia (Hemsl.) A. Gray leaves and its inhibition of key enzymes linked to Alzheimer's disease, Toxicology Reports 5: 585-592.

Orhan, I., Küpeli Akkol, E., Suntar, I. and Yesilada, E. (2019). Assessment of anticholinesterase and antioxidant properties of the extracts and (+)-catechin obtained from Arceuthobium oxycedri (DC) M. Bieb (dwarf mistletoe), South African Journal of Botany 120: 309-312.

Orlando, G., Zengin, G., Ferrante, C., Ronci, M., Recinella, L., Senkardes, I., Gevrenova, R., Zheleva-Dimitrova, D., Chiavaroli, A., Leone, S., Di Simone, S., Brunetti, L., Picot-Allain, C. M. N., Mahomoodally, M. F., Sinan, K. I. and Menghini, L. (2019). Comprehensive chemical profiling and multidirectional biological investigation of two wild Anthemis species (Anthemis tinctoria var. pallida and $A$. cretica subsp. tenuiloba) focus on neuroprotective effects, Molecules 24(14): 2582.

Otang-Mbeng, W. and Sagbo, I. J. (2020). Anti-melanogenesis, antioxidant and anti-tyrosinase activities of Scabiosa columbaria L., Processes 8(2): 236.

Ozkan, E. E., Ozsoy, N., Ozden, T. Y., Ozhan, G. and Mat, A. (2018b) Evaluation of chemical composition and in-vitro biological activities of three endemic Hypericum species from Anatolia ( $H$. thymbrifolium, $H$. spectabile and $H$. pseudolaeve), Iranian journal of pharmaceutical research: IJPR 17(3): 1036-1046.

Ozkan, E., Yilmaz Ozden, T., Ozsoy, N. and Mat, A. (2018a). Evaluation of chemical composition, antioxidant and anti-acetylcholinesterase activities of Hypericum neurocalycinum and Hypericum malatyanum, South African Journal of Botany 114: 104-110.

Parkinson's News Today (2021). [Accessed date: 09/20/2021].

URL: www.parkinsonsnewstoday.com/parkinsons-disease-statistics/

Pathak-Gandhi, N. and Vaidya, A. D. (2017). Management of Parkinson's disease in ayurveda: medicinal plants and adjuvant measures, Journal of Ethnopharmacology 197: 46-51.

Pavlić, B., Teslić, N., Zengin, G., Đurović, S., Rakić, D., Cvetanović, A., Gunes, A. and Zeković, Z. (2021). Antioxidant and enzymeinhibitory activity of peppermint extracts and essential oils obtained by conventional and emerging extraction techniques, Food Chemistry 338: 127724

Pendota, S. C., Aremu, A. O., Slavětínská, L. P., Rárová, L., Grúz, J., Doležal, K. and Van Staden, J. (2018). Identification and characterization of potential bioactive compounds from the leaves of Leucosidea sericea, Journal of Ethnopharmacology 220: 169-176.

Penumala, M., Zinka, R. B., Shaik, J. B., Mallepalli, S. K. R., Vadde, R. and Amooru, D. G. (2018). Phytochemical profiling and in vitro screening for anticholinesterase, antioxidant, antiglucosidase and neuroprotective effect of three traditional medicinal plants for Alzheimer's disease and diabetes mellitus dual therapy, BMC Complementary and Alternative Medicine 18(1): 77.

Pezzani, R., Salehi, B., Vitalini, S., Iriti, M., Zuñiga, F., Sharifi-Rad, J., Martorell, M. and Martins, N. (2019). Synergistic effects of plant derivatives and conventional chemotherapeutic agents: an update on the cancer perspective, Medicina 55(4): 110.

Pillaiyar, T., Manickam, M. and Namasivayam, V. (2017). Skin whitening agents: medicinal chemistry perspective of tyrosinase inhibitors, Journal of Enzyme Inhibition and Medicinal Chemistry 32(1): 403-425

Placines, C., Castañeda-Loaiza, V., João Rodrigues, M., G. Pereira, C., Stefanucci, A., Mollica, A., Zengin, G., Llorent-Martínez, E. J., Castilho, P. C. and Custódio, L. (2020). Phenolic profile, toxicity, enzyme inhibition, in silico studies, and antioxidant properties of Cakile maritima Scop. (Brassicaceae) from Southern Portugal, Plants 9(2): 142.

Podcasy, J. and Epperson, C. (2016). Considering sex and gender in Alzheimer disease and other dementias, Dialogues in Clinical Neuroscience 18(4): 437-446.

Politeo, O., Bektašević, M., Carev, I., Jurin, M. and Roje, M. (2018). Phytochemical composition, antioxidant potential and cholinesterase inhibition potential of extracts from Mentha pulegium L., Chemistry \& Biodiversity 15(12): e1800374.

Politeo, O., Stanislava, T. and Mirko, R. (2019). Edraianthus pumilio (Schult.) A. DC.: phytochemical and biological profile, Journal of Medicinal Plants Research 13(5): 96-103.
Popović-Djordjević, J., Cengiz, M., Ozer, M. S. and Sarikurkcu, C. (2019). Calamintha incana: essential oil composition and biological activity, Industrial Crops and Products 128: 162-166.

Puangpradab, R., Suksathan, R., Kantadoung, K. and Rachkeeree, A. (2020). Antioxidant and antityrosinase activities of rhizome extracts from six Zingiber species in Thailand, Medicinal Plants - International Journal of Phytomedicines and Related Industries 12(1): 27.

Rachkeeree, A., Kantadoung, K., Puangpradub, R. and Suksathan, R. (2020). Phytochemicals, antioxidants and anti-tyrosinase analyses of selected ginger plants, Pharmacognosy Journal 12(4): 872-883.

Raghunath, A., Sundarraj, K., Nagarajan, R., Arfuso, F., Bian, J., Kumar, A. P., Sethi, G. and Perumal, E. (2018). Antioxidant response elements: discovery, classes, regulation and potential applications, Redox Biology 17: 297-314.

Renda, G., Özel, A., Barut, B., Korkmaz, B. and Yayli, N. (2019). The volatile chemical compositions of the essential oil/SPME and enzyme inhibitory and radical scavenging activities of solvent extracts and the essential oils from Coronilla orientalis Miller and C. varia L. grows in Turkey, Iranian Journal of Pharmaceutical Research : IJPR 18(4): 18311842.

Rocchetti, G., Pagnossa, J. P., Blasi, F., Cossignani, L., Hilsdorf Piccoli, R., Zengin, G., Montesano, D., Cocconcelli, P. S. and Lucini, L. (2020). Phenolic profiling and in vitro bioactivity of Moringa oleifera leaves as affected by different extraction solvents, Food Research International 127: 108712.

Romes, N. B., Salleh, W. M. N. H. W., Sirat, H. M. and Assim, Z. (2020). Antityrosinase inhibitory activity of phytochemicals from Alpinia aquatica Roscoe, Pharmaceutical Sciences 26(2): 209-213.

Rowida, O., Amal, G. and Badria, F. (2019). Multi-target inhibitory activity of some medicinal plants on $\alpha$-amylase, tyrosinase and hyaluronidase: potential therapy for treatment diabetes and diabetic complications, Acta Scientifci Nutritional Health 3(10): 68-75.

Sadaoui, N., Bec, N., Barragan-Montero, V., Kadri, N., Cuisinier, F., Larroque, C., Arab, K. and Khettal, B. (2018). The essential oil of Algerian Ammodaucus leucotrichus Coss. \& Dur. and its effect on the cholinesterase and monoamine oxidase activities, Fitoterapia 130: 1-5.

Saleem, H., Ahmad, I., Zengin, G., Mahomoodally, F. M., Rehman Khan, K.-U., Ahsan, H. M., Abidin, S. A. Z. and Ahemad, N. (2020c). Comparative secondary metabolites profiling and biological activities of aerial, stem and root parts of Salvadora oleoides decne (Salvadoraceae), Natural Product Research 34(23): 3373-3377.

Saleem, H., Htar, T. T., Naidu, R., Ahmad, I., Zengin, G., Ahmad, M. and Ahemad, N. (2019b). Investigations into the therapeutic effects of aerial and stem parts of Buxus papillosa C.K. Schneid.: in vitro chemical, biological and toxicological perspectives, Journal of Pharmaceutical and Biomedical Analysis 166: 128-138.

Saleem, H., Htar, T. T., Naidu, R., Anwar, S., Zengin, G., Locatelli, M. and Ahemad, N. (2020a). HPLC-PDA polyphenolic quantification, UHPLC-MS secondary metabolite composition, and in vitro enzyme inhibition potential of Bougainvillea glabra, Plants 9(3): 388.

Saleem, H., Htar, T. T., Naidu, R., Nawawi, N. S., Ahmad, I., Ashraf, M. and Ahemad, N. (2019a). Biological, chemical and toxicological perspectives on aerial and roots of Filago germanica (L.) Huds: functional approaches for novel phyto-pharmaceuticals, Food and Chemical Toxicology 123: 363-373.

Saleem, H., Sarfraz, M., Ahsan, H. M., Khurshid, U., Kazmi, S. A. J., Zengin, G., Locatelli, M., Ahmad, I., Abdallah, H. H., Mahomoodally, M. F., Rengasamy, K. R. and Ahemad, N. (2020b). Secondary metabolites profiling, biological activities and computational studies of Abutilon figarianum Webb (Malvaceae), Processes 8(3): 336.

Saleem, H., Zengin, G., Khan, K.-U.-R., Ahmad, I., Waqas, M., Mahomoodally, F. M., Rengasamy, K. R., Zainol, N., Abidin, S. A. Z. and Ahemad, N. (2021). New insights into the phytochemical composition, enzyme inhibition and antioxidant properties of desert cotton (Aerva javanica (Bum.f) Shult. -Amaranthaceae), Natural Product Research 35(4): 664-668.

Saleem, H., Zengin, G., Locatelli, M., Mollica, A., Ahmad, I., Mahomoodally, F. M., Zainal Abidin, S. A. and Ahemad, N. (2019c). In vitro biological propensities and chemical profiling of Euphorbia milii Des Moul (Euphorbiaceae): a novel source for bioactive agents, Industrial Crops and Products 130: 9-15.

Salleh, W. M. N. H. W., Khamis, S., Nafiah, M. A. and Abed, S. A. (2021). Chemical composition and anticholinesterase inhibitory activity of the essential oil of Pseuduvaria macrophylla (Oliv.) Merr. from Malaysia, 
Natural Product Research 35(11): 1887-1892.

Santoro, V., Parisi, V., D’Ambola, M., Sinisgalli, C., Monné, M., Milella, L., Russo, R., Severino, L., Braca, A. and Tommasi, N. D. (2020). Chemical profiling of Astragalus membranaceus roots (Fish.) Bunge herbal preparation and evaluation of its bioactivity, Natural Product Communications 15(5): $1934578 X 2092415$.

Santos, T. C. d., Gomes, T. M., Pinto, B. A. S., Camara, A. L. and Paes, A. M. d. A. (2018). Naturally occurring acetylcholinesterase inhibitors and their potential use for Alzheimer's disease therapy, Frontiers in Pharmacology 9: 1192.

Sarikurkcu, C., Ceylan, O. and Zeljković, S. a. (2019). Micromeria myrtifolia: essential oil composition and biological activity, Natural Product Communications 14(6): 1934578X1985168.

Sarikurkcu, C., Sahinler, S. S., Ceylan, O. and Tepe, B. (2020). Onosma ambigens: phytochemical composition, antioxidant and enzyme inhibitory activity, Industrial Crops and Products 154: 112651.

Sarikurkcu, C. and Zengin, G. (2020). Polyphenol profile and biological activity comparisons of different parts of Astragalus macrocephalus subsp. finitimus from Turkey, Biology 9(8): 231.

Savelev, S. U., Okello, E. J. and Perry, E. K. (2004). Butyryl- and acetylcholinesterase inhibitory activities in essential oils of Salvia species and their constituents, Phytotherapy Research 18(4): 315-324.

Šavikin, K., Živković, J., Alimpić, A., Zdunić, G., Janković, T., DuletićLaušević, S. and Menković, N. (2018). Activity guided fractionation of pomegranate extract and its antioxidant, antidiabetic and antineurodegenerative properties, Industrial Crops and Products 113: 142-149.

Sekeroglu, N. and Gezici, S. (2019). Original article Astragalus neurocarpus Bioss. as a potential source of natural enzyme inhibitor associated with Alzheimer's and Parkinson diseases along with its rich polyphenolic content and antioxidant activities, Annals of Phytomedicine: An International Journal 8(1): 82-87.

Selkoe, D. J. and Hardy, J. (2016). The amyloid hypothesis of Alzheimer's disease at 25 years, EMBO Molecular Medicine 8(6): 595-608.

Senizza, B., Zhang, L., Rocchetti, G., Zengin, G., Ak, G., Yıldıztugay, E., Elbasan, F., Jugreet, S., Mahomoodally, M. F. and Lucini, L. (2021). Metabolomic profiling and biological properties of six Limonium species: novel perspectives for nutraceutical purposes, Food \& Function 12(8): 3443-3454.

Sevim, D. and Sener, B. (2020). Isolation and identification of cholinesterase inhibitors from the bulbs of Iris pseudacorus L., Eurasian Journal of Biological and Chemical Sciences 3(1): 6-9.

Sharifi-Rad, J., Tayeboon, G. S., Niknam, F., Sharifi-Rad, M., Mohajeri, M., Salehi, B., Iriti, M. and Sharifi-Rad, M. (2018). Veronica persica Poir. extract - antibacterial, antifungal and scolicidal activities, and inhibitory potential on acetylcholinesterase, tyrosinase, lipoxygenase and xanthine oxidase, Cellular and Molecular Biology 64(8): 50-56.

Sicak, Y. and Erdoğan Eliuz, E. A. (2019). Chemical content and biological activity spectrum of Nigella sativa seed oil, Journal Of Agriculture and Nature 22(6): 928-934.

Sinan, K. I., Etienne, O. K., Stefanucci, A., Mollica, A., Mahomoodally, M. F., Jugreet, S., Rocchetti, G., Lucini, L., Aktumsek, A., Montesano, D., Ak, G. and Zengin, G. (2021). Chemodiversity and biological activity of essential oils from three species from the Euphorbia genus, Flavour and Fragrance Journal 36(1): 148-158.

Sindhuja, P. R., Prabhakaran, G. and Gokulshankar, S. (2014). Synergistic effect of anti-oxidant, anti-tyrosinase and anti-bacterial activities of Tridax procumbens, Lantana camara, Euphorbia hirta and Thevetia peruviana plant extracts for cosmetic and personal care applications, International Journal of Pharmacy and Pharmaceutical Sciences 6(9): 91-94.

Singhal, A., Bangar, O. and Naithani, V. (2012). Medicinal plants with a potential to treat Alzheimer and associated symptoms, International journal of Nutrition, Pharmacology, Neurological Diseases 2(2): 84-91.

Sinha, S., Kumar, B., Luqman, S. and Singh, D. (2019). Neuroprotective potential of Cucurbita maxima Duchesne ex Poir, Caeselpenia bunduc (L.) Roxb and Bombax ceiba Linn extracts, South African Journal of Botany 120: 319-325.

Song, J.-X., Sze, S. C.-W., Ng, T.-B., Lee, C. K.-F., Leung, G. P., Shaw, P.C., Tong, Y. and Zhang, Y.-B. (2012). Anti-Parkinsonian drug discovery from herbal medicines: what have we got from neurotoxic models?, Journal of Ethnopharmacology 139(3): 698-711.

Srivastav, S., Fatima, M. and Mondal, A. C. (2017). Important medicinal herbs in Parkinson's disease pharmacotherapy, Biomedicine \& Pharmacotherapy 92: 856-863.
Stanković, J. S., Ceylan, R., Zengin, G., Matić, S., Jurić, T., Diuzheva, A., Jeko, J., Cziáky, Z. and Aktumsek, A. (2020). Multiple biological activities of two Onosma species ( $O$. sericea and $O$. stenoloba) and HPLC-MS/MS characterization of their phytochemical composition, Industrial Crops and Products 144: 112053.

Sut, S., Dall'Acqua, S., Ibrahime Sinan, K., Bene, K., Kumar, G., Fawzi Mahomoodally, M., Picot-Allain, C. and Zengin, G. (2020). Cola caricifolia (G.Don) K. Schum and Crotalaria retusa L. from Ivory Coast as sources of bioactive constituents, Industrial Crops and Products 147: 112246.

Sut, S., Dall'Acqua, S., Uysal, S., Zengin, G., Aktumsek, A., Picot-Allain, C. and Mahomoodally, F. (2019b). LC-MS, NMR fingerprint of Potentilla argentea and Potentilla recta extracts and their in vitro biopharmaceutical assessment, Industrial Crops and Products 131: 125-133.

Sut, S., Zengin, G., Dall'Acqua, S., Gazdová, M., Šmejkal, K., Bulut, G., Dogan, A., Haznedaroglu, M. Z., Aumeeruddy, M. Z., Maggi, F. and Mahomoodally, M. F. (2019a). Paeonia arietina and Paeonia kesrounansis bioactive constituents: NMR, LC-DAD-MS fingerprinting and in vitro assays, Journal of Pharmaceutical and Biomedical Analysis 165: $1-11$.

Tan, W.-N., Khairuddean, M., Khaw, K.-Y., Murugaiyah, V., Tong, W. Y., Leong, C. R. and Ibrahim, D. (2019). Phytochemical screening and biological evaluations of Garcinia atroviridis, Iranian Journal of Pharmaceutical Sciences 15(2): 91-104. Publisher: Iranian Association of Pharmaceutical Scientists.

Taram, F., Ignowski, E., Duval, N. and Linseman, D. (2018). Neuroprotection comparison of rosmarinic acid and carnosic acid in primary cultures of cerebellar granule neurons, Molecules 23(11): 2956.

Thakur, A., Chun, Y. S., October, N., Yang, H. O. and Maharaj, V. (2019). Potential of South African medicinal plants targeting the reduction of $A \beta 42$ protein as a treatment of Alzheimer's disease, Journal of Ethnopharmacology 231: 363-373.

Tlili, H., Hanen, N., Ben Arfa, A., Neffati, M., Boubakri, A., Buonocore, D., Dossena, M., Verri, M. and Doria, E. (2019a). Biochemical profile and in vitro biological activities of extracts from seven folk medicinal plants growing wild in southern Tunisia, PLOS ONE 14(9): e0213049.

Tlili, N., Kirkan, B. and Sarikurkcu, C. (2019b). LC-ESI-MS/MS characterization, antioxidant power and inhibitory effects on $\alpha$-amylase and tyrosinase of bioactive compounds from hulls of Amygdalus communis: the influence of the extracting solvents, Industrial Crops and Products 128: 147-152.

Tu, Y., Huang, J. and Li, Y. (2018). Anticholinesterase, antioxidant, and beta-amyloid aggregation inhibitory constituents from Cremastra ap pendiculata, Medicinal Chemistry Research 27(3): 857-863.

Turrini, F., Malaspina, P., Giordani, P., Catena, S., Zunin, P. and Boggia, R. (2020). Traditional decoction and PUAE aqueous extracts of pomegranate peels as potential low-cost anti-tyrosinase ingredients, Applied Sciences 10(8): 2795.

Tusevski, O., Krstikj, M., Stanoeva, J., Stefova, M. and Gadzovska Simic, S. (2018). Phenolic profile and biological activity of Hypericum perforatum L.: can roots be considered as a new source of natural compounds?, South African Journal of Botany 117: 301-310.

Ulaç, E., Köseoğlu Yılmaz, P. and Kolak, U. (2019). Evaluation of antioxidant and cholinesterase inhibitory activities of some medicinal plants, Food and Health 5(1): 39-47.

Uysal, A., Ozer, O. Y., Zengin, G., Stefanucci, A., Mollica, A., PicotAllain, C. M. N. and Mahomoodally, M. F. (2019a). Multifunctional approaches to provide potential pharmacophores for the pharmacy shelf: Heracleum sphondylium L. subsp. ternatum (Velen.) Brummitt., Computational Biology and Chemistry 78: 64-73.

Uysal, S., Aktumsek, A., Picot-Allain, C. M., Unuvar, H., Mollica, A., Georgiev, M. I., Zengin, G. and Mahomoodally, M. F. (2018a). Biological, chemical and in silico fingerprints of Dianthus calocephalus Boiss.: a novel source for rutin, Food and Chemical Toxicology 113: 179-186.

Uysal, S., Aumeeruddy-Elalfi, Z., Zengin, G., Aktumsek, A., Mocan, A., Custodio, L., Neng, N. R., Nogueira, J. M., Ćirić, A., Glamočlija, J., Soković, M. and Mahomoodally, M. (2018b). Insight into the biological properties and phytochemical composition of Ballota macrodonta Boiss. et Balansa, - an endemic medicinal plant from Turkey, Industrial Crops and Products 113: 422-428.

Uysal, S., Ugurlu, A., Zengin, G., Baloglu, M. C., Altunoglu, Y. C., Mollica, A., Custodio, L., Neng, N. R., Nogueira, J. M. and Mahomoodally, M. F. (2018c). Novel in vitro and in silico insights of the multi-biological activities and chemical composition of Bidens tripartita L., Food and Chemical Toxicology 111: 525-536. 
Uysal, S., Zengin, G., Mahomoodally, M., Yilmaz, M. and Aktumsek, A (2019b). Chemical profile, antioxidant properties and enzyme inhibitory effects of the root extracts of selected Potentilla species, South African Journal of Botany 120: 124-128.

Uysal, S., Zengin, G., Sinan, K. I., Ak, G., Ceylan, R., Mahomoodally, M. F., Uysal, A., Sadeer, N. B., Jekő, J., Cziáky, Z., Rodrigues, M. J., Yıldıztugay, E., Elbasan, F. and Custodio, L. (2021). Chemical characterization, cytotoxic, antioxidant, antimicrobial, and enzyme inhibitory effects of different extracts from one sage (Salvia ceratophylla L.) from Turkey: open a new window on industrial purposes, RSC Advances 11(10): 5295-5310.

Váradi, C. (2020). Clinical features of Parkinson's disease: the evolution of critical symptoms, Biology 9(5): 103.

Vujanović, M., Zengin, G., Đurović, S., Mašković, P., Cvetanović, A. and Radojković, M. (2019). Biological activity of extracts of traditional wild medicinal plants from the Balkan Peninsula, South African Journal of Botany 120: 213-218.

Wang, Y., Hao, M.-M., Sun, Y., Wang, L.-F., Wang, H., Zhang, Y.-J., Li, H.-Y., Zhuang, P.-W. and Yang, Z. (2018). Synergistic promotion on tyrosinase inhibition by antioxidants, Molecules 23(1): 106.

Wangkananon, W., Phuaksaman, C., Koobkokkruad, T. and Natakankitkul, S. (2018). An extreme vertices mixture design approach to optimization of tyrosinase inhibition effects, Engineering Journal 22(1): 175-185.

WHO (2021). Dementia. [Accessed date: 09/20/2021].

URL: https://www.who.int/news-room/fact-sheets/detail/dementia

Xie, P.-j., Huang, L.-X., Zhang, C.-h., Ding, S.-s., Deng, Y.-j. and Wang, X.j. (2018). Skin-care effects of dandelion leaf extract and stem extract: antioxidant properties, tyrosinase inhibitory and molecular docking simulations, Industrial Crops and Products 111: 238-246.

Yakoubi, R., Megateli, S., Hadj Sadok, T., Bensouici, C. and Bağci, E. (2021). A synergistic interactions of Algerian essential oils of Laurus nobilis L., Lavandula stoechas L. and Mentha pulegium L. on anticholinesterase and antioxidant activities, Biocatalysis and Agricultural Biotechnology 31: 101891.

Yener, I. (2020). Determination of antioxidant, cytotoxic, anticholinesterase, antiurease, antityrosinase, and antielastase activities and aroma, essential oil, fatty acid, phenolic, and terpenoid-phytosterol contents of Salvia poculata, Industrial Crops and Products 155: 112712.

Yilmaz, M. A., Ertas, A., Yener, I., Akdeniz, M., Cakir, O., Altun, M., Demirtas, I., Boga, M. and Temel, H. (2018). A comprehensive LC-MS/MS method validation for the quantitative investigation of 37 fingerprint phytochemicals in Achillea species: a detailed examination of $A$. coarctata and A. monocephala, Journal of Pharmaceutical and Biomedical Analysis 154: 413-424.

Yodthong, W. (2020). Influence of different extraction solvents on antioxidant and antityrosinase activities of Morus alba Linn. leave extract. Journal of Science and Agricultural Technology 1(1): 7-17. Number: 1

Zafar, R., Ullah, H., Zahoor, M. and Sadiq, A. (2019). Isolation of bioactive compounds from Bergenia ciliata (haw.) Sternb rhizome and their antioxidant and anticholinesterase activities, BMC Complementary and Alternative Medicine 19(1): 296.

Özcan, K. (2020). Antibacterial, antioxidant and enzyme inhibition activity capacities of Doronicum macrolepis (Freyn \& Sint): an endemic plant from Turkey, Saudi Pharmaceutical Journal 28(1): 95-100.

Zdunić, G., Aradski, A. A., Gođevac, D., Živković, J., Laušević, S. D., Milošević, D. K. and Šavikin, K. (2020). In vitro hypoglycemic, antioxidant and antineurodegenerative activity of chokeberry (Aronia melanocarpa) leaves, Industrial Crops and Products 148: 112328.

Zengin, G., Abdallah, H. H., Dogan, A., Mollica, A., Aumeeruddy-Elalfi, Z. and Mahomoodally, M. F. (2018a). Phenolic components and assessment of biological properties of Tchihatchewia isatidea Boiss. extracts: docking and functional approaches for designing novel products, Food and Chemical Toxicology 111: 423-431.

Zengin, G., Aktumsek, A., Mocan, A., Rengasamy, K., Picot, C. and Mahomoodally, M. (2019a). Asphodeline cilicica Tuzlaci: from the plant to its most active part extract and its broad bioactive properties, South African Journal of Botany 120: 186-190.

Zengin, G., Atasagun, B., Zakariyyah Aumeeruddy, M., Saleem, H., Mollica, A., Babak Bahadori, M. and Mahomoodally, M. F. (2019b). Phenolic profiling and in vitro biological properties of two Lamiaceae species (Salvia modesta and Thymus argaeus): a comprehensive evaluation, Industrial Crops and Products 128: 308-314.

Zengin, G., Aumeeruddy, M. Z., Diuzheva, A., Jekő, J., Cziáky, Z., Yıldıztugay, A., Yıldıztugay, E. and Mahomoodally, M. F. (2019c). A comprehen- sive appraisal on Crocus chrysanthus (Herb.) Herb. flower extracts with HPLC-MS/MS profiles, antioxidant and enzyme inhibitory properties, Journal of Pharmaceutical and Biomedical Analysis 164: 581-589.

Zengin, G., Bulut, G., Mollica, A., Nancy Picot-Allain, C. M. and Mahomoodally, M. F. (2018b). In vitro and in silico evaluation of Centaurea saligna (K.Koch) Wagenitz-an endemic folk medicinal plant, Computational Biology and Chemistry 73: 120-126.

Zengin, G., Ceylan, R., Katanić, J., Aktumsek, A., Matić, S., Boroja, T., Stanić, S., Mihailović, V., Seebaluck-Sandoram, R., Mollica, A. and Mahomoodally, M. F. (2018c). Exploring the therapeutic potential and phenolic composition of two Turkish ethnomedicinal plants - Ajuga orientalis L. and Arnebia densiflora (Nordm.) Ledeb., Industrial Crops and Products 116: 240-248.

Zengin, G., Diuzheva, A., Jekő, J., Cziáky, Z., Bulut, G., Dogan, A. Haznedaroglu, M. Z., Rengasamy, K. R., Lobine, D., Bahadori, M. B. and Mahomoodally, M. F. (2018d). HPLC-MS/MS-based metabolic profiling and pharmacological properties of extracts and infusion obtained from Amelanchier parviflora var. dentata, Industrial Crops and Products 124: 699-706.

Zengin, G., Ferrante, C., Gnapi, D. E., Sinan, K. I., Orlando, G., Recinella, L., Diuzheva, A., Jekő, J., Cziáky, Z., Chiavaroli, A., Leone, S., Brunetti, L., Picot-Allain, C., Mahomoodally, M. F., Angelini, P., Covino, S., Venanzoni, R., Tirillini, B. and Menghini, L. (2019d). Comprehensive approaches on the chemical constituents and pharmacological properties of flowers and leaves of American basil (Ocimum americanum $\mathrm{L}$ ), Food Research International 125: 108610.

Zengin, G., Ferrante, C., Orlando, G., Zheleva-Dimitrova, D., Gevrenova, R., Recinella, L., Chiavaroli, A., Leone, S., Brunetti, L., Aumeeruddy, M. Z., Aktumsek, A., Mahomoodally, M. F., Angelini, P., Covino, S. Venanzoni, R., Tirillini, B. and Menghini, L. (2019e). Chemical profiling and pharmaco-toxicological activity of Origanum sipyleum extracts: exploring for novel sources for potential therapeutic agents, Journal of Food Biochemistry 43(11): 1-16.

Zengin, G., Llorent-Martínez, E. J., Córdova, M. L. F.-d., Bahadori, M. B. Mocan, A., Locatelli, M. and Aktumsek, A. (2018e). Chemical composition and biological activities of extracts from three Salvia species: S. blepharochlaena, S. euphratica var. leiocalycina, and S. verticillata subsp. amasiaca, Industrial Crops and Products 111: 11-21.

Zengin, G., Llorent-Martínez, E. J., Molina-García, L., Fernández-de Córdova, M. L., Aktumsek, A., Uysal, S., Rengasamy, K. R. R. Aumeeruddy, M. Z., Bahadori, M. B. and Mahomoodally, M. F. (2019f). Chemical profile, antioxidant, and enzyme inhibitory properties of two Scutellaria species: S. orientalis L. and S. salviifolia Benth, Journal of Pharmacy and Pharmacology 71(2): 270-280.

Zengin, G., Mahomoodally, F., Picot-Allain, C., Diuzheva, A., Jekő, J., Cziáky, Z., Cvetanović, A., Aktumsek, A., Zeković, Z. and Rengasamy, K. R. (2019g). Metabolomic profile of Salvia viridis L. root extracts using HPLC-MS/MS technique and their pharmacological properties: a comparative study, Industrial Crops and Products 131: 266-280.

Zengin, G., Mahomoodally, M. F., Aktumsek, A., Ceylan, R., Uysal, S., Mocan, A., Yilmaz, M. A., Picot-Allain, C. M. N., Ćirić, A., Glamočlija, J. and Soković, M. (2018f). Functional constituents of six wild edible Silene species: a focus on their phytochemical profiles and bioactive properties, Food Bioscience 23: 75-82.

Zengin, G., Mahomoodally, M. F., Paksoy, M. Y., Picot-Allain, C., Glamocilja, J., Sokovic, M., Diuzheva, A., Jekő, J., Cziáky, Z., Rodrigues, M. J., Sinan, K. I. and Custodio, L. (2019h). Phytochemical characterization and bioactivities of five Apiaceae species: natural sources for novel ingredients, Industrial Crops and Products 135: 107-121.

Zengin, G., Mahomoodally, M. F., Picot-Allain, M. C. N., Sinan, K. I., Ak, G., Etienne, O. K., Sieniawska, E., Maciejewska-Turska, M., Świątek, u., Rajtar, B. and Polz-Dacewicz, M. (2021). Chemical composition, biological properties and bioinformatics analysis of two Caesalpina species: a new light in the road from nature to pharmacy shelf, Journal of Pharmaceutical and Biomedical Analysis 198: 114018.

Zengin, G., Mahomoodally, M. F., Rocchetti, G., Lucini, L., Sieniawska, E., Świątek, u., Rajtar, B., Polz-Dacewicz, M., Senkardes, I., Aktumsek, A., Picot-Allain, M. C. N. and Montesano, D. (2020a). Chemical characterization and bioactive properties of different extracts from Fibigia clypeata, an unexplored plant food, Foods 9(6): 705.

Zengin, G., Mahomoodally, M. F., Sinan, K. I., Picot-Allain, M. C. N., Yildiztugay, E., Cziáky, Z., Jekő, J., Saleem, H. and Ahemad, N. (2020b). Chemical characterization, antioxidant, enzyme inhibitory and cytotoxic properties of two geophytes: Crocus pallasii and Cyclamen cilicium 
Food Research International 133: 109129

Zengin, G., Mahomoodally, M., Picot-Allain, C., Cakmak, Y., Uysal, S. and Aktumsek, A. (2019i). In vitro tyrosinase inhibitory and antioxidant potential of Consolida orientalis, Onosma isauricum and Spartium junceum from Turkey, South African Journal of Botany 120: 119-123.

Zengin, G., Mollica, A., Aumeeruddy, M. Z., Rengasamy, K. R. and Mahomoodally, M. F. (2018g). Phenolic profile and pharmacological propensities of Gynandriris sisyrinchium through in vitro and in silico perspectives, Industrial Crops and Products 121: 328-337.

Zengin, G., Paksoy, M. Y., Aumeeruddy, M. Z., Glamocilja, J., Sokovic, M., Diuzheva, A., Jekő, J., Cziáky, Z., Rodrigues, M. J., Custodio, L. and Mahomoodally, M. F. (2019j). New insights into the chemical profiling, cytotoxicity and bioactivity of four Bunium species, Food Research International 123: 414-424.

Zengin, G., Rodrigues, M. J., Abdallah, H. H., Custodio, L., Stefanucci, A., Aumeeruddy, M. Z., Mollica, A., Rengasamy, K. R. and Mahomoodally, M. F. (2018h). Combination of phenolic profiles, pharmacological properties and in silico studies to provide new insights on Silene salsuginea from Turkey, Computational Biology and Chemistry 77: 178-186.

Zengin, G., Sieniawska, E., Senkardes, I., Picot-Allain, M. C. N., Ibrahime Sinan, K. and Fawzi Mahomoodally, M. (2019k). Antioxidant abilities, key enzyme inhibitory potential and phytochemical profile of Tanacetum poteriifolium Grierson, Industrial Crops and Products 140: 111629 .

Zengin, G., Stefanucci, A., Rodrigues, M. J., Mollica, A., Custodio, L., Aumeeruddy, M. Z. and Mahomoodally, M. F. (2019l). Scrophularia lucida $\mathrm{L}$. as a valuable source of bioactive compounds for pharmaceutical applications: in vitro antioxidant, anti-inflammatory, enzyme inhibitory properties, in silico studies, and HPLC profiles, Journal of Pharmaceutical and Biomedical Analysis 162: 225-233.

Zengin, G., Zheleva-Dimitrova, D., Gevrenova, R., Nedialkov, P., Mocan, A., Ćirić, A., Glamočlija, J., Soković, M., Aktumsek, A. and Mahomoodally, M. (2018i). Identification of phenolic components via LC-MS analysis and biological activities of two Centaurea species: $C$. drabifolia subsp. drabifolia and C. Iycopifolia, Journal of Pharmaceutical and Biomedical Analysis 149: 436-441.

Özer, Z. (2019). The phenolıc compounds, antıoxıdant and antıcholınesterase activities of Cyclotrıchıum orıganıfolıum (Labıll.) Manden and Scheng and Thymus sipyleus Boiss. teas from Turkey, Studia Universitatis Babeș-Bolyai Chemia 64(3): 217-228.

Zhang, B., Yu, H., Lu, W., Yu, B., Liu, L., Jia, W., Lin, Z., Wang, H. and Chen, S. (2019). Four new honokiol derivatives from the stem bark of Magnolia officinalis and their anticholinesterase activities, Phytochemistry Letters 29: 195-198.

Zhang, Z., Zhang, B., Yang, R. and Zhao, W. (2020). Recent developments in the preservation of raw fresh food by pulsed electric field, Food Reviews International 137: 1-19.

Zolghadri, S., Bahrami, A., Hassan Khan, M. T., Munoz-Munoz, J., GarciaMolina, F., Garcia-Canovas, F. and Saboury, A. A. (2019). A comprehensive review on tyrosinase inhibitors, Journal of Enzyme Inhibition and Medicinal Chemistry 34(1): 279-309.

Zouari-Bouassida, K., Trigui, M., Makni, S., Jlaiel, L. and Tounsi, S. (2018). Seasonal variation in essential oils composition and the biological and pharmaceutical protective effects of Mentha longifolia leaves grown in Tunisia, BioMed Research International 2018: 1-12.

Zucca, F. A., Basso, E., Cupaioli, F. A., Ferrari, E., Sulzer, D., Casella, L. and Zecca, L. (2014). Neuromelanin of the human substantia nigra: an update, Neurotoxicity Research 25(1): 13-23. 